\title{
Cancer exosomes are unique and complex mechanisms that suppress effector T lymphocyte functions
}

Yueting Wu

Follow this and additional works at: https://researchrepository.wvu.edu/etd

\section{Recommended Citation}

Wu, Yueting, "Cancer exosomes are unique and complex mechanisms that suppress effector $T$ lymphocyte functions" (2015). Graduate Theses, Dissertations, and Problem Reports. 6982. https://researchrepository.wvu.edu/etd/6982

This Dissertation is protected by copyright and/or related rights. It has been brought to you by the The Research Repository @ WVU with permission from the rights-holder(s). You are free to use this Dissertation in any way that is permitted by the copyright and related rights legislation that applies to your use. For other uses you must obtain permission from the rights-holder(s) directly, unless additional rights are indicated by a Creative Commons license in the record and/ or on the work itself. This Dissertation has been accepted for inclusion in WVU Graduate Theses, Dissertations, and Problem Reports collection by an authorized administrator of The Research Repository @ WVU.

For more information, please contact researchrepository@mail.wvu.edu. 


\title{
CANCER EXOSOMES ARE UNIQUE AND COMPLEX MECHANISMS THAT SUPPRESS EFFECTOR T LYMPHOCYTE FUNCTIONS
}

\author{
Yueting Wu \\ Dissertation submitted to the Benjamin M. Statler College of Engineering and Mineral Resources \\ at West Virginia University \\ in partial fulfillment of the requirements \\ for the degree of \\ Doctor of Philosophy \\ in \\ Chemical Engineering
}

David J. Klinke II, Ph.D., Committee Chairperson

Robin S. Hissam, Ph.D.

Cerasela-Zoica Dinu, Ph.D.

Yong Yang, Ph.D.

Christopher F. Cuff, Ph.D.

Michael (JM) Ruppert, Ph.D.

Department of Chemical Engineering

Morgantown, West Virginia

2015

Keywords: Exosomes, Melanoma, Breast Cancer, Tumor, Cancer Immunology, T lymphocytes, Cancer Therapy, Immunosuppression, RNA, IL12RB2, IL2, IL12, IFN- $\gamma$

Copyright 2015 Yueting Wu 


\section{Abstract}

It is still unknown how tumor exosomes influence malignant cell survival and alter cell-tocell communication to modulate the immune system by, in part, manipulating the activity of cytotoxic T lymphocytes. This study focuses on two critical parts regarding cancer exosomes. The first part is to tailor existing bionanotechnology methods to account for the nanoscale aspects of exosome biology. SEM, TEM, Bioanalyzer and flow cytometry were used to characterize exosome morphologies, identify specific protein biomarkers HER1 and HER2, as well as the quality of RNAs enclosed in exosomes. Competing methods related to exosome isolation, production, preservation, stability and analysis were evaluated. Based on these studies, we recommend improved experimental methods that aim to ensure a consistent framework to identify the roles that exosomes play. With these improved methods, the second part is to characterize the immunosuppressive role that melanoma exosomes play, especially from the perspective of delivering a payload of mRNAs to immune cells. Toward this second aim, melanoma exosomes were purified and cytokine receptor IL12R $\beta 2$ and specific mRNA enrichment were identified. Microarray and pathway analysis suggested that mRNAs derived from melanoma impact a variety of immune signaling pathways. Induction effects of PTPN11 and DNMT3A from the exosomal mRNAs were characterized in T lymphocytes. Specifically, we showed that PTPN11 upregulation impeded CTLL-2 cytotoxic T cell proliferation in response to IL2 stimulation, and DNMT3A upregulation hindered IFN- $\gamma$ production in 2D6 TH1 cells. These findings provide insights regarding the specific immunosuppression effects that tumor-infiltrating lymphocytes (TILs) may encounter in tumor microenvironment. Understanding those 
immunosuppression effects is important to engineer anti-tumor immunity for innovative and improved treatments against cancer. 


\section{DEDICATION}

The author wishes to dedicate this dissertation to human health worldwide. 
ACKNOW LEDGMENTS

This work was supported by grants from the National Science Foundation (NSF CAREER 1053490), the National Cancer Institute (NCI R15CA123123), and the National Institutes of Health (NIH P30GM103488, P30RR032138, RR020866, PC-P1101809).

The author wishes to express special gratitude to Dr. David J. Klinke II, Ph.D., for his mentoring and guidance throughout my Ph.D. study in West Virginia University (WVU). I thank him for being always supportive and encouraging, leading my explore into several of the cutting-edge, scientific issues that are substantial barriers in current cancer immunotherapy. Without his time, effort and mentoring contributed to my research, the completion of this dissertation will end up with immeasurable difficulties. I am grateful that the experience and knowledge obtained from working with him have inspired my research interests in cancer and the therapy, hence, helping me with uniquely defining myself as an interdisciplinary scientist for cancer clinicians, as for my future career choice. I also would like to thank all previous and current group members working in Dr. Klinke's lab, Yogesh M. Kulkarni, Ph.D., Emily Chambers, Wentao Deng, Ph.D., Christina Byrne-Hoffman, Jason Ware, Venessa A. Cuppett, Rania Kanj, Ph.D., etc. To my committee members, Dr. Christopher F. Cuff, Ph.D., Dr. Michael (JM) Ruppert, M.D., Ph.D., Dr. Robin S. Hissam, Ph.D., Dr. Cerasela-Zoica Dinu, Ph.D. and Dr. Yong Yang, Ph.D., I am grateful for your contributions of time, effort, brilliant comments and suggestions in my Ph.D. work.

For experimental and technical assistance, I thank Kathy M. Brundage, Ph.D. for her help in flow cytometry, Kolin. S. Brown, Ph.D. and many co-workers in WVU's ESB 
Cleanroom, for sharing their hands-on experience on micro- and nanofabrications, Adrian. C. MacLeod, Jeremy S. Hardinger and Marcela. L. Redigolo, Ph.D. for training me using the SEM and TEM imaging, respectively, Woila. Szeszel-Fedorowicz, Ph.D. for assistance with Bioanalyzer and NanoDrop analysis. I would like to express my appreciation to Dr. John B. Barnett for letting me use his laboratory and equipments, to Dr. Rosana Schafer, Ph.D. and Dr. Christopher F. Cuff for mouse anatomy and surgery training, to Dr. Scott A. Weed's lab and his Ph.D. student Steve M. Markwell for training and sharing the experience on electroporation and transduction, to Dr. Steve M. Frisch's lab and Dr. Michael (JM) Ruppert's lab for letting me use the imaging and ultracentrifuge equipments, respectively. I would like to thank Dr. Rakesh K. Gupta, Ph.D. and Department of Chemical Engineering in WVU, for accepting me as a Ph.D. student in 2011, under Dr. Klinke's full sponsorship from grants, when I was for one time in the face of adversity and hesitated in continuing my Ph.D. pursuit. I enjoyed the time I spent in WVU, the classes and seminars with professors and fellow students in Chemical Engineering, and for sure the working with my advisor Dr. Klinke and other labmates. As my research is interdisciplinary, I also attended classes, seminars and conferences being held in many other departments. Especially I appreciate faculty members and staffs in Department of Microbiology, Immunology \& Cell Biology (MICB) and Department of Mechanical and Aerospace Engineering (MAE), for their educational efforts and administrative work during my learning in WVU.

Finally, my sincere thanks for friends, Yuan, Xiaoyan, Chenbo, Qiaowen (Sophia), Weiping, Hui, Xiaoxiao and Guang, Xiaolong Zhou and Jianhua Dong, Qin and Guochang, 
Fangping and Zhenhua, Chuck, Mary and many other fellows from Morgantown, WV, for 
all the support and help in my life, and for sure, I am very grateful for having great families and parents, especially to Anthony W. Gao, my 4-year-old boy, the source of love and power accompanying me throughout my Ph.D. work. 
TABLE OF CONTENTS

\section{Table of Contents}

Abstract..

ii

Dedication.. iv

Acknowledgments V

Table of Contents ............................................................................................. viii

LIST OF FIGURES ....................................................................................... ix

LIST OF TABLES ..........................................................................................

CHAPTER 1: INTRODUCTION ..................................................................... 1

CHAPTER 2: EXOSOMES: IMPROVED METHODS TO

CHARACTERIZE THEIR MORPHOLOGY, RNA CONTENT, AND

SURFACE PROTEIN BIOMARKERS

CHAPTER 3: B16FO MELANOMA EXOSOMES DELIVER A COMPLEX BIOLOGICAL PAYLOAD THAT INCLUDES PTPN11 TO SUPPRESS T LYMPHOCYTE FUNCTION 56 CHAPTER 4: PATH FORWARD. 


\section{LIST OF FIGURES}

\section{CHAPTER 1:}

Figure 1 One patient with metastatic melanoma on right arms showed complete clinical response with total resolution of the skin metastasis

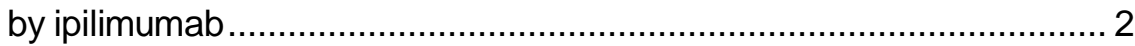

Figure 2 The Cancer-Immunity Cycle …....................................................... 4

Figure 3 Different types of secreted membrane vesicles ................................... 9

Figure 4. Bioanalyzer electropherogram of exosomal total RNA isolated using seven different methods.

Figure 5 Previous publications showing "exosomes" images lacking proper number of sampling or including obvious impurities

\section{CHAPTER 2:}

Figure 1 Different extracellular vesicles exhibited different morphologies and size distributions, as imaged by SEM and TEM

Figure 2 Exosome quality was evaluated in terms of vesicle morphology and exosomal RNA as a function of production condtions 35

Figure 3 Biochemical characterization of exosomes from B16F0 cells. 36

Figure 4 Freezing of exosomes decreased their size and degraded exosomal RNA

Figure 5 SEM images of frozen exosomes from mouse melanoma cells B16F0 and human breast cancer cells SKBR3

Figure 6 The abundance of the membrane proteins, HER1 and HER2, were quantified on SKBR3 exosomes and the parental cells by flow cytometry $43-44$

Figure 7 Calibration of HER1 and HER2 expression on SKBR3 cells to equivalent copy numbers per cell by flow cytometry using quantum calibration beads 45

Figure 8 Forward scatter area is proportional to particle size.

Figure 9 Flow cytometric analysis of B16F0 exosomes stained using APC conjugated IL12Rß2 mAb and the lipophilic dye Dil

Figure 10 Exosomes were clustered using the lipophilic tracer Dil. Exosome clusters had more HER1 copies and bigger particle sizes, which 
enhanced HER1 detection by conventional flow cytometry using

\section{CHAPTER 3:}

Figure 1 Mouse melanoma and immortalized melanocytes release exosomes. . 70

Figure 2 Similar to parental cells, exosomes isolated from B16F0 cells contain IL12 receptor beta 2 (IL12RB2), which is localized on the exosome surface

Figure 3 B16F0 exosomes contain mRNAs that are differentially expressed relative to parental cells

Figure 4 Relative mRNA abundance between B16F0 exosomes and cells were consistent between qRT-PCR and microarray analyses

Figure 5 PTPN11 was dose-dependently increased in T lymphocytes when treated with exosomes from B16F0 but not Cloudman S91 or Melan-A cell lines.

Figure 6 An increase in PTPN11 inhibited the proliferation of CTLL-2 cells in response to IL2.

Figure 7 Dnmt3a protein upregulation inhibited IFN-y production . 81

Figure 8 B16F0 exosomes inhibit multiple aspects of primary CD8+ T cell response to antigen stimulation 83 


\section{LIST OF TABLES}

\section{CHAPTER 1:}

Table 1 Melanoma and cellular immune response

5

\section{CHAPTER 2:}

Table 1 Primers used for semi-quantitative PCR 25

Table 2 Size comparisons and statistics of exosomes, apoptotic vesicles and necrotic bodies that were isolated and observed by electron

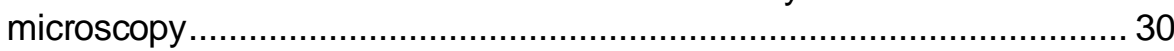

\section{CHAPTER 3:}

Table 1 Pathways that influenced by the enriched mRNAs from B16F0 exosomes 


\section{CHAPTER 1 INTRODUCTION}

Cancer is the leading cause of death for humans in the modern world. In 2012, 8.2 million cancer deaths occurred worldwide and is projected to increase to 13.1 million by $2030^{1}$. Cancer is a disease involving growth enlargement of malignant cells that can induce death when the cancer cells invade to adjacent tissues and disrupt organ function ${ }^{2}$. Treatment for cancer depends on the type and the metastatic stage of the disease when detected $^{3}$. Current treatments include surgery, radiotherapy, chemotherapy, molecularly targeted drugs, and immunotherapy. Following a century long incubation period, immunotherapy has emerged in the past 5 years as one of the most promising methods to achieve a durable response ${ }^{4-8}$. Cancer immunotherapy promotes the patients' own immune system to attack the tumor ${ }^{5}$. Since 2011 to 2015, immunotherapy drugs called immune checkpoint inhibitors - represented by Yervoy (ipilimumab), Keytruda (pembrolizumab), Opdivo (nivolumab) and Arzerra (ofatumumab) - have been approved by FDA and used to treat metastatic melanoma and many other types of malignancies ${ }^{9-11}$. Since it is capable of boosting durable immune response in patients, immune checkpoint modulators have achieved remarkable success in improving patient survival. In 2013, a complete cured case by ipilimumab for a metastatic melanoma patient was reported (see Figure 1) ${ }^{12}$. Cancer immunotherapies provides proof-of-concept in that harnessing the patient's immune system can be an effective weapon against cancer $^{13}$. Despite the remarkable effect in some patients, the main challenge for broader clinical benefit of these therapies is the low response rate, prompting extensive investigations on the disease mechanisms and potential improvements in a purpose of enhancing the durable response in immunotherapies ${ }^{14-16}$. 

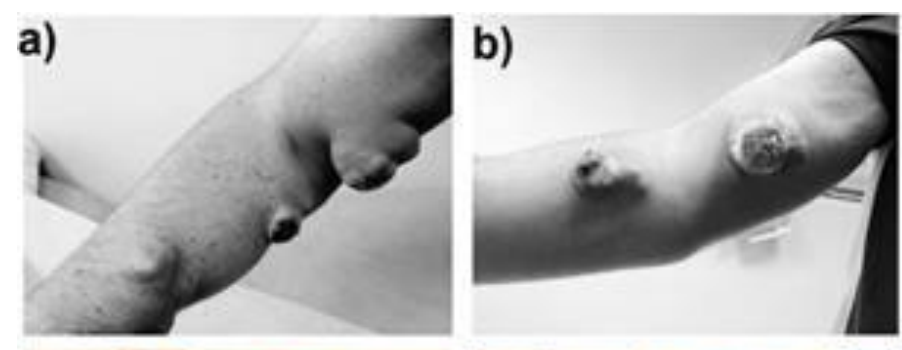

Figure 1. This case report showed one patient with metastatic melanoma on his right arms displayed total resolution of the skin metastasis by ipilimumab.
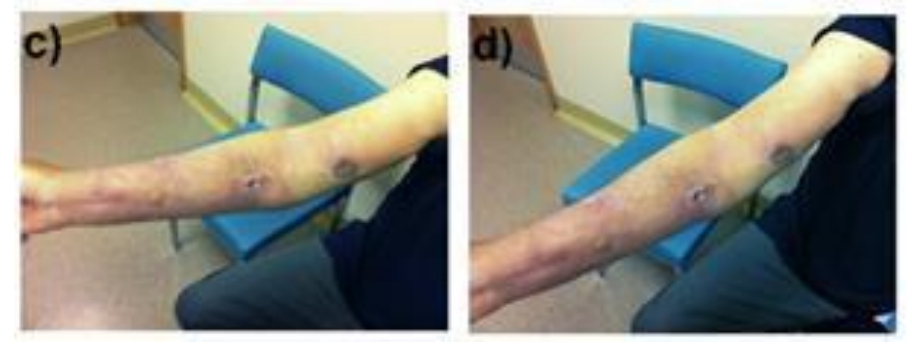
( $a$ and $b$ ) Before treatment, (c and d) Similar images that were taken after treatment with ipilumimab. $^{12}$

While only $2 \%$ of all skin cancers, melanoma accounts for the majority deaths of skin cancers, with approximately 200,000 cases diagnosed worldwide and 48,000 deaths annually ${ }^{17}$. Risk factors for melanoma incidence include extensive or repeated exposure to sunlight, individuals with family history of melanoma (5-12\% of all reported cases), high nevi counts, and dysplastic nevus. Surgical removal of a melanoma at an early stage is effective. Once it metastasizes, melanoma is characterized by rapid progression and a low response rate to most conventional cancer treatments ${ }^{5,18}$, with an average survival ranging between $8-18$ months prior to immune checkpoint modulators ${ }^{9,13}$. As melanoma tumors are frequently infiltrated with immune cells, melanoma has long been considered an attractive target for immunotherapy ${ }^{19}$. Moreover, a persistent challenge has been to identify how the tumor escapes immune surveillance despite the presence of effector lymphocytes inside tumors $^{14,15,20,21}$.

Immune system of vertebrates is resourceful, complex and adaptive to various disease pathogens including cancer ${ }^{22}$. The host immunity contains two distinct but interrelated 
immunological systems: 1) the innate system to protect against evolutionarily defined pathogen-associated molecular patterns, and 2) the adaptive system to protect against pathogens by reacting with a nearly limitless molecular patterns and to provide the system with long term memory against the specific pathogens. Current cancer immunotherapy is mostly based on boosting the adaptive immunity against cancer antigens, in that a cyclic process can be generated, leading to an accumulation of immune stimulatory factors and amplifying $\mathrm{T}$ cell responses (Figure 2$)^{23}$. As a start of such cancer immunity cycle, malignant cells constantly release tumor-antigens into the tissue microenvironment. This release is caused by malignant cell death within the tumor that occurs due to the absence of appropriate blood supply, which deprives the malignant cells of nutrients and efficient waste removal. Dendritic cells (DCs) can sample those tumor-antigens, process the captured antigens and present the antigens on MHC class I and/or class II molecules to prime effector cellss. The activated dendritic cells migrate to lymph nodes where they can stimulate effectors such as $\mathrm{T}$ cells and natural killing (NK) cells. Those tumor-specific effector $\mathrm{T}$ cells together with other effector cells can traffic to the tumor site, recognize tumor-antigens through $\mathrm{T}$ cell receptor (TCR) and release the cytotoxins (i.e. perforins, granzymes, and granulysins) to kill malignant cells that express the corresponding tumor antigens. The most common effector cells that can destroy cancer cells are CD8+ and CD4+ T cells, and NK cells, through separate mechanisms ${ }^{24-31}$ (see Table 1). When immune cells destroy tumors, more antigens are released, thereby, promote the anti-tumor immunity cycle to control tumor growth. 


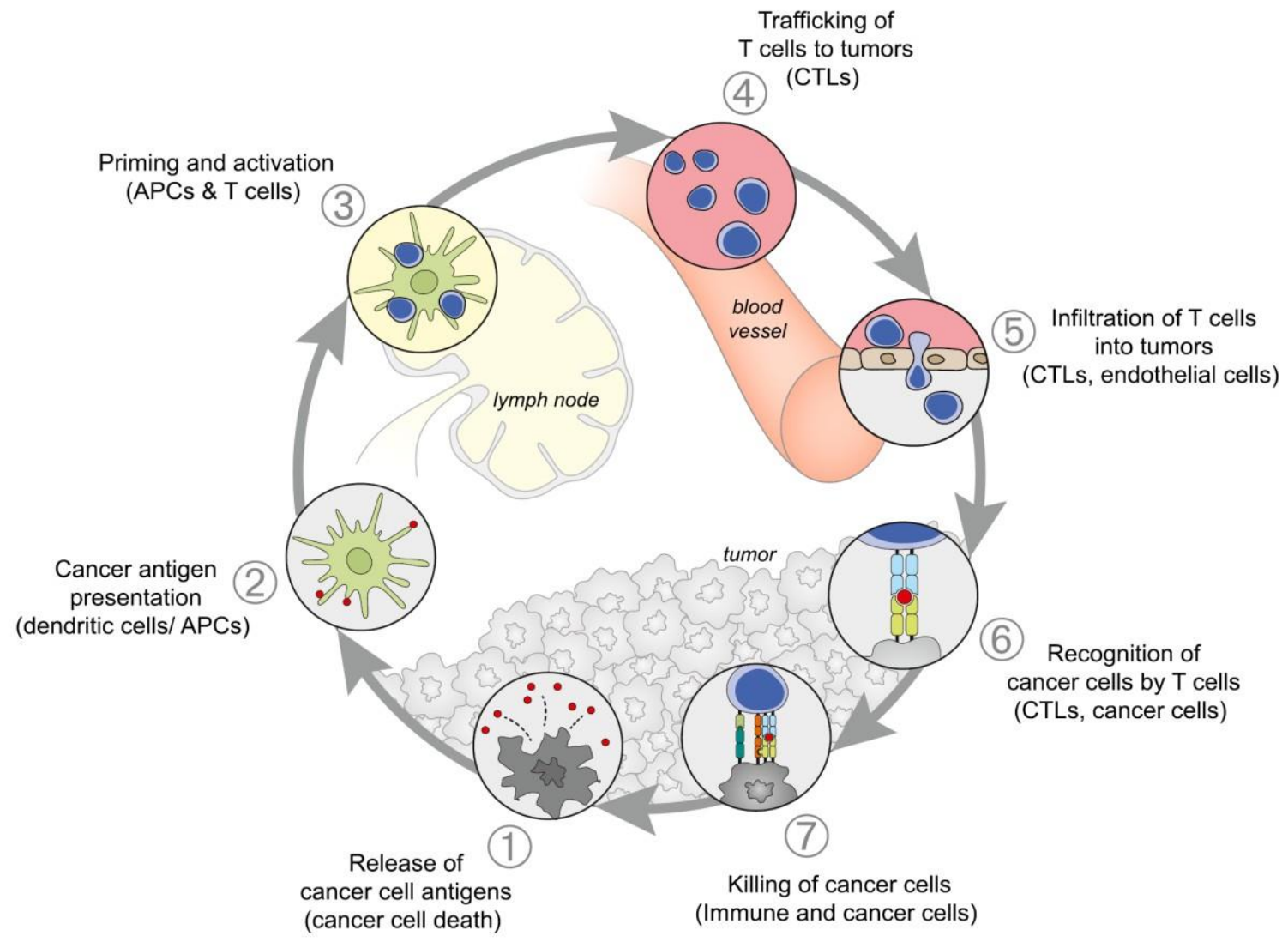

Figure 2. The Cancer-Immunity Cycle Against Cancer $^{23}$. Immune response against cancer can boost the cytotoxic T cell activity that is specific to cancer antigens. There are 7 major steps in this cycle. Each step involves multiple stimulating and inhibitory factors. Step 1 is release of cancer antigens from dying cancer cells due to limited nutrition or oxygen at the inner core of a tumor. The APCs detect and intake those antigens nearby the tumors (Step 2), get stimulated and migrate to the regional lymph nodes, where naive T cells can be activated and TCR-primed by APCs to recognize cancer antigens (Step 3). At this step, native T cells differentiate into CD4+ and CD8+ effector T cells, with TCRs specific to cancer antigens. In Steps 4 and 5, effector T cells leave lymph, circulate and infiltrate inside tumors, looking for specific cancer antigens expressed on MHC class I of tumor cells. TCRs can combine to such antigens on MHC class I (Step 6) and anchor circulating effector $T$ cells to cancer cells, stimulates $T$ cell degranulation secreting cytotoxic agents, i.e. perforins, grazyme-B, that can destruct cancer cells, as illustrated in Step 7. Notably, it is a self-stimulated cycle from Step 1 to 7 . Abbreviations are as follows: APCs, antigen presenting cells; CTLs, cytotoxic T lymphocytes. 
Table 1. Melanoma and cellular immune response.

\begin{tabular}{|c|c|c|c|}
\hline $\begin{array}{c}\text { Immune } \\
\text { cells }\end{array}$ & Specificity & MHC restricted & Killing mechanisms \\
\hline NK & $\begin{array}{l}\text { Innate } \\
\text { immunity, } \\
\text { not tumor- } \\
\text { specific. }\end{array}$ & $\begin{array}{l}\text { Lyse a variety of cell lines that have no or } \\
\text { low MHC class I. Melanomas express } \\
\text { low level of MHC class I will be killed } \\
\text { by NK cells. }\end{array}$ & $\begin{array}{l}\text { NK receptors primarily recognized } \\
\text { "stressed" cells, i.e. tumor cells or } \\
\text { virus infected cells. Other } \\
\text { unlicenced killing exists yet is well } \\
\text { understood. }\end{array}$ \\
\hline $\mathrm{CD} 8+\mathrm{T}$ & $\begin{array}{l}\text { Adaptive } \\
\text { immunity, } \\
\text { tumor- } \\
\text { specific. }\end{array}$ & $\begin{array}{l}\text { MHC class I restricted, recognize/check } \\
\text { their targets first by TCR. Most } \\
\text { melanoma express MHC class I, not } \\
\text { MHC class II are to be killed by tomor- } \\
\text { specific CD } 8+\text { T cells. }\end{array}$ & $\begin{array}{l}\text { Cytotoxic } \mathrm{T} \text { lymphocytes that } \\
\text { infiltrate into tumor and kill cancer } \\
\text { cells expressing the TCR targets on } \\
\text { surface. Activated by TCR, could } \\
\text { kill autologous and allogeneic } \\
\text { melanoma. }\end{array}$ \\
\hline $\mathrm{CD} 4+\mathrm{T}$ & $\begin{array}{l}\text { Adaptive } \\
\text { immunity, } \\
\text { tumor- } \\
\text { specific. }\end{array}$ & $\begin{array}{l}\text { MHC class II restricted recognize/check } \\
\text { their targets first by TCR. Some } \\
\text { melanomas express MHC class II and are } \\
\text { able to be processed and present by } \\
\text { antigen-presenting cells (i.e. DCs), then } \\
\text { the antigen will be recognized by CD4+ } \\
\mathrm{T} \text { cells, who is the mediator/helper of } \\
\mathrm{CD} 8+\mathrm{T} \text { cells. }\end{array}$ & $\begin{array}{l}\text { CD4+ } \mathrm{T} \text { cells mostly are helper } \\
\text { cells, bridging the antigen } \\
\text { presenting cells and CD8+ } \mathrm{T} \text { cells. } \\
\text { Recent study showed they are } \\
\text { capable of killing too. }\end{array}$ \\
\hline
\end{tabular}

Current development of immunotherapy approaches amplify the cancer immunity cycle in six main ways (AACR 2015): immune checkpoint inhibitors, adoptive cell transfer, cancer vaccines, oncolytic virus therapies, tumor-specific monoclonal antibodies and cytokines. In particular, immune checkpoint proteins, such as CTLA4 and PD-1, are a variety of surface receptors expressed on the lymphocytes and function in inhibiting $\mathrm{T}$ cell development, proliferation and effector activities. Immune checkpoint inhibitors target those immune regulatory receptors or their ligands, promoting an active anti-tumor immune response ${ }^{4,32,33}$. Adoptive cell transfer (ACT) for cancer therapy expands the patient's tumor-infiltrating lymphocytes (TILs), primarily effector T cells, into large numbers (up to $10^{11}$ cells) in vitro using cytokines, selects $\mathrm{T}$ cells having high avidity to tumor antigens 
and infuses them back to the donor for cancer regression ${ }^{7,28,34,35}$. As an improved alternative to the initial ACT based on TILs, T cells isolated from blood (PBMC) can be genetically engineered to express $\mathrm{T}$ cell receptors (TCRs) or chimeric antigen receptors (CARs) that recognize tumor antigens and are then transferred back to patients. ACT/CAR T-cell therapy for metastatic melanoma treatment has achieved an impressive 50\% response rate in clinical tests with durable tumor eradiation, representing a promising direction for cancer therapy ${ }^{36-38}$. From the cancer-immunity cycle in Figure 2, the immune checkpoint inhibitors are trying to enhance the step 7, killing of cancer cells, whilst the ACT/CART method promotes effector $\mathrm{T}$ cell numbers and tumor-antigen recognition to enhance steps 3,6 and 7, and potentially the steps 4 and 5 are also improved due to more T cells in the circulation system. In current development of cancer immunotherapy, immune checkpoint inhibitors (i.e. anti-CTLA4 ${ }^{4,39}$, anti-PD-1/PD-L1 ${ }^{40,41}$ ) and ACT ${ }^{7,42,43}$ (i.e. CAR T) represent the main therapeutic approaches that promote durable anti-tumor response by enhancing CD8+ $\mathrm{T}$ cell numbers and activity. As they can influence almost all steps in the cancer-immunity cycle (Figure 2), cytokines can be used therapeutically to regulate antitumor immunity, as illustrated by therapeutic use of IL2, interferon- $\alpha$ (IFN- $\alpha$ ) and granulocyte-macrophage colony-stimulating factor $(\mathrm{GM}-\mathrm{CSF})^{7,33,44,45}$. IFN- $\alpha$ is being used in a variety of cancer treatment ${ }^{45,46}$ whereas clinical trial with GM-CSF is undergoing investigation $^{47,48}$. High-dose IL2 has been used as adjuvant for melanoma treatment but has been replaced of due to poor responses ${ }^{49,50}$. IL7, IL12, IL15 and IL21 also are promising immunotherapies ${ }^{7,51}$. 
Therapeutic cancer vaccines promote the cancer-immunity cycle by providing a source of tumor antigens and activating dendritic cells to attack hidden cancer cells ${ }^{52,53}$. Approved by FDA in 2010, Provenge (also named sipuleucel-t) is a personalized therapy for prostate cancer. It uses a cancer antigen, prostatic acid phosphatase (PAP) to stimulate the patient's own DCs in vitro and infuses the DCs back to the patient to mount immune response. Provenge has been shown to extend survival for about 4 months in certain metastatic prostate cancer ${ }^{53}$. Besides, vaccines can be used to prevent cancer as some viruses cause cancers, such as hepatitis B virus (HBV) and human papillomavirus (HPV) ${ }^{54-56}$. Alternatively, oncolytic viruses can specifically induce tumor cell lysis, thus releasing tumor antigens to initiate therapeutic immune response and can be used to treat multiple types of cancers ${ }^{57,58}$. Another class of immunotherapies are monoclonal antibodies (mAbs). One example is bispecific T cell engagers (BiTE, i.e. Blinatumomab) that consists of two joined mAbs binding CD3 on T cells and CD19 cancer marker, and bridge T cells with cancer cells. Blinatumomab induces $41.6 \%$ complete remission in patients and received FDA approval in 2014 for acute lymphoblastic leukemia (ALL) ${ }^{59-62}$. The anti-cancer mechanism of blinatumomab is that it enhances the trafficking to and tumor-infiltrating by effector T cells (see Figure 2, step 4 and 5), thereby, stimulating the cancer-immunity cycle for anti-tumor immune response. Those innovative methods for immunotherapy provides improvements and alternative choices in the clinic to radiation, surgery and chemotherapy.

Despite the promise of immunotherapy, tumor resists anti-cancer immunity through potent and local mechanisms of immunosuppression. Indentifying such interplay between cancer and immune cells that modulate tumor progression is a key barrier for expanding the 
durable immune response in cancer immunotherapy ${ }^{32,63,64}$. Recently, one type of extracellular vesicles with nanoscaled sizes, called exosomes, has been reported vigorously in almost all mammalian cells as one special mode of mediators that potentially delivery a variety of functional molecules ${ }^{65-68}$. Exosomes have motivated intense research interests for their multiplex roles in intercellular communications within the tumor microenvironment, such as between cancer cells and the effector T lymphocytes. Exosomes originate from multivesicular bodies (MVBs) of endosomes, as illustrated in Figure $3^{69}$, and are released to the extracellular environment when the MVBs fuse with cell membrane. In mammalian cells, exosomes are extracellular vesicles that are about $100 \mathrm{~nm}$ in diameter, with a lipid bilayer membrane that encloses protein and nucleotide contents derived from the donor cells. Functional molecules contained in exosomes include protein molecules, both from the membrane or the cytosol, as well as coding and non-coding RNAs ${ }^{67,70,71}$. Cancer exosomes derived from cancer cells or cancer patients have been widely reported in a variety of cancers, i.e. melanomas, colorectal cancer, breast cancer, prostate cancer and others $^{67,72-75}$. Regarding the protein contents, exosomes from various cell types contain 300-500 molecules of proteins that are enriched in exosomes, as well as proteins that are similarly expressed in donor cells ${ }^{69,76}$. Previous studies have shown that exosomes derived from cancer patients can either stimulate or repress the anti-tumor immune response, as tumor-antigens, immunosuppressive receptors and onco-proteins have all been identified from tumor exosomes ${ }^{77,78}$. In addition, exosomes contain various coding and non-coding RNAs (mRNAs and miRNAs) ${ }^{70,71}$, plus small RNAs ${ }^{79-81}$, which adds an extra layer of complexity in evaluating the biological functions of cancer exosomes. One of the challenges with identifying the roles of exosomes is that exosome samples are commonly 


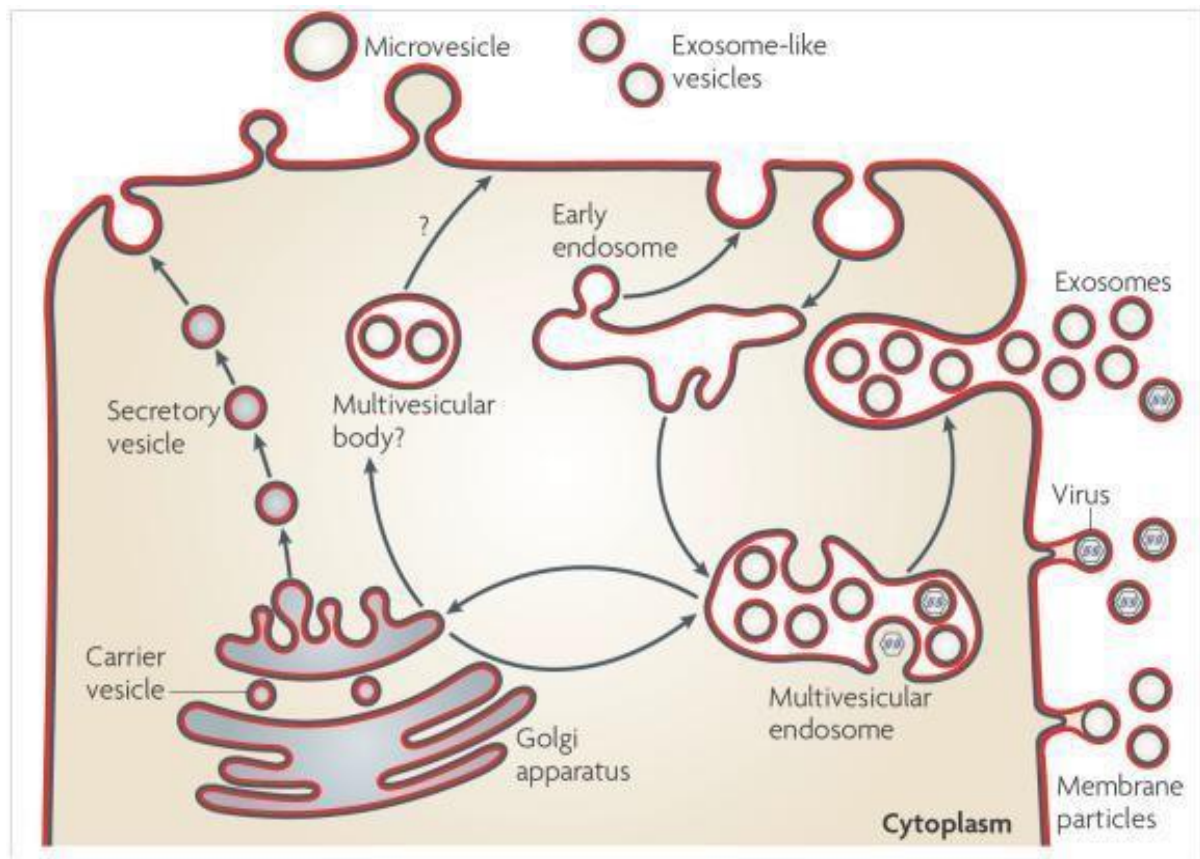

Figure 3. Mammalian cells secrete membrane vesicles ${ }^{69}$. The constitutive formation of exosomes (around $100 \mathrm{~nm}$ in diameter) is special in that it originates from the inward budding of cell membrane, forming endosomes that conduct a second inward budding on luminal membranes. This process generates multivesicular bodies (MVBs) and exosomes are released to extracellular microenvironment when MVBs fuse with cell membrane. Microvesicles (100-1000 $\mathrm{nm}$ in diameters) are constitutively formed by outward budding of the cellular membrane. Similarly outward budding occurs for virus secretion in transfected cells. Membrane particles, exosome-like vesicles and others have been found from specific types of mammalian cells, yet, the mechanisms of their formations have not been fully unraveled.

contaminated with a number of micro- and nano-scaled vesicles, vesicle-free protein-RNA complexes, lipoproteins and soluble factors that are all present at the extracellular milieu $^{69,82}$. Exosomes, as one specific type of nanoscale vesicles have a relatively uniform size and morphology under the electron microscopes ${ }^{69,83}$. Unfortunately, many methods used for sample isolation, characterization and preservation have not been tailored for exosome biology, resulting in the controversial and inconsistent findings in this rapidly developing field ${ }^{79,84}$. For instance, different RNA isolation and preparation methods vary in exosomal RNA yield and distributions ${ }^{85}$ (see Figure 4). In addition, many "exosomes" 
images shown in the literatures either lack appropriate sampling or contain obvious impurities, as shown in Figure $5^{70,86-88}$, which suggest improper sample handling.

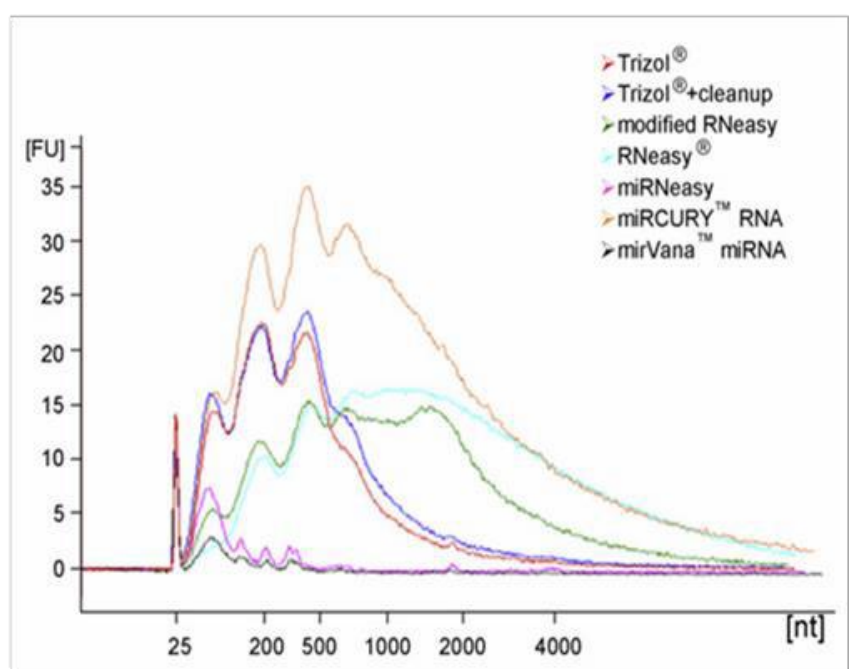

Figure. 4. Total RNAs isolated from exosomes using seven different isolation kits was analyzed by Bioanalyzer ${ }^{85}$.
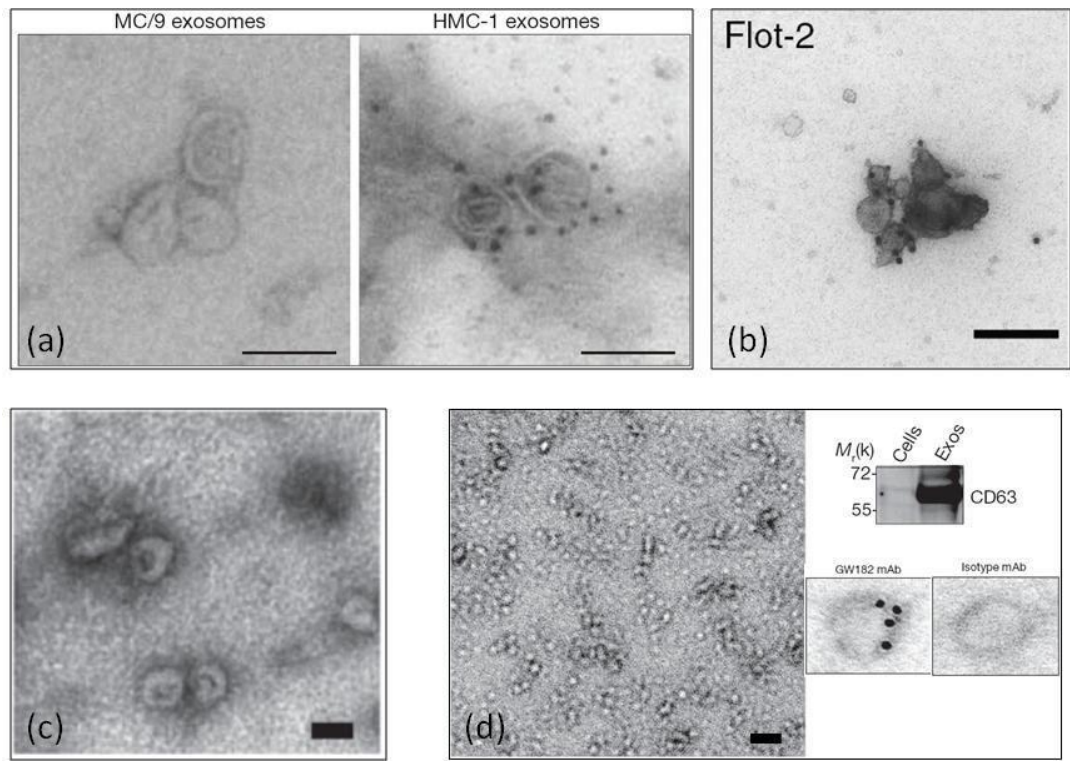

Figure 5. Previous publications show "exosomes" images lacking proper number of sampling or including obvious impurities. $(a)^{70},(b)^{86},(c)^{78}$ and $(d)^{88}$ are electron microscopy images of exosomes derived from different types of mammalian cells, respectively in previous publications. Sample number $n$ are less than 6 in (a), (b) and (c). Left panel in (d) shows more vesicles, however, its resolution is low for recognizing vesicle features, size distribution or morphological characteristics. $100 \mathrm{~nm}$ scale bar in all panels (a-d). 
Based on this scientific context, this thesis focuses on two aspects. First, we tailored the existing methods for isolating, characterizing and preserving exosomes derived from cancer cells as a way to provide standard and efficient methods for broader use. The methods reviewed include electron microscopy for morphological characterization, flow cytometry for protein biomarker identification, bioanalyzer to analyze nucleotide acids. Using these improved methods, we next characterized the role of cancer exosomes in suppressing anti-tumor immunity in a number of melanoma cell models. Specifically, we focused on mRNAs from B16F0 melanoma, identified novel expression of mRNA enrichments in exosomes compared with the parent cells, and investigated the specific functions of PTPN11 and DNMT3A in repressing effector lymphocytes. For the first time, we show that B16F0 melanoma exosomes contain intact coding mRNAs that are enriched for following genes - Ptpn11, Eif4ebp2, Wsb2, Ptp4a3, Kpnb1, Rnd2 and Actb. Collectively, the results provide evidence indicating that coding mRNAs from exosomes are functional. We also identified IL12RB2 protein receptors on the surface of B16F0 exosomes, which suggests that exosomes reinforce a cytokine sink for IL12 within the tumor microenvironment. Taking together, this study provides novel insights into exosomeassociated immunosuppressive mechanisms present at the tumor sites. 


\section{Reference for Chapter 1}

1. Stewart, B. W. \& Wild, C. P. World Cancer Report 2014. World Health Organization: Geneva (2014).

2. Hanahan, D. \& Weinberg, R. a. Hallmarks of cancer: the next generation. Cell 144, 646-674 (2011).

3. Jemal, A., Bray, F. \& Ferlay, J. Global Cancer Statistics. 61, 69-90 (2011).

4. Pardoll, D. M. The blockade of immune checkpoints in cancer immunotherapy. Nat Rev Cancer. 12, 252-264 (2012).

5. Lesterhuis, W. J., Haanen, J. B. a G. \& Punt, C. J. a. Cancer immunotherapy-revisited. Nat. Rev. Drug Discov. 10, 591-600 (2011).

6. Vanneman, M. \& Dranoff, G. Combining immunotherapy and targeted therapies in cancer treatment. Nature Reviews Cancer 12, 237-251 (2012).

7. Restifo, N. P., Dudley, M. E. \& Rosenberg, S. a. Adoptive immunotherapy for cancer: harnessing the T cell response. Nat. Rev. Immunol. 12, 269-281 (2012).

8. Svane, I. M. \& Verdegaal, E. M. Achievements and challenges of adoptive T cell therapy with tumor-infiltrating or blood-derived lymphocytes for metastatic melanoma: what is needed to achieve standard of care? Cancer Immunol. Immunother. 1081-1091 (2014). doi:10.1007/s00262-014-1580-5

9. Hodi, F. S. et al. Improved Survival with Ipilimumab in Patients with Metastatic Melanoma. New England Journal of Medicine 363, 711-723 (2010).

10. Robert, C. et al. Ipilimumab plus dacarbazine for previously untreated metastatic melanoma. N. Engl. J. Med. 364, 2517-2526 (2011).

11. Robert, C. et al. Pembrolizumab versus Ipilimumab in Advanced Melanoma. N. Engl. J. Med. 372, 2521-2532 (2015).

12. Addeo, A. \& Rinaldi, C. R. Treatment with ipilimumab: a case report of complete response in a metastatic malignant melanoma patient. Case Rep. Oncol. 6, 285-8 (2013).

13. Kaufman, H. L. et al. The Society for Immunotherapy of Cancer consensus statement on tumour immunotherapy for the treatment of cutaneous melanoma. Nat. Rev. Clin. Oncol. 10, 588-98 (2013).

14. Hölzel, M., Bovier, A. \& Tüting, T. Plasticity of tumour and immune cells: a source of heterogeneity and a cause for therapy resistance? Nat. Rev. Cancer 13, 365-76 (2013).

15. Landsberg, J. et al. Melanomas resist T-cell therapy through inflammation-induced reversible dedifferentiation. Nature 490, 412-6 (2012).

16. Sethi, N. \& Kang, Y. Unravelling the complexity of metastasis - molecular understanding and targeted therapies. Nat. Rev. Cancer 11, 735-48 (2011).

17. Howlader, N. et al. SEER Cancer Statistics Review, 1975-2009 (Vintage 2009 Populations). National Cancer Institute Bethesda MD (2011). at <http://seer.cancer.gov/csr/1975_2009_pops09/>

18. Umansky, V. \& Sevko, A. Melanoma-induced immunosuppression and its neutralization. Semin. Cancer Biol. 22, 319-26 (2012).

19. Curran, M. A., Montalvo, W., Yagita, H. \& Allison, J. P. PD-1 and CTLA-4 combination blockade expands infiltrating $\mathrm{T}$ cells and reduces regulatory $\mathrm{T}$ and 
myeloid cells within B16 melanoma tumors. Proc. Natl. Acad. Sci. U. S. A. 107, 4275-4280 (2010).

20. Balkwill, F. \& Mantovani, A. Inflammation and cancer: Back to Virchow? Lancet 357, 539-545 (2001).

21. Navarini-Meury, A. A. \& Conrad, C. Melanoma and innate immunity--aActive inflammation or just erroneous attraction? Melanoma as the source of leukocyteattracting chemokines. Semin. Cancer Biol. 19, 84-91 (2009).

22. Mukherji, B. Immunology of melanoma. Clin. Dermatol. 31, 156-65 (2013).

23. Chen, D. S. \& Mellman, I. Oncology meets immunology: the cancer-immunity cycle. Immunity 39, 1-10 (2013).

24. Mackensen, A. et al. Evidence for in situ amplification of cytotoxic T-lymphocytes with antitumor activity in a human regressive melanoma. Cancer Res. 53, 35693573 (1993).

25. Ferradini, L. et al. Analysis of $\mathrm{T}$ cell receptor variability in tumor-infiltrating lymphocytes from a human regressive melanoma: Evidence for in situ $\mathrm{T}$ cell clonal expansion. J. Clin. Invest. 91, 1183-1190 (1993).

26. Mackensen, A. et al. Direct evidence to support the immunosurveillance concept in a human regressive melanoma. J. Clin. Invest. 93, 1397-1402 (1994).

27. Hellstrom K.E., Hellstrom I. Cellular immunity against tumor antigens. Adv. Cancer Res 12, 167-214 (1969).

28. Rosenberg, S. A., Spiess, P. \& Lafreniere, R. A new approach to the adoptive immunotherapy of cancer with tumor-infiltrating lymphocytes. Science 233, 13181321 (1986).

29. Mukherji, B. \& MacAlister, T. Clonal analysis of cytotoxic T cell response against human melanoma. J. Exp. Med. 158, 240-245 (1983).

30. Knuth, A., Danowski, B., Oettgen, H. F. \& Old, L. J. T-cell-mediated cytotoxicity against autologous malignant melanoma: analysis with interleukin 2-dependent Tcell cultures. Proc. Natl. Acad. Sci. U. S. A. 81, 3511-3515 (1984).

31. Kawakami, Y. et al. T cell immune responses against melanoma and melanocytes in cancer and autoimmunity. Pigment Cell Res. 13 Suppl 8, 163-169 (2000).

32. Mocellin, S., Benna, C. \& Pilati, P. Coinhibitory molecules in cancer biology and therapy. Cytokine Growth Factor Rev. 24, 147-61 (2013).

33. Mellman, I., Coukos, G. \& Dranoff, G. Cancer immunotherapy comes of age. Nature 480, 480-489 (2011).

34. Dudley, M. E. \& Rosenberg, S. a. Adoptive-cell-transfer therapy for the treatment of patients with cancer. Nat. Rev. Cancer 3, 666-675 (2003).

35. Rosenberg, S. A. \& Restifo, N. P. Adoptive cell transfer as personalized immunotherapy for human cancer. Science. 348, 62-68 (2015).

36. Dudley, M. E. et al. Adoptive cell therapy for patients with metastatic melanoma: Evaluation of intensive myeloablative chemoradiation preparative regimens. J. Clin. Oncol. 26, 5233-5239 (2008).

37. Rosenberg, S. A. et al. Durable complete responses in heavily pretreated patients with metastatic melanoma using T-cell transfer immunotherapy. Clin. Cancer Res. 17, 4550-4557 (2011). 
38. Besser, M. J. et al. Adoptive transfer of tumor-infiltrating lymphocytes in patients with metastatic melanoma: Intent-to-treat analysis and efficacy after failure to prior immunotherapies. Clin. Cancer Res. 19, 4792-4800 (2013).

39. Leach, D. R., Krummel, M. F. \& Allison, J. P. Enhancement of antitumor immunity by CTLA-4 blockade. Science 271, 1734-1736 (1996).

40. Blank, C. et al. PD-L1/B7H-1 Inhibits the Effector Phase of Tumor Rejection by T Cell Receptor (TCR) Transgenic CD8+ T Cells. Cancer Res. 64, 1140-1145 (2004).

41. Okazaki, T. \& Honjo, T. PD-1 and PD-1 ligands: From discovery to clinical application. Int. Immunol. 19, 813-824 (2007).

42. Rosenberg, S. A., Yang, J. C. \& Restifo, N. P. Cancer immunotherapy: moving beyond current vaccines. Nat. Med. 10,909-915 (2004).

43. Rosenberg, S. a. et al. Durable Complete Responses in Heavily Pretreated Patients with Metastatic Melanoma Using T-Cell Transfer Immunotherapy. Clin. Cancer Res. 17, 4550-4557 (2011).

44. Lee, S. \& Margolin, K. Cytokines in cancer immunotherapy. Cancers 3, 3856-3893 (2011).

45. Zitvogel L, Galluzzi L, Kepp O, Smyth MJ, K. G. Type I interferons in anticancer immunity. Nat. Rev. Immunol. 15, 405-414 (2015).

46. Rafique, I., Kirkwood, J. M. \& Tarhini, A. a. Immune Checkpoint Blockade and Interferon- $\alpha$ in Melanoma. Semin. Oncol. 42, 436-447 (2015).

47. Goldberg, J. et al. Biologic Activity of Autologous, Granulocyte-Macrophage Colony Stimulating Factor Secreting Alveolar Soft Parts Sarcoma and Clear Cell Sarcoma Vaccines. Clin. Cancer Res. 21, 3178-3187 (2015).

48. Chen G. et al. A feasibility study of cyclophosphamide, trastuzumab, and an allogeneic GM-CSF-secreting breast tumor vaccine for HER2+ metastatic breast cancer. Cancer Immunol. Res. 2, 949-961 (2014).

49. Jason B Muhitch \& Thomas Schwaab. High-dose IL-2 for metastatic renal cell carcinoma: can the first antitumor immunotherapy be reinvented? Immunotherapy $\mathbf{6}$, 955-958 (2014).

50. Foureau DM, Amin A, White RL, Anderson W, Jones CP, Sarantou T, McKillop $\mathrm{IH}$, S. J. Sequential immune monitoring in patients with melanoma and renal cell carcinoma treated with high-dose interleukin-2: immune patterns and correlation with outcome. Cancer Immunol Immunother 63, 1329-1340 (2014).

51. Floros, T. \& Tarhini, A. A. Anticancer Cytokines: Biology and Clinical Effects of Interferon- $\alpha 2$, Interleukin (IL)-2, IL-15, IL-21, and IL-12. Semin. Oncol. 42, 539548 (2015).

52. Odunsi, K. et al. Efficacy of vaccination with recombinant vaccinia and fowlpox vectors expressing NY-ESO-1 antigen in ovarian cancer and melanoma patients. Proc. Natl. Acad. Sci. U. S. A. 109, 5797-5802 (2012).

53. Kantoff, P. W. et al. Sipuleucel-T immunotherapy for castration-resistant prostate cancer. N. Engl. J. Med. 363, 411-422 (2010).

54. De Martel, C. et al. Global burden of cancers attributable to infections in 2008: A review and synthetic analysis. Lancet Oncol. 13, 607-615 (2012). 
55. Buonaguro, L., Petrizzo, A., Tornesello, M. L. \& Buonaguro, F. M. Translating tumor antigens into cancer vaccines. Clinical and Vaccine Immunology 18, 23-34 (2011).

56. Chu NJ, Armstrong TD, J. E. Nonviral oncogenic antigens and the inflammatory signals driving early cancer development as targets for cancer immunoprevention. Clin Cancer Res 21, 1549-1557 (2015).

57. Breitbach, C. J. et al. Intravenous delivery of a multi-mechanistic cancer-targeted oncolytic poxvirus in humans. Nature 477, 99-102 (2011).

58. Lichty, B. D., Breitbach, C. J., Stojdl, D. F. \& Bell, J. C. Going viral with cancer immunotherapy. Nat. Rev. Cancer 14, 559-567 (2014).

59. Topp, M. S. et al. Phase II Trial of the Anti-CD19 Bispecific T Cell-Engager Blinatumomab Shows Hematologic and Molecular Remissions in Patients With Relapsed or Refractory B-Precursor Acute Lymphoblastic Leukemia. J. Clin. Oncol. 32, 4134-4140 (2014).

60. Topp, M. S. et al. Targeted therapy with the T-cell-engaging antibody blinatumomab of chemotherapy-refractory minimal residual disease in B-lineage acute lymphoblastic leukemia patients results in high response rate and prolonged leukemia-free survival. J. Clin. Oncol. 29, 2493-2498 (2011).

61. Weiner, L. M., Surana, R. \& Wang, S. Monoclonal antibodies: versatile platforms for cancer immunotherapy. Nat. Rev. Immunol. 10, 317-327 (2010).

62. Sanford, M. Blinatumomab: First Global Approval. Drugs 75, 321-327 (2015).

63. Zitvogel, L., Tesniere, A. \& Kroemer, G. Cancer despite immunosurveillance: immunoselection and immunosubversion. Nat. Rev. Immunol. 6, 715-727 (2006).

64. Mantovani, A., Allavena, P., Sica, A. \& Balkwill, F. Cancer-related inflammation. Nature 454, 436-444 (2008).

65. Meckes, D. G. et al. Human tumor virus utilizes exosomes for intercellular communication. Proc. Natl. Acad. Sci. U. S. A. 107, 20370-20375 (2010).

66. Filipazzi, P., Bürdek, M., Villa, A., Rivoltini, L. \& Huber, V. Recent advances on the role of tumor exosomes in immunosuppression and disease progression. Semin Cancer Biol. 22, 342-349 (2012).

67. Iero, M. et al. Tumour-released exosomes and their implications in cancer immunity. Cell Death Differ. 15, 80-88 (2008).

68. Benito-Martin, A., Di Giannatale, A., Ceder, S. \& Peinado, Hã@. The New Deal: A Potential Role for Secreted Vesicles in Innate Immunity and Tumor Progression. Front. Immunol. 6, 66 (2015).

69. Théry, C., Ostrowski, M. \& Segura, E. Membrane vesicles as conveyors of immune responses. Nat. Rev. Immunol. 9, 581-593 (2009).

70. Valadi, H. et al. Exosome-mediated transfer of mRNAs and microRNAs is a novel mechanism of genetic exchange between cells. Nat. Cell Biol. 9, 654-659 (2007).

71. Taylor, D. D. \& Gercel-Taylor, C. MicroRNA signatures of tumor-derived exosomes as diagnostic biomarkers of ovarian cancer. Gynecol. Oncol. 110, 13-21 (2008).

72. Andre, F. et al. Mechanisms of disease Malignant effusions and immunogenic tumour-derived exosomes. Lancet. 360, 295-305 (2002). 
73. Taylor, D. D. \& Gerçel-Taylor, C. Tumour-derived exosomes and their role in cancer-associated T-cell signalling defects. Br. J. Cancer 92, 305-311 (2005).

74. Whiteside, T. L. Tumour-derived exosomes or microvesicles: another mechanism of tumour escape from the host immune system? Br. J. Cancer 92, 209-211 (2005).

75. Wolfers, J. et al. Tumor-derived exosomes are a source of shared tumor rejection antigens for CTL cross-priming. Nat. Med. 7, 297-303 (2001).

76. Simpson, R. J., Lim, J. W., Moritz, R. L. \& Mathivanan, S. Exosomes: proteomic insights and diagnostic potential. Expert Rev. Proteomics 6, 267-283 (2009).

77. Somasundaram, R. \& Herlyn, M. Melanoma exosomes: messengers of metastasis. Nat. Med. 18, 853-854 (2012).

78. Peinado, H. et al. Melanoma exosomes educate bone marrow progenitor cells toward a pro-metastatic phenotype through MET. Nat. Med. 18, 883-891 (2012).

79. Raposo, G. \& Stoorvogel, W. Extracellular vesicles: exosomes, microvesicles, and friends. J. Cell Biol. 200, 373-383 (2013).

80. Bellingham, S. A., Coleman, B. M. \& Hill, A. F. Small RNA deep sequencing reveals a distinct miRNA signature released in exosomes from prion-infected neuronal cells. Nucleic Acids Res. 40, 10937-10949 (2012).

81. Nolte'T Hoen, E. N. M. et al. Deep sequencing of RNA from immune cell-derived vesicles uncovers the selective incorporation of small non-coding RNA biotypes with potential regulatory functions. Nucleic Acids Res. 40, 9272-9285 (2012).

82. Cocucci, E., Racchetti, G. \& Meldolesi, J. Shedding microvesicles: artefacts no more. Trends Cell Biol. 19, 43-51 (2009).

83. Théry, C., Amigorena, S., Raposo, G. \& Clayton, A. Isolation and characterization of exosomes from cell culture supernatants and biological fluids. Curr. Protoc. Cell Biol. Chapter 3, Unit 3.22 (2006).

84. Mathivanan, S., Ji, H. \& Simpson, R. J. Exosomes: Extracellular organelles important in intercellular communication. J. Proteomics 73, 1907-1920 (2010).

85. Eldh, M., Lötvall, J., Malmhäll, C. \& Ekström, K. Importance of RNA isolation methods for analysis of exosomal RNA: Evaluation of different methods. Mol. Immunol. 50, 278-286 (2012).

86. Grapp, M. et al. Choroid plexus transcytosis and exosome shuttling deliver folate into brain parenchyma. Nat. Commun. 4, 2123 (2013).

87. Peinado, H., Lavotshkin, S. \& Lyden, D. The secreted factors responsible for premetastatic niche formation: old sayings and new thoughts. Semin. Cancer Biol. 21, 139-146 (2011).

88. Gibbings, D. J., Ciaudo, C., Erhardt, M. \& Voinnet, O. Multivesicular bodies associate with components of miRNA effector complexes and modulate miRNA activity. Nat. Cell Biol. 11, 1143-1149 (2009). 


\section{CHAPTER 2:}

\section{EXOSOMES: IMPROVED METHODS TO CHARACTERIZE THEIR MORPHOLOGY, RNA CONTENT, AND SURFACE PROTEIN BIOMARKERS}

\subsection{Introduction}

Coordinated action among a diverse collection of individual cell types within a tissue requires robust modes for intercellular communication. Cells receive and transmit information through a variety of mechanisms, some of which are wellcharacterized while others remain hazy. Conventional study of these mechanisms focuses on direct modes of communication that require cell-to-cell contact or indirect modes that rely on the release of soluble biochemical cues. These soluble cues are relayed through diffusive and convective transport mechanism and signal via receptors. An emerging and controversial mode of communication that blends aspects from both categories are exosomes ${ }^{1-3}$.

Exosomes are nanoscale vesicles derived from the luminal membranes of multivesicular bodies (MVBs) and are released to the extracellular milieu when MVBs fuse with the cell membrane $e^{4,5}$. Exosomes are reported to convey coding $\mathrm{RNA}^{6}$, non-coding $\mathrm{RNA}^{7,8}$, oncoproteins ${ }^{9-11}$, and antigen presentation molecules ${ }^{12}$, or even DNA ${ }^{13}$ between cells. By carrying a complex payload of proteins and RNAs, exosomes may manipulate recipient cells and other organs over a long distance ${ }^{6,7,10,14-21}$. For instance, tumor-derived exosomes have been reported to 
prepare distant sites for metastatic colonization ${ }^{10,22,23}$ or serve as disease biomarkers $^{7,31-34}$. Alternatively, exosomes may play a local role in shaping the development and homeostasis of normal tissues ${ }^{35-38}$ or in oncogenesis; including

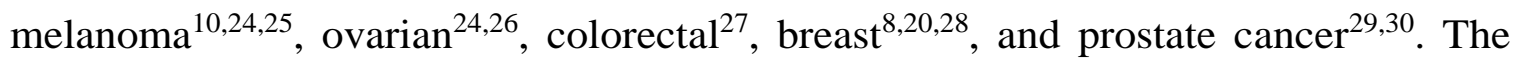
spatial organization of tissues depends on convective and diffusive transport mechanisms to relay intercellular information. Thus, the specific role that exosomes play may depend highly on size, given the inverse relationship between diffusivity in extracellular matrices and molecular size ${ }^{39}$.

However, one of the challenges with identifying the biological role of exosomes in transmitting information between cells is that they are one of a number of extracellular nano- and micro-scaled vesicles that are constitutively produced by cells and vary in size, molecular composition, and biological function $^{1,40}$. While the extracellular vesicles field has grown significantly in recent years, the controversy associated with the exosome literature is fueled by inconsistent nomenclature and isolation methods that result in impure preparations $^{41,42}$. Wondering whether existing methods could distort our view of exosome biology, we focused on three important aspects related to obtaining and assessing the quality of exosome samples. First, we compared electron microscopy methods for assessing population-level exosome morphology, as a way to distinguish between exosomes and other confounding extracellular vesicles based on their size distributions. Second, we compared conditions for producing and storing exosomes in vitro in relation to the quality of exosome samples. Third, we 
developed methods to improve the sensitivity of flow cytometry to assay of protein expression on exosomes.

\subsection{Experimental}

\subsubsection{Materials and reagents}

B16F0 cells, a murine model of metastatic melanoma, were acquired from American Type Culture Collection (ATCC, Manassas, VA). A HER2+ human breast cancer cell line, SKBR3, was kindly provided by Dr. Jia Luo (University of Kentucky, Lexington, KY). Dulbecco's Modification of Eagle's Medium (DMEM) was from Cellgro (Manassas, VA). Improved Modified Eagle Medium Zn2+ option (IMEM, no phenol red) was from Invitrogen (Grand Island, NY). Dulbecco's Phosphate-Buffered Saline (DPBS, $0.1 \mu \mathrm{m}$ sterile filtered) and heat inactivated fetal bovine serum (FBS) was from Hyclone, Inc (Logan, Utah).

TEM (transmission electron microscopy) copper grids (200 mesh and coated by formvar carbon film), glutaraldehyde solution, paraformaldehyde (16\% paraformaldehyde aqueous solution) and 4\% uranyl acetate solution were from Electron Microscopy Sciences (Hatfield, PA). DNA-free ${ }^{\mathrm{TM}}$ DNA removal kit, mirVana $^{\mathrm{TM}}$ miRNA isolation kit, and SuperScript III First-Strand Synthesis System were from Invitrogen. RNA 6000 pico kit, reagents and ladders for Agilent 2100 Bioanalyzer was from Agilent Technologies (Santa Clara, CA). DEPC water was made by mixing distilled water with $0.1 \% \mathrm{v} / \mathrm{v}$ diethylpyrocarbonate for at least 2 hours at $37^{\circ} \mathrm{C}$ and then the water was autoclaved for $30 \mathrm{~min}$. 
Allophycocyanin (APC) conjugated mouse anti-human Her1/ErbB1 monoclonal antibody (SC-120), phycoerythrin (PE) conjugated mouse anti-human $\mathrm{HER} 2 / \mathrm{Neu} / \mathrm{ErbB} 2 \mathrm{mAb}$ (SC-23864) and PE conjugated mouse isotype control mAbs (SC-2866) were purchased from Santa Cruz Biotechnology (Dallas, TN). Human IgG and mouse IgG were from Jackson ImmunoResearch Laboratories (West Grove, PA). APC or PE conjugated mouse anti human/mouse IL-12 receptor beta 2 (IL12RB2) mAbs (FAB1959) was from R\&D systems (Minneapolis, MN). Quantum Simply Cellular microspheres conjugated to anti-mouse $\operatorname{IgG}$ were purchased from Bangs Laboratories (Fishers, IN). Polystyrene beads with respective diameters $2.19,0.84$ and $0.054 \mu \mathrm{m}$ and labeled with Nile red were from Spherotech, Inc. (Lake Forest, IL). PBSAz for cells was prepared by mixing 2\% FBS and $0.02 \%$ sodium azide in DPBS. PBSAz for exosomes was prepared by mixing $0.5 \%$ BSA and filtered twice using sterile $0.22 \mu \mathrm{m}$ filters to exclude nanoparticles. Vybrant ${ }^{\circledR}$ DiI lipophilic tracer (DiI, Cat\#: V22888) was from Invitrogen (Grand Island, NY).

\subsubsection{Tissue culture}

B16F0 was maintained in DMEM supplemented with 10\% FBS and penicillin/streptomycin at $37^{\circ} \mathrm{C}, 5 \% \mathrm{CO}_{2}$, passaged at $1: 5$ every 2 days or until $100 \%$ confluence of cells as described previously ${ }^{43}$. SKBR3 cell culture was maintained in $37^{\circ} \mathrm{C}, 5 \% \quad \mathrm{CO}_{2}$, correspondingly in supplemented medium as described previously ${ }^{20,44}$. Briefly, SKBR3 was maintained in IMEM supplemented with $10 \%$ FBS and penicillin/streptomycin that was replaced of every 2 days, and passaged at 1:3 every 4-6 days when cells reached $80 \%$ confluence. To detach 
adherent cells, B16F0 or SKBR3, trypsin-EDTA was applied for $7-10 \mathrm{~min}$ at $37^{\circ} \mathrm{C}$, $5 \% \mathrm{CO}_{2}$ after one wash by DPBS. After trypsin treatment, FBS was added to neutralize and resuspend cells. Cells were washed once in medium before further culture or any treatment.

\subsubsection{Exosome preparation and isolation}

Exosomes were isolated as described previously ${ }^{45}$. In brief, cell lines were cultured until $70 \%$ confluence, washed once by DPBS, and incubated with fresh serum-free medium for $30 \mathrm{~min}$ at $37^{\circ} \mathrm{C}$ and $5 \% \mathrm{CO}_{2}$. After 30 minutes, the medium was replaced either by serum-free medium (SFM) or exosome-free serum containing medium (EFM) and returned to the incubator for the indicated exosome production period. The cell-conditioned media were collected at different time points and exosomes were isolated by differential centrifugation as follows: 300 $\times \mathrm{g}$ for 10 minutes to remove cells, $2,600 \times \mathrm{g}$ for 10 minutes to remove residual cells and debris, $10,000 \times \mathrm{g}$ for 60 minutes to remove microvesicles, and 100,000 $\times_{\mathrm{g}}$ for 2 hours to collect nano-scaled vesicles in pellets. The resulting pellet was resuspended, washed once in DMEM, and re-pelleted at 100,000 $\times_{\mathrm{g}}$ for 2 hours. Differential centrifugation was conducted using a Beckman Coulter X-14R centrifuge and a Beckman Coulter XL90 ultracentrifuge with proper rotors, opentop (Cat\#: 355631) or capped (Cat\#: 355618, Cat\#: 355655) thickwall polycarbonate tubes (Beckman Coulter). Once isolated, nano-scaled vesicles were resuspended in DPBS and kept on ice.

\subsubsection{Exosome cryopreservation}


Exosomes were preserved in two different ways: directly frozen at $-80^{\circ} \mathrm{C}$ and cryopreserved in liquid nitrogen $\left(-196^{\circ} \mathrm{C}\right)$ as is typically done with mammalian cells. The cryopreservation protocol involved mixing isolated exosomes with equal volume of medium containing $2 \times$ DMSO $(10 \%$ or $20 \%)$, aliquoting $1 \mathrm{ml}$ into each cryopreservation tube, wrapping tubes in heat isolated materials and storing in a $-80^{\circ} \mathrm{C}$ freezer overnight (about $16 \mathrm{hr}$ ). Samples were then put in liquid nitrogen for preservation. To remove from cryopreservation, exosomes were thawed on ice for $30 \mathrm{~min}$ according $\mathrm{to}^{45}$, or $1-2 \mathrm{~min}$ at $37^{\circ} \mathrm{C}$ according to recovering cell lines, washed once in $20 \mathrm{ml}$ PBS, and ultracentrifuged to pellet. The supernatant was discarded and exosome pellet was resuspended in $200 \mu \mathrm{L}-1 \mathrm{~mL}$ PBS for SEM inspection.

\subsubsection{Induction of apoptotic and necrotic cell death in B16F0 cells}

Extracellular vesicles constitutively produced by cells were compared to vesicles released during cell death. To induce apoptosis, B16F0 cells were cultured in serum-free medium containing $10 \mu \mathrm{M}$ 7-ethyl-10-hydroxycamptothecin (Cayman Chemical Company, USA) for 24 hours, as reported previously ${ }^{46}$. After treatment, B16F0 cells were 70-80\% confluence, with visible detached and dead cells in the culture. Extracellular vesicles (i.e., apoptotic vesicles) were subsequently collected from the B16F0 cell conditioned medium. To induce necrotic cell death, B16F0 cells exposed to high shear conditions by vigorous vortex and extracellular vesicles (i.e., necrotic bodies) were subsequently collected from conditioned media. Apoptotic vesicles and necrotic bodies were isolated by differential (ultra)-centrifugation that was identical with the exosome isolation. 
Biological experiments were performed independently at least three times. Each biological sample was diluted 4-6 fold, fixed and mounted on substrates, and imaged by electron microscopy (EM). At least $3 \mathrm{EM}$ images were acquired for each sample.

\subsubsection{Scanning electron microscopy (SEM)}

Pellets containing extracellular vesicles isolated from healthy cells (i.e., exosomes) and from apoptotic and necrotic cells were vortexed and resuspended in $0.2-1 \mathrm{ml}$ DPBS. Exosomes and nano-scaled apoptotic vesicles or necrotic bodies (micro-scaled parts of apoptotic vesicles or necrotic bodies were removed prior to ultracentrifugation) were fixed in a $2 \%$ EMS-quality paraformaldehyde aqueous solution. The samples were then diluted in distilled (dl) water in serial dilutions, added in 1-5 $\mu \mathrm{l}$ vesicle mixtures to cleaned silicon chips, which were sonicated in acetone, ethanol and distilled water for $5 \mathrm{~min}$ in each solvent, flushed by water and blown dry, and immobilized after drying vesicles under a ventilation hood. Samples on silicon chips were mounted on a SEM stage by carbon paste. To make surface conductive, a coating of $2-5 \mathrm{~nm}$ gold-palladium alloy was applied by sputtering (SPI-Module Sputtering, Argon as gas for plasma) before imaging by scanning electron microscopy Hitachi S-4700 or a JEOL JSM-7600F SEM. SEM was performed under low beam energies (5.0-10.0 kV). For best vesicle morphology under SEM, fresh isolated exosomes were fixed and immobilized on silicon right after isolation, and imaged within 7 days. Analysis of exosome sizes were done using the SEM images via ImageJ and the density distribution of exosome diameters were obtained using R/Bioconductor. 


\subsubsection{Transmission electron microscopy (TEM)}

Exosomes were produced by incubating cells in serum free medium for $24 \mathrm{hrs}$. Freshly isolated exosomes from mouse melanoma B16F0 cells were resuspended in cold DPBS containing 2\% para-formaldehyde. Exosome samples were prepared for TEM inspection as described previously ${ }^{45}$. Briefly, exosomes were mounted on copper grids, fixed by $1 \%$ glutaraldehyde in cold DPBS for $5 \mathrm{~min}$ to stabilize the immunoreaction, washed in sterile distilled water, contrasted by uranyl-oxalate solution at $\mathrm{pH} 7$ for $5 \mathrm{~min}$, and embedded by methyl cellulose-UA for $10 \mathrm{~min}$ on ice. Excess cellulose was removed and samples were dried for permanent preservation. A JEOL 1010 TEM was used to image exosome samples at a voltage of $80 \mathrm{kV}$.

\subsubsection{Statistical analysis}

Extracellular vesicle sizes are reported in terms of diameters (mean \pm standard deviation). Comparisons among multiple groups were performed with one-way or two-way ANOVA methods depending on the factors using SPSS statistics 20. The statistical difference in means between two different groups were compared using a two-sided Student's t-test with unequal variance, where a $\mathrm{P}$ value $<0.05$ was considered as significant.

\subsubsection{Exosomal RNA (esRNA)}

To characterize exosomal RNA, total RNA were isolated from cells, fresh exosome or frozen exosome pellets using a mirVana ${ }^{\mathrm{TM}}$ miRNA isolation kit (Life Technologies) according to the manufacturer's protocol. DNase digestion was then 


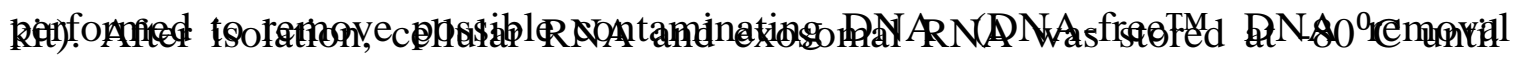
characterized using a NanoDrop 2000 Spectrophotometer (Thermo Scientific) and on-chip-electrophoresis via Agilent 2100 Bioanalyzer and RNA 6000 pico kit. Strict RNA handling guidelines were followed during assays with RNA.

B16F0 cellular RNA and esRNA were reversely transcribed with the SuperScript III system. B16F0 genomic DNA was isolated using Genomic DNA Purification Kit (Thermo Scientific). The cDNAs, together with genomic DNA about $10 \%$ of RNA input, were used to amplify the full-length coding sequences (ORFs) or part of introns of the indicated genes by semi-quantitative PCR, in which the amplified DNA products were monitored from certain cycles after the desired fragments showed up, and compared before the amplification was saturated. The primer sequences are listed in Table 1.

Table 1. Primers used for semi-quantitative PCR.

\begin{tabular}{|l|c|l|l|}
\hline Genes (mouse) & Amplicon & Primers & \multicolumn{1}{c|}{ Sequences } \\
\hline Eif4ebp2 & ORF & $\begin{array}{l}\text { Forward } \\
\text { Reverse }\end{array}$ & $\begin{array}{l}\text { ATGTCCGCGTCGGCCGGTG } \\
\text { TCAGATGTCCATCTCAAACTGAG }\end{array}$ \\
\cline { 2 - 4 } & Intron \# 1 & $\begin{array}{l}\text { Forward } \\
\text { Reverse }\end{array}$ & $\begin{array}{l}\text { GTAGAGGCGCTGTCAGGTTT } \\
\text { CCCGACTAGTGTGTGCTGTT }\end{array}$ \\
\hline Wsb2 & ORF & $\begin{array}{l}\text { Forward } \\
\text { Reverse }\end{array}$ & $\begin{array}{l}\text { ATGGAGGCCGGAGAGGAG } \\
\text { CTAGAAAGTCCTGTATGTGAGG }\end{array}$ \\
\cline { 2 - 5 } & Intron \# 1 & $\begin{array}{l}\text { Forward } \\
\text { Reverse }\end{array}$ & $\begin{array}{l}\text { GTAGGTCCCGACACCCTAGT } \\
\text { CCATCCCTAGCATCTCTGCG }\end{array}$ \\
\hline Rnd2 & ORF & $\begin{array}{l}\text { Forward } \\
\text { Reverse }\end{array}$ & $\begin{array}{l}\text { ATGGAGGGGCAGAGTGGC } \\
\text { TCACATGAGGTTACAGCTCTTG }\end{array}$ \\
& Intron \# 1 & $\begin{array}{l}\text { Forward } \\
\text { Reverse }\end{array}$ & $\begin{array}{l}\text { GCATCAGAGGATCCGGAAGG } \\
\text { GGTCCAGCTCAGTCCCTAGA }\end{array}$ \\
\cline { 2 - 4 } & & & \multicolumn{2}{|c}{} \\
\hline
\end{tabular}




\subsubsection{Western blot analysis}

Western blot analysis was used to confirm that exosome samples contained proteins commonly associated with exosomes. For immunoblotting, rabbit antiCD9, CD63, CD81, Hsp70 antibodies were from System Biosciences (Mountain View, CA), mouse anti- $\beta$-actin and $\beta$-tubulin were from Santa Cruz Biotechnology, Inc. (Dallas, Texas). B16F0 cells and exosomes were lysed with ice-cold radio immunoprecipitation assay buffer (RIPA, $150 \mathrm{mM}$ sodium chloride, $1.0 \%$ Triton $\mathrm{X}-100,0.5 \%$ sodium deoxycholate, $0.1 \%$ SDS, $50 \mathrm{mM}$ Tris, $\mathrm{pH}$ 8.0) supplemented with protease and phosphatase inhibitors. The protein concentration was determined using Pierce BCA Protein Assay Kit (Life Technologies), and $20 \mu \mathrm{g}$ of each sample was resolved for SDS-polyacrylamide gel electrophoresis. Proteins were transferred to Bio Trace PVDF membrane (PALL Life Sciences, Pensacola, FL) and detected using Pierce ECL Western Blotting Substrate (Life Technologies).

\subsubsection{Flow cytometry}

Isolated exosomes and cells were resuspended in PBSAz, blocked by 1/100 (v/v) human IgG in PBSAz for 15 min on ice, and stained using appropriate antibodies for $30 \mathrm{~min}$ on ice in the dark. After staining, exosomes were washed

with PBSAz and ultracentrifuged by $150,000^{\times} \mathrm{g}$ for 1 hour at $4^{\circ} \mathrm{C}$. The

exosome

pellet was resuspended in PBSAz and a final volumetric percent of $2 \%$ paraformaldehyde was added to preserve samples at $4^{\circ} \mathrm{C}$ for flow cytometry for up 
to 2 weeks. 
Flow cytometry was performed as described previously using a FACSAria or a LSRFortessa flow cytometer and analysis software (BD Biosciences). Briefly, cellular copy numbers of HER1 and HER2 were estimated using Quantum Simply Cellular calibration beads. The fluorescent intensity for each parameter was reported as a pulse area using 18-bit resolution. Unstained cells and exosomes were used as negative flow cytometry controls and singly stained cells and exosomes were used to establish fluorescent compensation parameters. When exosomes were analyzed by flow cytometry, events were detected when the side scatter area was above a threshold that was established using running buffer. Following acquiring at least 20,000 events, flow cytometry data was exported as FCS3.0 files and analyzed using R/Bioconductor, as described previously ${ }^{48}$.

\subsection{Results and discussion}

\subsubsection{SEM provides a quick alternative to TEM for characterizing the morphology and distribution of exosomes.}

Exosomes are one of a number of different micro- and nano-scaled vesicles released by cells that can be distinguished based upon their morphology and size distribution. Electron microscopy (EM) is necessary to characterize their morphology since particles smaller than $300 \mathrm{~nm}$ are invisible in optical methods ${ }^{49}$. Though transmission EM (TEM) is considered a standard tool for characterizing the morphology of exosomes, scanning EM (SEM) is an alternative approach that has recently emerged ${ }^{50}$. In general, TEM and SEM both require ultracentrifugation to isolate exosomes, include sample processing steps prior to EM, and use electron 
beams to detect the nanostructures with high resolution. However, the number of sample processing steps are different between the two methods. The first aim of this study was to compare these two EM methods for characterizing the morphology of exosomes, as to distinguish them from other extracellular vesicles. To illustrate these methods, exosomes were isolated by differential centrifugation from two cell lines - B16F0, a mouse melanoma cell line, and SKBR3, a human breast cancer cell line - and were processed immediately for electron microscopy to image fresh vesicles Under SEM, extracellular vesicles isolated from normal cells exhibited a round morphology and uniform, unimodal distribution in size that was consistent with exosomes (Figure 1A, subpanels i and ii for B16F0 exosomes, subpanels iii and iv for SKBR3 exosomes). In contrast to exosomes, apoptotic vesicles and necrotic bodies derived from B16F0 cells displayed irregular shapes and a heterogeneous size distribution, as observed by SEM (Figure 1B, apoptotic vesicles, APV (left); necrotic bodies, NCB (right) ). TEM was also used to characterize the morphology of $\mathrm{B} 16 \mathrm{~F} 0$ exosomes, where a central depression was observed, which is a characteristic for exosomes under TEM (Figure 1C). The size distributions of the different extracellular vesicles and exosomes imaged using different EM methods were compared (Figure 1D and Table 2). Using both EM methods, we also noted that dispersing samples containing extracellular vesicles as a monolayer on the silicon substrate improved the image quality significantly. In summary, we found that B16F0 exosome diameters were not significantly different between the two EM methods ( $\mathrm{P}$ value > 0.05). This is interesting as it suggests that the two EM methods provide the same measurement of exosome sizes 
Figure 1
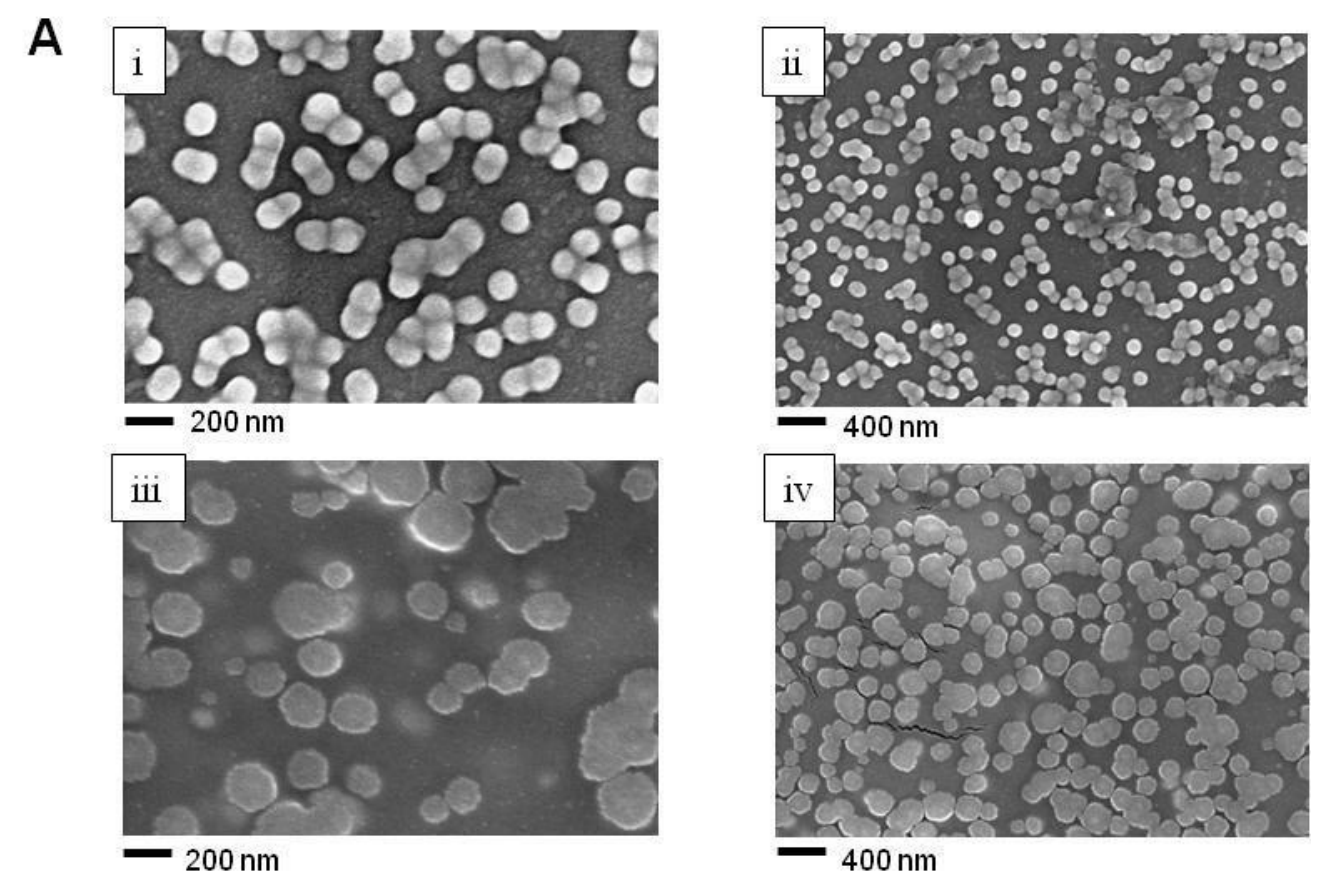

B
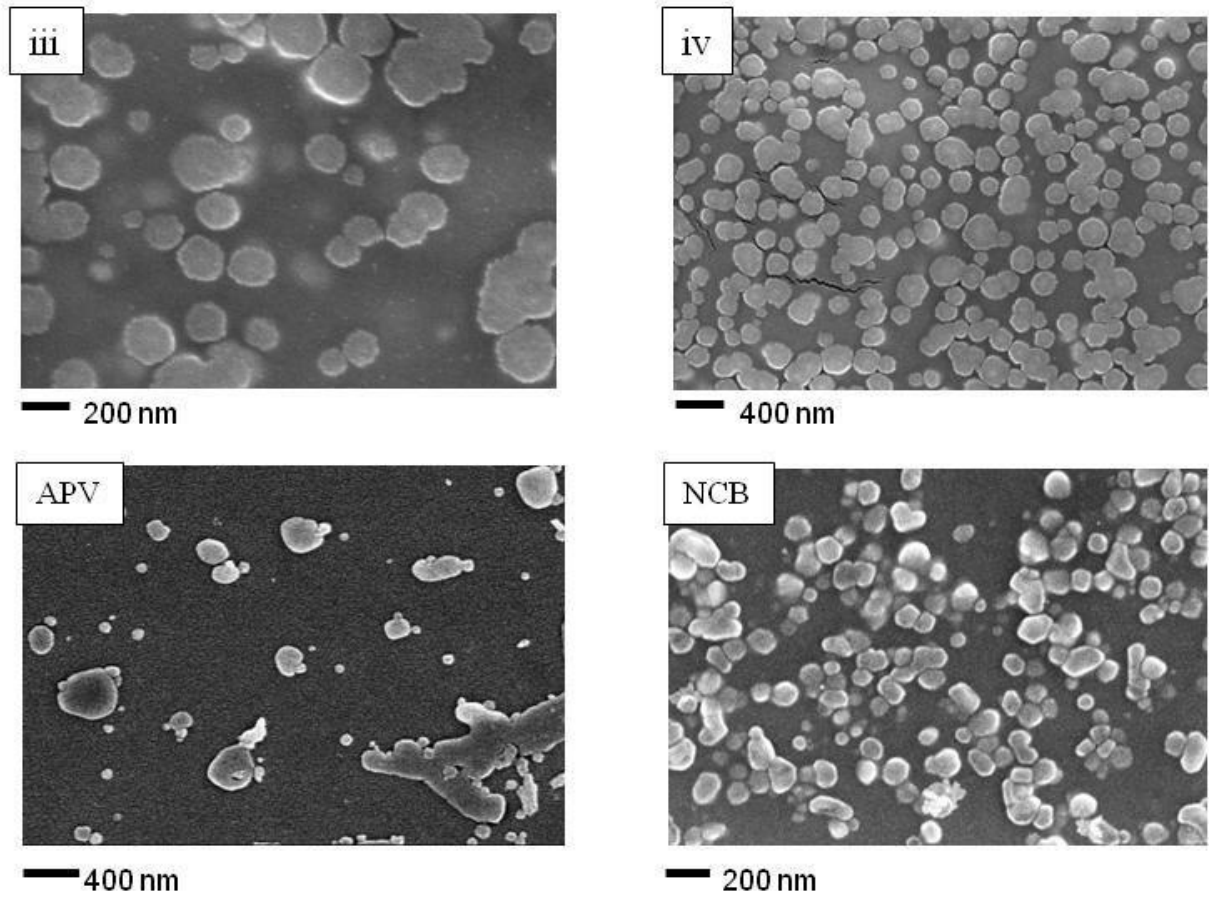

C
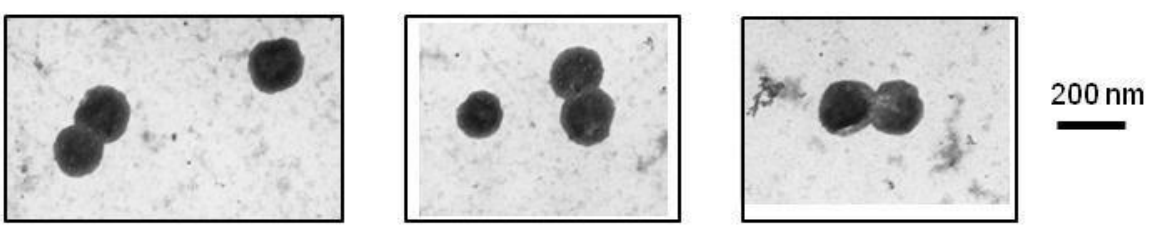

D
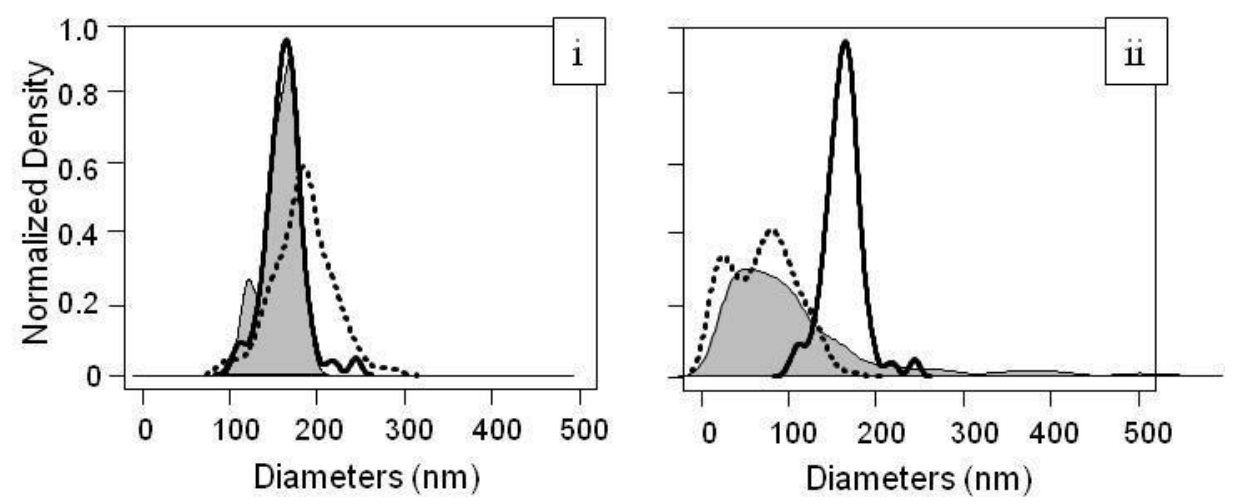
Figure 1 Different extracellular vesicles exhibited different morphologies and size distributions, as imaged by SEM and TEM. (A) Exosomes (EXO) isolated from B16F0 mouse melanoma cells (subpanels $\mathrm{i}$ and ii) and SKBR3 human breast cancer cells (subpanels iii and iv) were imaged by SEM. (B) Extracellular vesicles isolated from apoptotic B16FO cells that were treated with 7-ethyl-10-hydroxycamptothecin (left panel, apoptotic vesicles APV). Necrotic bodies (NCB) were isolated from B16F0 cells following exposure to high shear conditions (right panel). APV and NCB were imaged by SEM. (C) Exosomes from B16F0 cells were imaged by TEM (scale bar $=200 \mathrm{~nm}$ ). (D) The size distributions of EXO, APV, and NCB observed by electron microscopy. (left panel) B16F0 EXO observed by SEM (black solid line; $n=113$ ) or TEM (gray shaded; $n=14$ ), and SKBR3 EXO under SEM (dotted line; $n$ = 237). (right panel) B16F0 vesicles observed by SEM, including EXO (black solid line; same data as in left panel), APV (gray shaded) and NCB (dotted line). All images were representative of a least three biological replicates. See Table 2 for comparisons and statistics.

Table 2 Size comparisons and statistics of exosomes, apoptotic vesicles and necrotic bodies that were isolated and observed by electron microscopy.

\begin{tabular}{|c|c|c|c|c|}
\hline Vesicle Isolated & EM & $\begin{array}{l}\text { Diameter } \pm \\
\text { SD }\end{array}$ & $\mathbf{N}$ & $\begin{array}{c}* * \text { P values for statistical } \\
\text { significance }\end{array}$ \\
\hline $\begin{array}{l}\text { B16F0 Exosomes } \\
(\mathrm{EXO})\end{array}$ & SEM & $162 \pm 23 \mathrm{~nm}$ & 113 & \multirow{2}{*}{$\begin{array}{l}\text { N.S., B16F0 EXO imaged by SEM vs. } \\
\text { TEM; } \\
\text { P<0.001, B16F0 EXO vs. APV or NCB } \\
\text { in SEM. }\end{array}$} \\
\hline B16F0 Exosomes & TEM & $158 \pm 19 \mathrm{~nm}$ & 14 & \\
\hline SKBR3 Exosomes & SEM & $183 \pm 34 \mathrm{~nm}$ & 237 & $\begin{array}{l}\mathrm{P}<0.001, \text { SKBR3 EXO vs. B16F0 } \\
\text { EXO, in SEM }\end{array}$ \\
\hline $\begin{array}{l}\text { B16F0 Apoptotic } \\
\text { vesicles (APV) }\end{array}$ & SEM & $131 \pm \underset{*}{148} \mathrm{~nm}$ & 602 & $\begin{array}{l}\mathrm{P}<0.001, \mathrm{~B} 16 \mathrm{~F} 0 \text { APV vs. B16F0 EXO } \\
\text { or } \mathrm{NCB} \text {, in SEM. }\end{array}$ \\
\hline $\begin{array}{l}\text { B16F0 Necrotic bodies } \\
\text { (NCB) }\end{array}$ & SEM & $70 \pm 38 \mathrm{~nm} *$ & 222 & $\begin{array}{l}\mathrm{P}<0.001, \mathrm{~B} 16 \mathrm{~F} 0 \mathrm{NCB} \text { vs. B16F0 EXO } \\
\text { or APV, in SEM. }\end{array}$ \\
\hline
\end{tabular}

* Size distributions did not exhibit unimodal distributions. Mean diameters were calculated from projected areas of all particles that exhibit round or irregular shapes. **P values were accessed using one-way ANOVA or Student's t-test. SD is standard deviation. N is sample number of observed vesicles in EM. N.S. is not significant.

regardless of the morphological differences observed under the two EMs, such as the "cup-shape" observed by TEM. In contrast, APC and NCB from B16F0 cells did not exhibit unimodal distributions as observed with exosomes. In addition, the size distributions of APC and NCB were significantly different from exosomes (P 
$<0.001)$. B16F0 exosomes were also slightly smaller than the SKBR3 exosomes (162 nm vs. $183 \mathrm{~nm}$, respectively; $\mathrm{P}<0.001)$.

Similar diameters have been observed by EM imaging for cancer exosomes from B16F10 (closely related to $\mathrm{B} 16 \mathrm{~F} 0$ ) mouse melanoma cells ${ }^{25}$, from human plasma of melanoma patients ${ }^{10}$ and from SKBR3 human breast cancer cells ${ }^{20}$. While the average sizes of the extracellular vesicles that we have observed are slightly higher than previous reports of exosomes ${ }^{50,51}$, their uniform size distribution rules out apoptotic and necrotic bodies, which were heterogeneously distributed and irregularly shaped (Figure 1 A-D). Discrepancies could be attributed to the cellular source of exosomes or to differences in sample isolation and SEM preparation. For instance, it has been reported that exosomes derived from the human HEK cell line 293T shrunk in size by $50 \%$ within 8 days, from 116 to $63 \mathrm{~nm}$ in diameter, when stored in PBS at $4{ }^{\circ} \mathrm{C}{ }^{50}$.

Morphological differences were apparent when identical samples of exosomes were imaged with these two different EM techniques, where TEM images show a characteristic central depression in the exosomes and SEM images show exosomes as round spheroids. We observed that the SEM images for exosomes derived from two different cell lines were consistently spheroidal, as similarly observed with exosomes from human saliva ${ }^{51}$. While early work suggests that exosomes exhibit a characteristic central depression, this trait is an artifact attributed to TEM sample preparation, such as embedding the exosomes in polymeric cellulose, rather a physiological features of exosomes ${ }^{41,52}$. In comparing these two EM methods, 
TEM sample preparation includes steps for gradient dehydration, contrasting staining by heavy metals and embedding the sample in polymeric cellulose, which are omitted in preparing SEM samples. We also note that all the images shown in Figure 1 were obtained using fresh samples. Differences in methods for storing extracellular vesicles can also introduce artifacts, as we will discuss a later section.

Collectively, the imaging results suggested that SEM and TEM provide similar information regarding the size distribution but a slightly different morphological view of exosomes and other extracellular vesicles. Currently, EM methods are the standard practice for direct imaging the size and morphology of exosomes. However, there are some trade-offs to consider when comparing the TEM and SEM. For instance, preparing TEM samples requires more steps compared with SEM sample preparation. The SEM images of exosomes, apoptotic vesicles, necrotic bodies, shown in Figure 1, exhibited intact membrane structures and the morphologies were distinctly different for each type of nanoscale vesicles. This finding suggested that SEM is a valid alternative to TEM for direct imaging of extracellular vesicles, with advantages based on the improved sample process methods.

The morphology and size of extracellular vesicles, including exosomes, are critical in defining their physiological roles, distribution, and concentrations in $\operatorname{organs}^{53,54,55}$. Observing nanoscale vesicles under physiological conditions in situ using an electron beam is a challenge, as a high vacuum, $10^{-5}$ to $10^{-8}$ Torr, and anhydrous atmosphere are required. However, reducing the number of sample 
fixing and processing steps streamlined the pursuit of the native morphologies of exosomes. To illustrate this point, we also found that B16F0 and SKBR3 exosomes frequently appeared as clusters of multiple exosomes (2-10 particles, approximately) with membranes connected tightly or even merged in SEM images, suggesting that the natural morphology of B16F0 and SKBR3 exosomes are as multi-exosome clusters instead of isolated exosomes (Figure 1A). In contrast, the clustering phenomena were not observed under SEM with other nanoscale vesicles, such as apoptotic vesicles or necrotic bodies (Figure 1B). This suggests that clustering is not due to sample processing, such as forming clusters due to the capillary effects of water drops during evaporation. This observation may be due to minimal processing of the samples afforded by SEM imaging. However, clustering of native exosomes has implications for other indirect methods for characterizing exosomes, like dynamic light scattering or nanoparticle tracking analysis, that assume that the particles are isolated vesicles ${ }^{49,56,57}$. The results also imply that filtering samples through a 0.2 micron filter prior to ultracentrifugation, which is common practice, would actually enrich for vesicles associated with cell death. In addition, TEM imaging using nanoparticle-conjugated antibodies can be used to identify whether exosomes contain membrane proteins ${ }^{45}$, The use of SEM for immuno-gold labeling studies of cell samples remains in development ${ }^{58,59}$. Alternative methods also exist for quantifying membrane protein expression on exosomes, as we discuss in a later section. Next, we used SEM to evaluate the effects of other process parameters associated with producing, isolating, and storing exosomes from cell-conditioned media. 


\subsubsection{A survey of exosome production methods and their impact on exosomal RNA quality}

Fetal bovine serum (FBS) is a common supplement to eukaryotic cell culture media; yet, animal serum can contain exosomes that can contaminate cell-derived exosome populations. In this study, we evaluated the impact of two media options for limiting FBS-derived exosome contamination on in vitro production of cellderived exosomes. The two media options were serum-free medium (SFM) and medium supplemented with serum that had been cleared of exosomes by ultracentrifugation, that is exosome-free serum-containing medium (EFM). Media were conditioned with $\mathrm{B} 16 \mathrm{~F} 0$ cells for different lengths of time. In both SFM and EFM, B16F0-derived exosomes could be isolated under all conditions. The size distributions of exosomes isolated from the B16F0-conditioned SFM and EFM at each time point were determined from SEM images (Figure 2A), The size distributions of $\mathrm{B} 16 \mathrm{~F} 0$ exosomes purified from SFM or EFM, at the indicated incubation times (12-48 hrs) with the B16F0 parental cells, were assessed for statistical differences by two-way and one-way ANOVA analysis. These size distributions were found to be not significantly different with respect to the incubation medium types and with respect to the incubation times. A shift in particle size distribution towards smaller sizes would suggest that the culture conditions decreased cell viability, as observed by the tail in the distribution of vesicles obtained after conditioning for 48 hours in serum free media. 
A
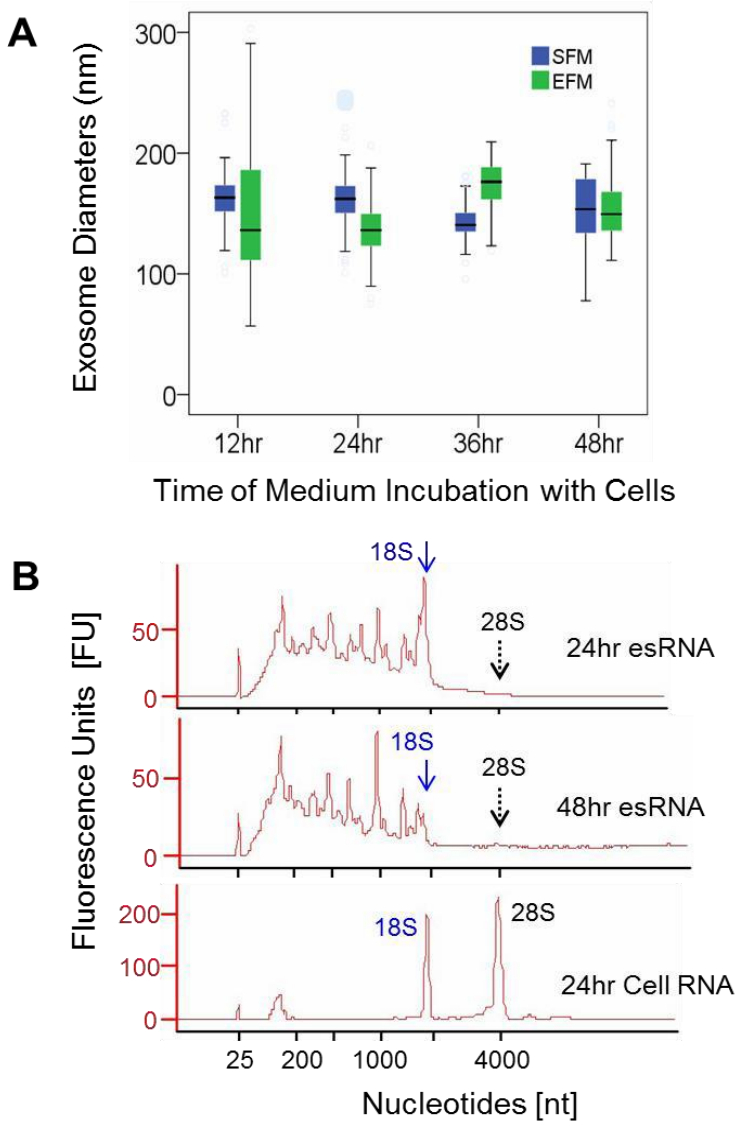

Figure 2 Exosome quality was evaluated in terms of vesicle morphology and exosomal RNA as a function of production condtions. (A) B16F0 exosomes were produced using serum free medium (SFM) or exosome-free serum medium (EFM) for 12, 24, 36 and 48 hours and characterized using SEM ( $n=51,73,76$ and 53 for SFM exosomes, from 12-48 hrs,; $n=68,213$, 91, 210 for EFM exosomes, from 12-48 hrs, respectively). In the box plots, the top and bottom of the boxes indicate the $75 \%$ and $25 \%$ of the distribution in sizes, black bands on the boxes indicate the median sizes, top and bottom bars indicated the maximum and minimum of the sizes. The exosome sizes were assessed using two-way and one-way ANOVA and found to be not significantly different. Multiple SEM pictures and biological samples, $n \geq 3$, were used to determine the exosome sizes. (B) Electrophoresis spectrums of exosomal and cellular RNA derived from B16F0 cells using Agilent Bioanalyzer. The positions of $18 \mathrm{~S}$ and $28 \mathrm{~S}$ peaks on the RNA spectrums were indicated in diagrams by arrows and labels. esRNAis for exosomal RNAs. Representative figures of RNA analyses were shown, $\mathrm{n}>3$.

In addition, exosomal RNA (esRNA) was also characterized by on-chipelectrophoresis using an Agilent Bioanalyzer (Figure 2B), which can quickly assess the quality of RNAs purified from exosomes. As RNA become degraded, longer RNAs become fragmented such that the distribution shifts entirely towards the low end (< $200 \mathrm{nt}$ in length). Following a single wash of exosome pellets in DMEM alone, exosomal RNAs were isolated from exosome pellets obtained from B16F0-conditioned serum free medium after 24 (top panel) and 48 (middle panel) hours incubation with cells. For comparison, RNA was isolated from whole B16F0 cell lysates and analyzed similarly (bottom panel). The results are representative of at least three replicates. 
Overall, we found that fresh exosomes contained high quality RNA. Analysis of esRNA did not contain the characteristic peaks associated with ribosomal RNA, as observed previously ${ }^{7}$ (see reduced $18 \mathrm{~S}$ and $28 \mathrm{~S}$ peaks labeled in Figure 2B). The presence of the $28 \mathrm{~S}$ peak, in particular, may indicate the presence of contaminating cell debris. The distribution in esRNA was primarily uniform but was limited to below 1800 nucleotides in length. This distribution in RNAs is not surprising, as we used the mirVana miRNA isolation kit that uses a column to enrich small RNAs. Finally, longer production times were also associated with a shift in distribution in esRNA to smaller length RNA, as illustrated by the difference between the $24 \mathrm{hr}$ and $48 \mathrm{hr}$ esRNA samples. While this shift in esRNA
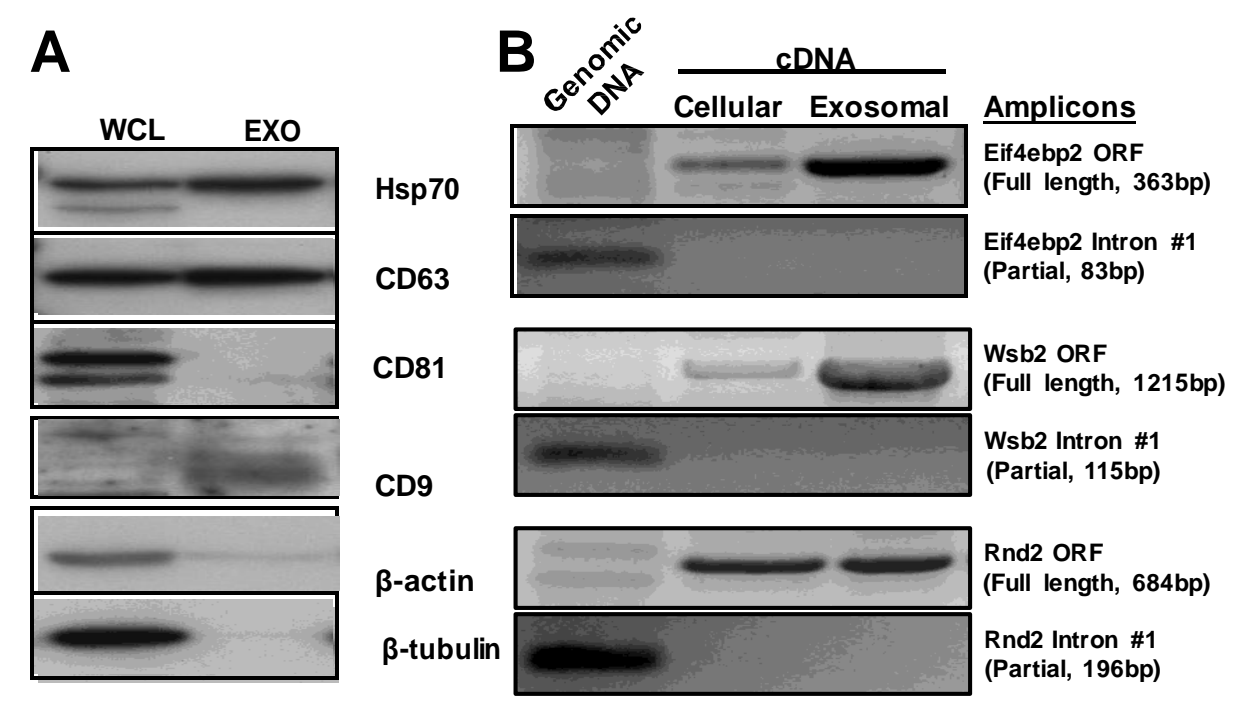

Figure 3 Biochemical characterization of exosomes from B16F0 cells. (A). Immunoblotting analysis of common exosome markers, where $20 \mu \mathrm{g}$ of total protein was loaded in each lane (WCL, whole cell lysate; Exo, exosome lysate). (B). Amplification of the full-length protein ORFs and partial introns by semi-quantitative RT-PCR suggested that a group of functional mRNAs are enriched in exosomes. 100ng of RNAs were reverse-transcribed into CDNA and subject to PCR amplification as indicated. 10ng of genomic DNA (10\%) was also used as quality control (left lane). 
was slight, degradation of RNA shifts the distribution towards lengths below 200 nucleotides ${ }^{7}$. Collectively, we observed no difference in exosome quality between SFM and EFM and that prolonged production conditions slightly degraded the quality of esRNA.

We also biochemically characterized samples to support the claim that these samples contain exosomes with high quality RNA. Specifically, Western blot analysis of samples indicated the presence of common markers of exosomes, such as Hsp70, CD63, and CD9 (Figure 3A), while CD81, $\beta$-actin and $\beta$-tubulin were absent. Whole cell lysates were used as a positive control; yet, the absence of appropriate loading controls renders the analysis qualitative. In our hands, we found that exosomal RNA contained mRNA transcripts of protein open reading frames with no contaminating genomic DNA (Figure 3B). This is in contrast to

reports that suggest that exosomes contain mRNA fragments ${ }^{63}$, which may be an artifact of storage conditions that we will discuss next.

\subsubsection{Preservation and stability of exosomes and RNAs at low temperatures}

To understand the role that exosomes play in intercellular communication, cellular assays need to be performed that identify how exosomes influence cellular function in a dose-dependent fashion and independent from direct cell-to-cell interaction. To demonstrate these influences in a reproducible manner, exosomes should be stored under conditions that preserve their biological activity once isolated from cell-conditioned media. Conventional methods suggest that exosomes can be preserved by freezing at $-80^{\circ} \mathrm{C}^{12}$. Alternatively, dimethyl 
sulfoxide (DMSO) is used as a cryoprotectant when cells are preserved in liquid nitrogen. To determine the impact of these two different freezing options on exosome quality, we froze $\mathrm{B} 16 \mathrm{~F} 0$ and SKBR3 exosomes at $-80^{\circ} \mathrm{C}$ in serum free medium and in serum free medium supplemented with $10 \%$ DMSO. Following thawing on ice, the exosomes were imaged using SEM (see Figure 4A for B16F0 frozen exosomes, and Figure 5B for SKBR3 frozen exosomes). Images show that cryopreservation in serum free medium alone resulted in smaller $(10-100 \mathrm{~nm}$ in diameter) and more heterogeneous shapes to the frozen exosome samples, in comparison with the fresh exosomes (Figure 4B). Specifically, SEM images indicated that the diameters of the frozen exosomes were $44 \pm 15 \mathrm{~nm}$ for B16F0 (n $=508)$ and $34 \pm 8 \mathrm{~nm}$ for SKBR3 $(\mathrm{n}=354)$. These size distributions were significantly different from each other as well as from fresh exosomes (see Figure 1D and Table 2), which was assessed using one-way ANOVA (P value $<0.001$ ). Our analyses suggested that direct freezing affects the stability of the exosome membranes and degrades the samples.

In contrast, the morphology of exosomes cryopreserved using DMSO was similar to SEM images of fresh exosomes (compare panels C and D in Figure 5, with Figure 1A). Though sizes and shapes of a certain percentage of exosomes were preserved, DMSO was unable to preserve the morphology of all vesicles in the sample. Collectively, the results suggested that DMSO could be used as a cryoprotectant to help maintain the morphology of these vesicles for long-term 

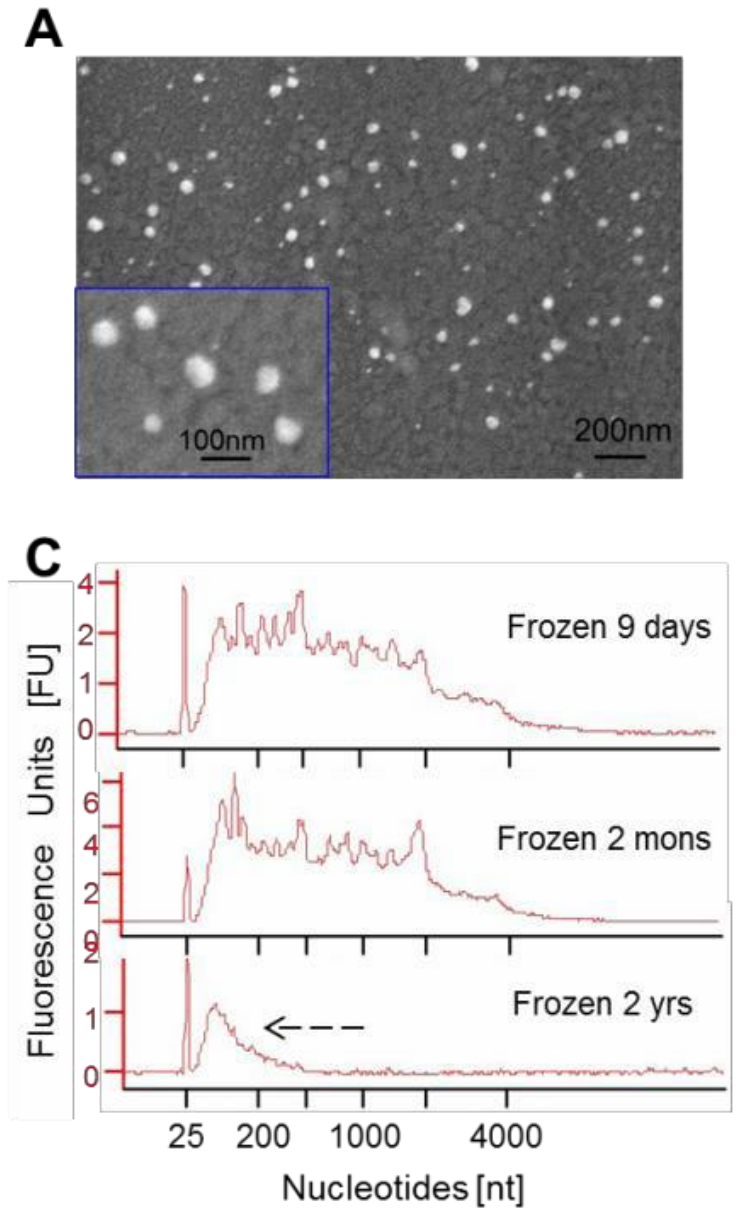
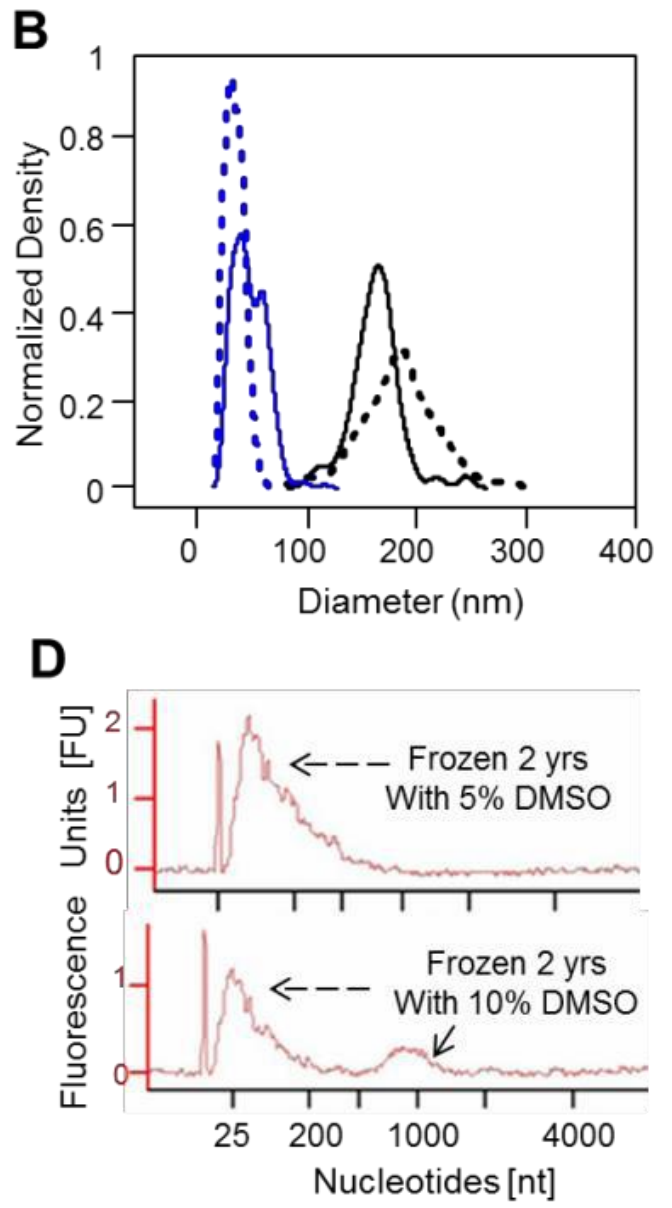

Figure 4 Freezing of exosomes decreased their size and degraded exosomal RNA. (A) SEM pictures of B16F0 exosomes subjected to a freeze-and-thaw cycle. (B) The size distributions of frozen exosomes processed from B16F0 (blue solid line, diameter $44 \pm 15 \mathrm{~nm}, \mathrm{n}=508$ ) and SKBR3 (blue dotted line, diameter $34 \pm 8 \mathrm{~nm}, \mathrm{n}=354$ ) cells, in comparison with the fresh exosomes from B16F0 (black solid line, diameter $162 \pm 23 \mathrm{~nm}, \mathrm{n}=113$ ) and SKBR3 (black dotted line, diameter $183 \pm 34 \mathrm{~nm}, \mathrm{n}=237$ ) cells. The data for fresh exosomes are also shown in Figure 1D-i and Table 2. The sizes of the four exosome samples are statically different as assessed by one-way ANOVA ( $P$ value $<0.001$ ). ( $C$ and $D$ ) Bioanalyzer results for exosomal RNAs isolated from

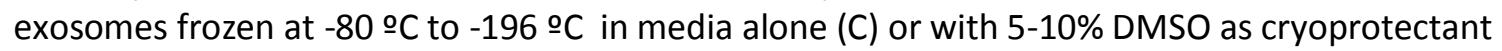
(D). Exosomes were stored frozen for 9 days ( $C$ top panel), 2 months ( $C$ middle panel), or 2 years ( $C$ bottom panel and $D$ ). The shift in nucleotide size towards small, degraded RNA is indicated by black dashed arrows. A hump around 1000 nt was observed in samples frozen for 2 years in $10 \%$ DMSO (solid arrow in D bottom panel). Representative figures were shown, $n>3$ as for SEM of the biological samples; $n>3$ for RNA analysis and isolation.

storage. However, cryostorage also negatively impacted the morphology of exosomes, as the exosomes became smaller and more heterogeneous in size. This 

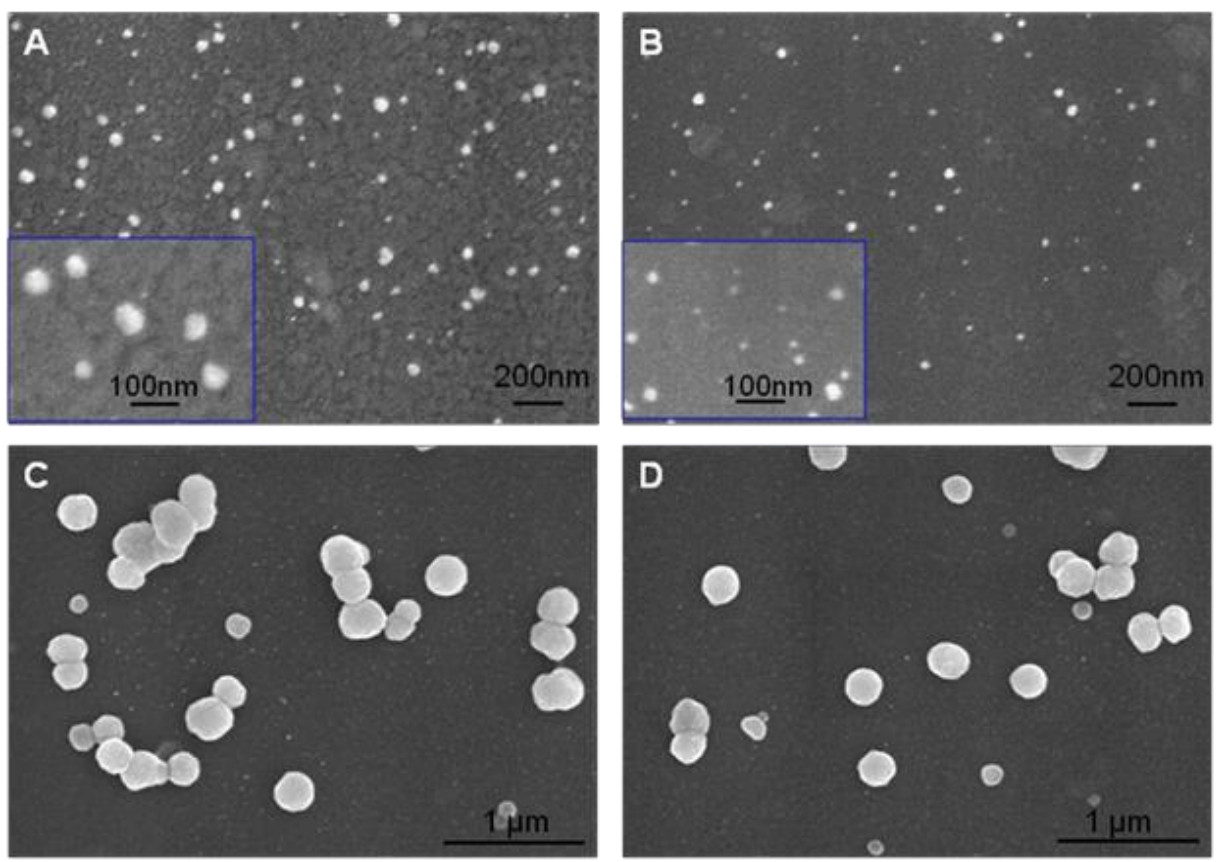

Figure 5 SEM images of frozen exosomes from mouse melanoma cells B16F0 ( $A, C$ and $D)$ and human breast cancer cells SKBR3 (B). (Panels $A$ and $B$ ) Exosomes were stored at $-80^{\circ} \mathrm{C}$ in serum free medium for 1-2 weeks, thawed on ice, fixed by paraformaldehyde and examined by SEM. (C and D) Exosomes from B16F0 were frozen at -80 $\mathrm{C}$ in serum free medium with 5$10 \%$ DMSO as a cryoprotectant and thawed on ice, or at $37^{\circ} \mathrm{C}$ quickly as thawing cells.

implies that cryostorage makes it more difficult to assess the quality of the sample by distinguishing between exosomes and vesicles derived from dead cells. Without confirming the quality of the exosome sample, the biological implications of downstream assays using these samples would be unclear.

Besides morphology, preserving the biological activity of RNAs in exosomes is also crucial for studying exosome biology in a reproducible manner. Using an Agilent Bioanalyzer, we characterized exosomal RNAs that were isolated from exosomes frozen for various periods of time (Figure 4C) or cryopreserved with DMSO (Figure 4D). In Figure 4C, RNAs isolated from exosomes frozen for 9 days and 2 months, still contained a variety of RNA molecules spanning from $18 \mathrm{~S}$ to 
smaller length nucleotides, featuring the characteristics of RNAs isolated from fresh exosomes (compare with Figure 2B, top and middle). However, freezing those exosomes for 2 years resulted loss of the $18 \mathrm{~S}$ and obvious shifting in RNA distributions towards smaller nucleotides (Figure 4C, bottom), as indicated by a dashed black arrow. Collectively, the results suggest that exosomal RNA was preserved in frozen exosomes for a couple of months, but was degraded with longer times. This degraded RNA signature can also be observed in previous exosome studies (for example ${ }^{6},{ }^{64,65}$ ). To check whether DMSO could also preseve exosomal RNAs, exosomal RNAs purified from frozen exosomes stored for 2 years with 5-10 \% DMSO were analyzed by Bioanalyzer (see Figure 4D). In these samples, RNA appeared to be degraded, as shown by the enrichment of smaller RNAs (see the dashed black arrows in Figure 4D). There was also an odd peak at around 1000 nucleotides of the RNA spectrum (see the solid arrow in Figure 4D bottom), which is possibly an artifact attributed to DMSO. The results here indicated that DMSO was unable to preserve exosomal RNAs (Figure 4D), though the size and morphology of vesicles could be protected by DMSO during low temperature storage and the thawing process (C and D in Figure 5). Collectively, the results suggest that sample quality should be established using fresh exosomes and that prolonged storage in the freezer degrades biological activity. 


\subsubsection{Flow cytometry as an unbiased tool to characterize exosomal membrane protein expression}

A number of different techniques have been proposed to isolate exosomes from biological fluids. To bypass the time-consuming ultra-centrifugation step, exosomes have been isolated using "exosome markers", that are proteins contained in the external lipid bilayer. Exosomes can be purified using these exosome markers and capture beads. Exosomes bound to these capture beads can then be analyzed using a conventional flow cytometer ${ }^{60}$. Collectively, flow cytometric analysis of exosomes is high-throughput with the capacity for quantitative protein characterization ${ }^{60}$. Recently, a high-end dedicated flow cytometer with higher sensitivity forward scatter detection and fluorescent amplification has been developed to separate stained exosomes from background contaminants ${ }^{61}$. However, it is unclear whether these isolation and detection methods are biased. A potential source of bias may be exosome heterogeneity, as translating cellular the protein copy numbers on exosomes may be in the single digits. Since many institutions do not have dedicated instruments for studying extracellular vesicles, we modified a conventional flow cytometer to use SSC instead of FSC to detect transmembrane protein copy number to nanometer-sized exosomes suggests that flow cytometric events and characterized the heterogeneity of transmembrane protein abundance among an exosome population and assessed the sensitivity of this approach. 
SKBR3 cells and exosomes isolated from conditioned media were stained using fluorophore conjugated antibodies against two members of the epidermal growth factor family of receptors: HER1 and HER2 (Figure 6). As the SKBR3 cell line is considered a cell model for HER2+ breast cancer, the cells exhibited positive staining for both HER1 and HER2 (Figure 6A). Using antibody calibration beads (see Figure 7), the median cellular copy numbers of HER1 and H ER2 on SKBR3 cells were estimated to be $1.41 \times 10^{5}$ copies of HER 1 and $1.43 \times 10^{6}$ copies of HER2 per cell. As expected, SKBR3 cells contained ten times higher copy numbers of HER2 than HER1 on the surface. Next, we assayed HER1 and HER2 abundance in SKBR3 exosomes by flow cytometry (see Figure 6B). The SKBR3 exosomes were clearly positive for HER2 staining, while HER1 staining was not significantly different from unstained exosomes. Cells and exosomes stained using isotype controls also displayed no difference from unstained cells or exosomes (data not shown here).

Figure 6 The abundance of the membrane proteins, HER1 and HER2, were quantified on SKBR3 exosomes and the parental cells by flow cytometry. SKBR3 cells (A) and SKBR3 exosomes (B) were assayed for HER2 (left panels) and HER1 (right panels) abundance using fluorophoreconjugated antibodies and flow cytometry. Unstained exosomes and SKBR3 cells were used as negative controls (gray shaded). (C) Flow cytometric analysis of SKBR3 exosomes double-stained with APC-conjugated HER1 mAbs and Dil, a lipophilic fluorescent dye. (left panel: (i)) The density distribution of fluorescence associated with HER1 staining in Dil-positive events (black line) was bimodal and was deconvoluted into two normal distributions associated with single (red curve) and Dil-clustered exosomes (blue curve). The upper limit for APC-MFI of single exosomes is indicated by the gray vertical line. (right panel (ii)) A scatterplot of MFIs associated with HER1 staining versus Dil staining of SKBR3 exosome samples. The threshold to detect Dil-MFI is indicated by the red dashed horizontal line. The vertical green line indicates a data-driven threshold where 95 percent of unstained exosomes (gray shaded in left panel) exhibited a lower $\mathrm{MFI}$ associated with APC fluorescence. 
Figure 6

A

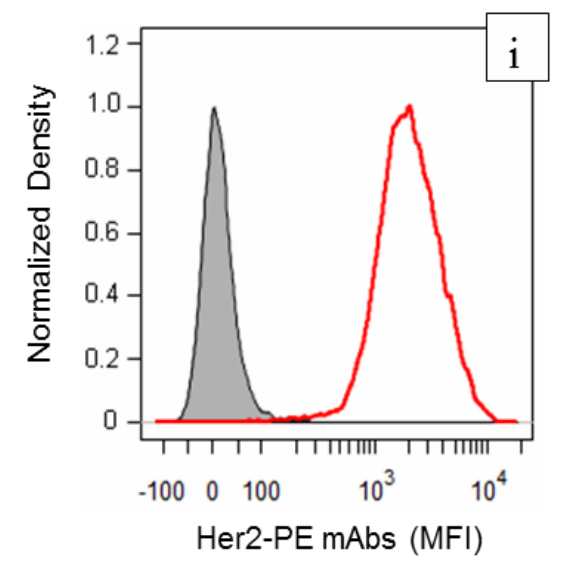

B

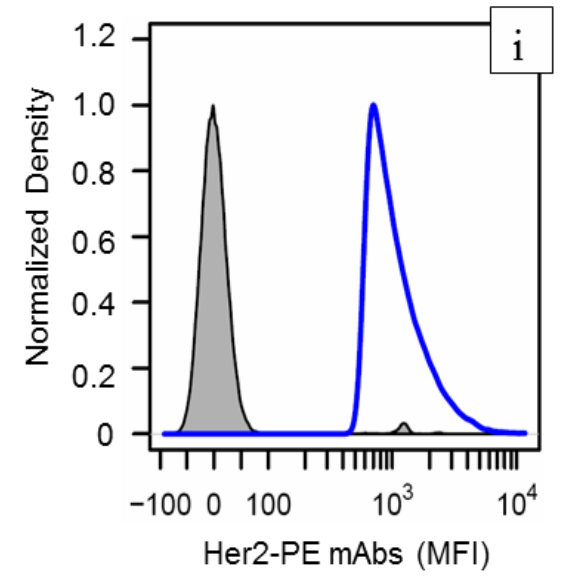

C Dil \& mAbs-APC stained Exo
$\quad$ No Stain Exo

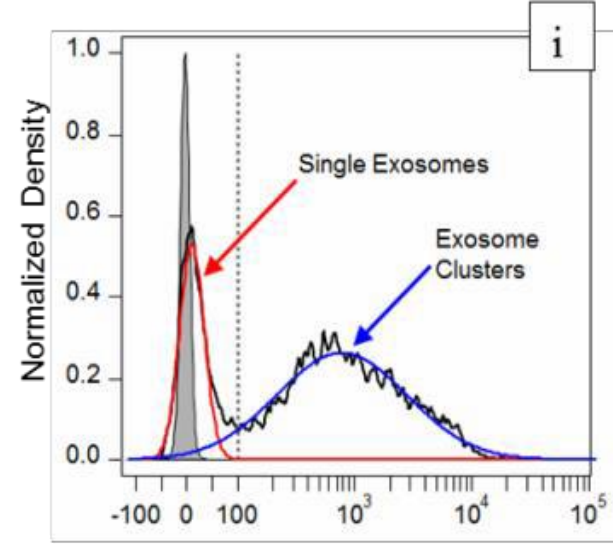

Her1-APC mAbs (MFI)
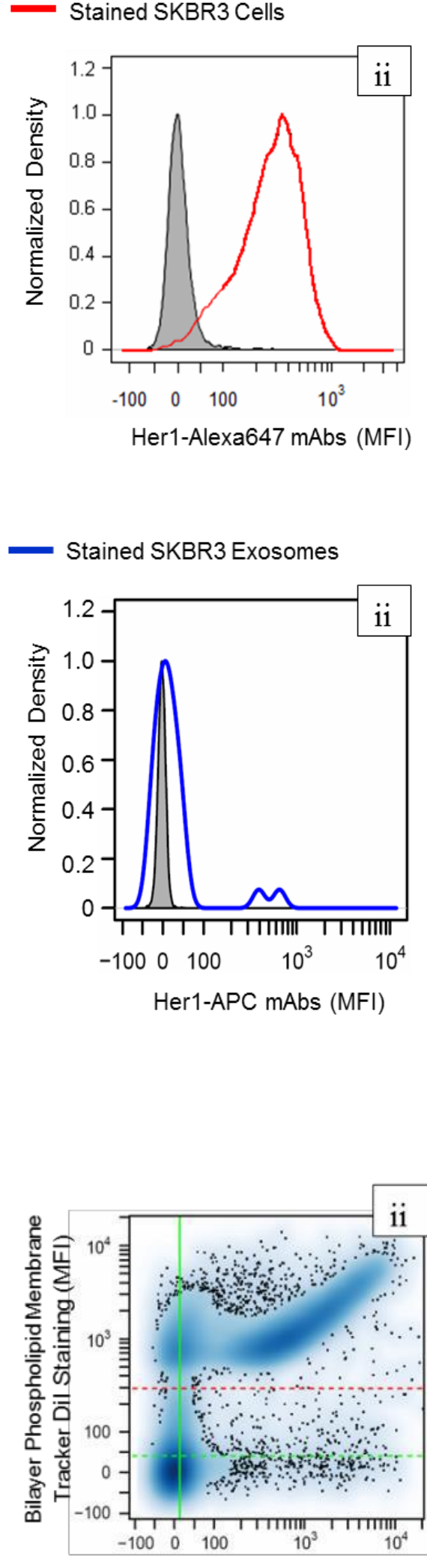

Her1-APC mAbs (MFI) 
A

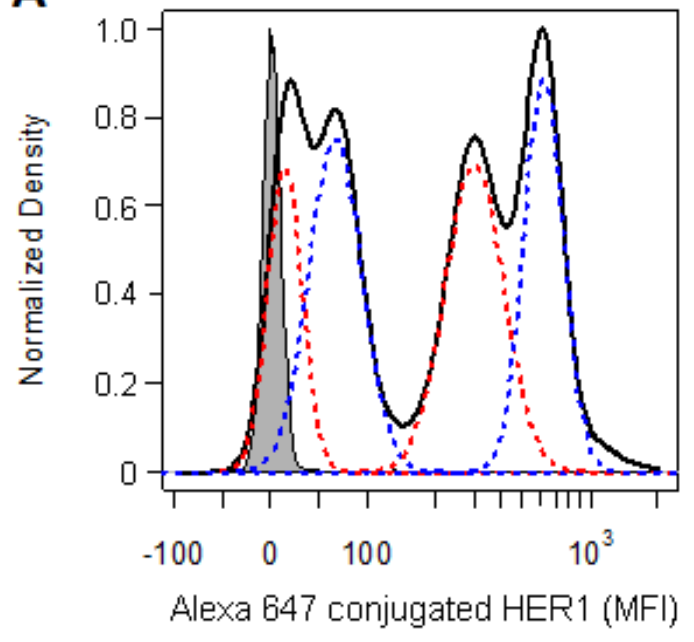

B

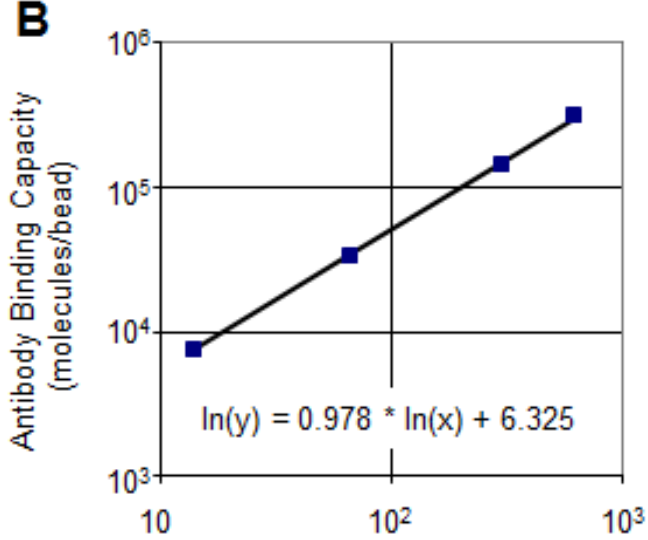

Alexa 647 conjugated HER1 (MFI)
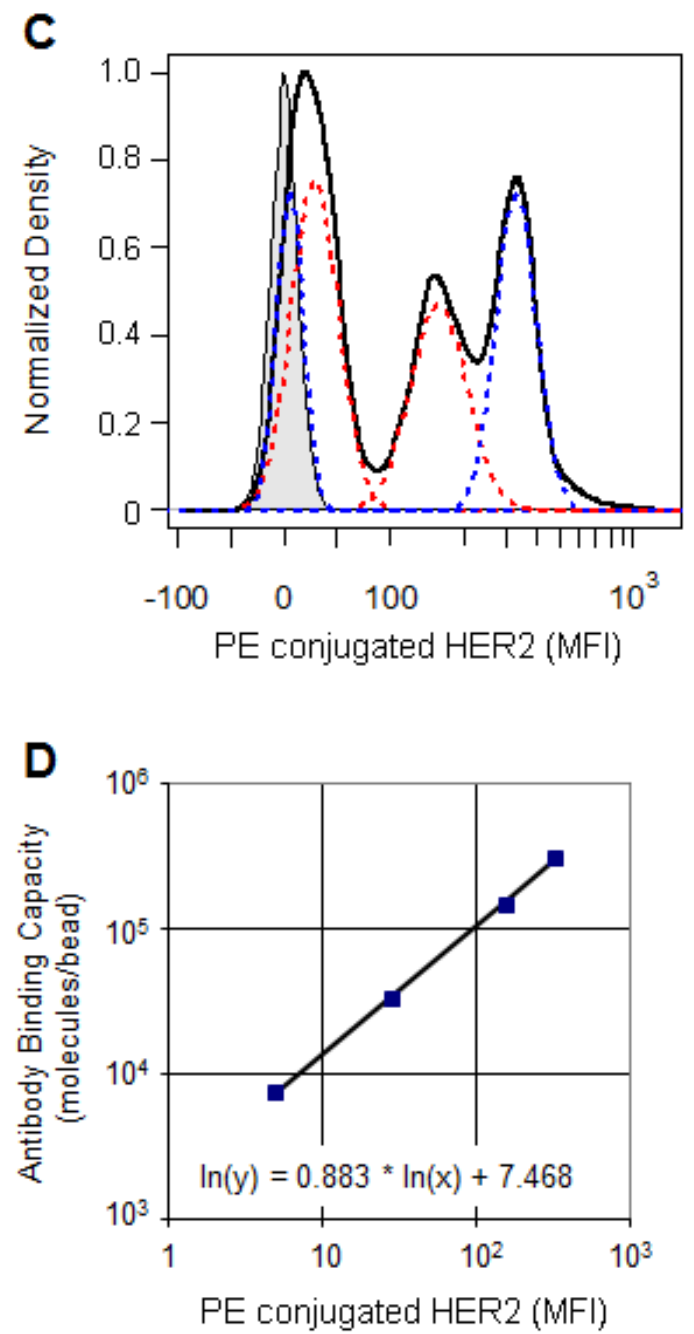

Figure 7 Calibration of HER1 and HER2 expression on SKBR3 cells to equivalent copy numbers per cell by flow cytometry using quantum calibration beads. Copy number expression was obtained using five quantum simply cellular microsphere populations, one blank and four labeled with increasing amounts of anti-mouse IgG antibody, that exhibit a defined antibody binding capacity. Probability density functions for the five microsphere populations stained using Alexa 647-conjugated anti-HER1 mAb (Panel A) and uing PE-conjugated mouse antiHER2 $\mathrm{mAb}$ (Panel C). Plots of the median MFI for the four antibodystained microspheres versus the corresponding antibody binding capacity, expressed in molecules per bead (HER1 panel B, HER2 - panel D).

Conventionally, cellular events are recognized in flow cytometry by their forward and side scatter properties. The forward scatter area is proportional to the cross-sectional area of an object as it flows by the laser and side scatter is related 
to the complexity of the object to scatter light. To identify whether we could distinguish exosomes from background debris, we used flow cytometry to quantify the forward scatter properties of fluorescent nanoparticles that bracketed the expected size range of exosomes (Figure 8). In comparison to the fluorescent nanoparticles, we found that exosomes exhibited forward scatter areas between the forward scatter area of $54 \mathrm{~nm}$ PE beads and $840 \mathrm{~nm}$ PE beads and similar to background debris. These results suggest that non-exosome events may confound the interpretation of HER1 staining of SKBR3 exosomes. In addition, flow cytometry using fluorophore-conjugated antibodies may not be sufficiently sensitive to detect the low copy number of HER1 on exosomes. Using the cellular copy numbers of HER1 on SKBR3 cells, the average HER1 copy number on each exosome is 47 and ranges from 30-70, assuming that a SKBR3 cell can be modelled as a sphere with a diameter of $10 \mu \mathrm{m}^{52}$ and that SKBR3 exosomes have an average diameter of $183 \pm 34 \mathrm{~nm}$ (Figure 1B).

Similar to the detection of fluorescent nanoparticles, fluorescence can be used to distinguish a flow cytometric event associated with true particle different from background debris. Therefore, we used a lipophilic dialkylcarbocyanine dye, DiI, to label exosomes for flow cytometric detection. To determine whether DiI improved exosome detection by the flow cytometry, we stained B16F0 exosomes using a 2x2 factorial experimental design with APC-conjugated monoclonal antibody against IL12RB2 and DiI as the two factors (see Figure 9). We found that the no stain and the mAb-stained only groups were very similar in their forward scatter area. Interestingly, we also found that DiI-stained samples increased the 
A

A
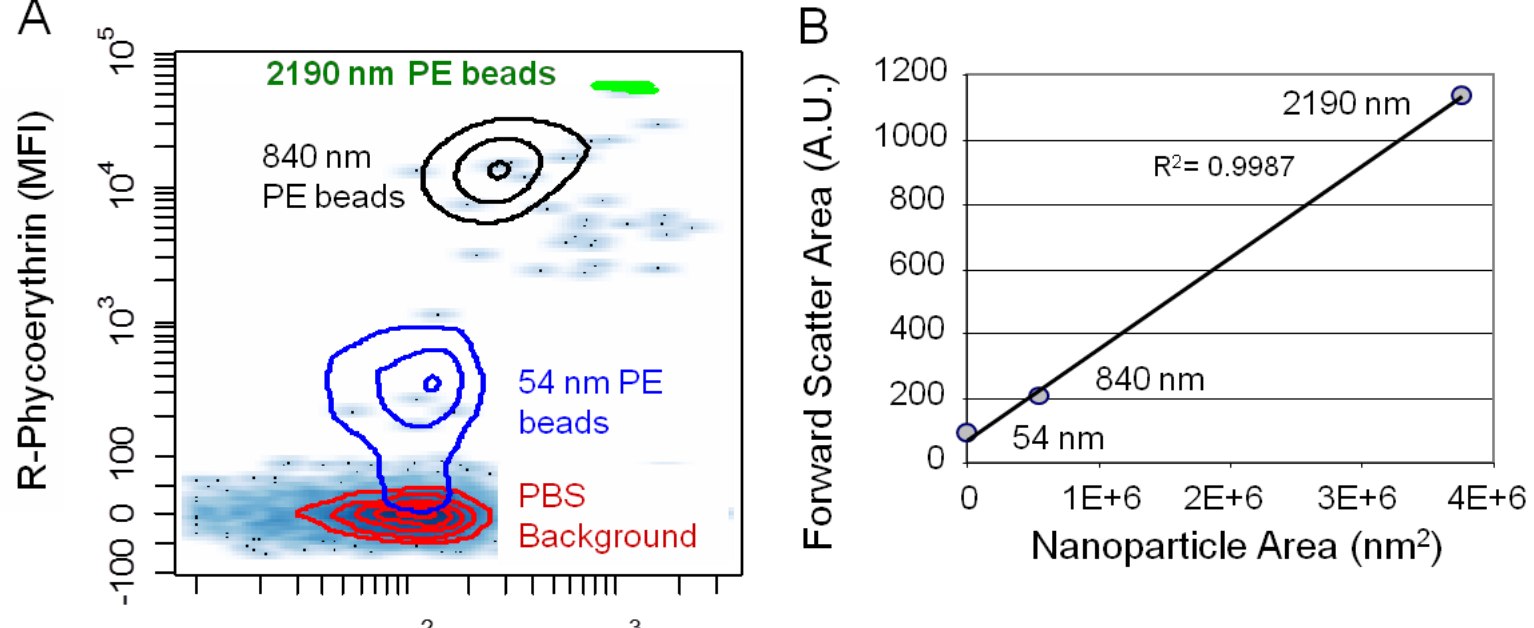

$10 \quad 10^{2} \quad 10^{3}$

Forward Scatter Area (A.U.)

Figure 8 Forward scatter area is proportional to particle size. Forward scatter area versus the fluorescence levels of 3 different sized beads that are fluorescently labeled $(A)$ and the standard curve of particle sizes versus their respective forward scatter area (B). The three sets of beads have nominal diameters of $2.19,0.84$ and $0.054 \mu \mathrm{m}$, respectively.

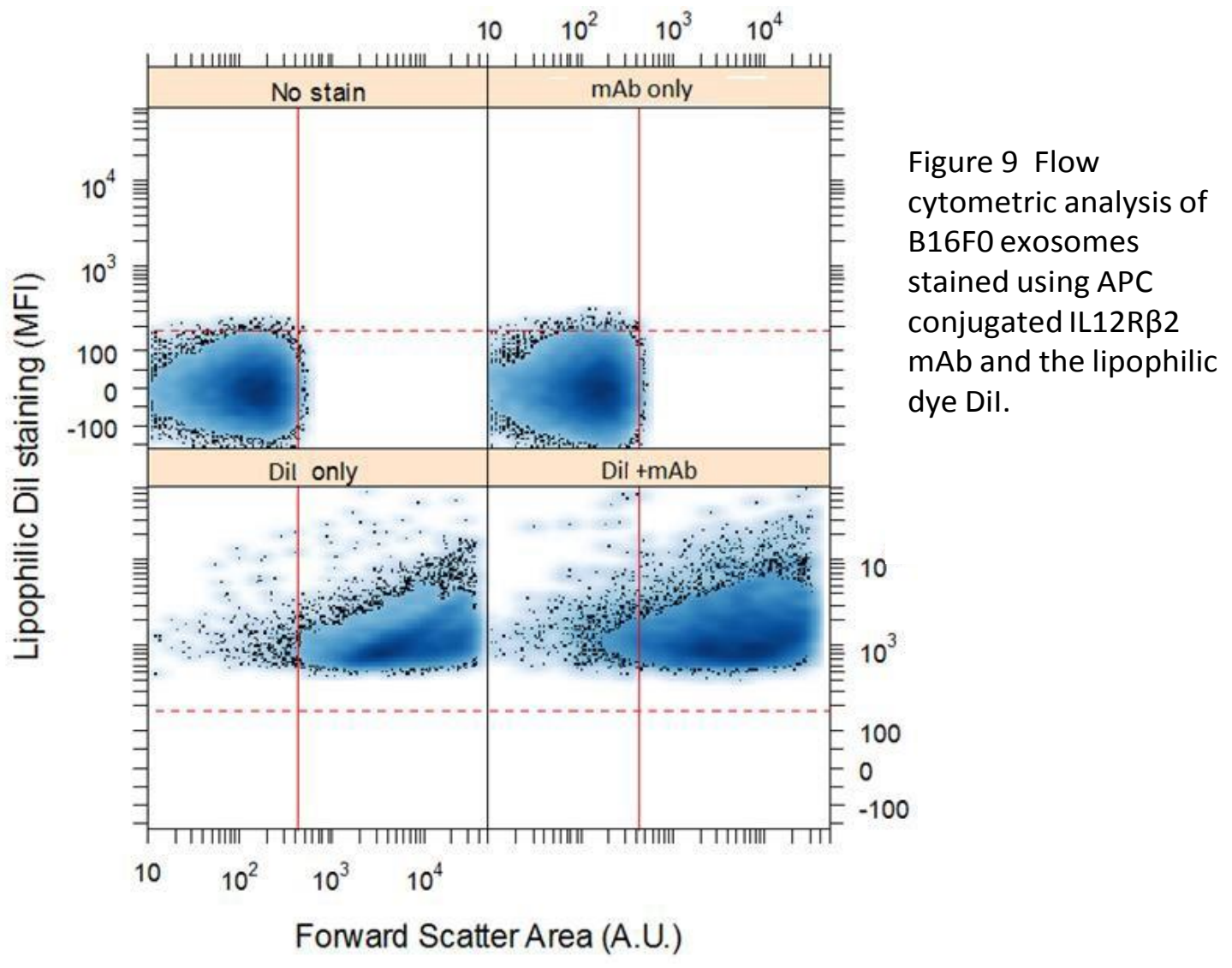


forward scatter areas above the background, suggesting that DiI may be clustering the exosomes. To demonstrate how the lipophilic tracer DiI can be used to enhance detection of proteins on exosomes using flow cytometry, we revised the flow cytometry assay to detect HER1 proteins on SKBR3 exosomes. As single exosomes, SKBR3 exosomes were negative for HER1 staining (see Figure 6B) in our result, to increase the HER1 signal, we stained SKBR3 exosomes using an APC-conjugated HER1 mAb and then clustered them into larger particles using DiI (Figure 6C). The DiI positive events exhibited a bimodal distribution, where single exosomes exhibited a distribution similar to the unstained control (mean MFI $=11.4$ a.u. versus mean MFI $=0$ a.u. for unstained) and exosome clusters exhibited a broad distribution (mean MFI $=778$ a.u.). On a flow cytometric event basis, the single exosomes seem to be a large fraction of the population. However considering that events exhibiting a MFI greater than 100 a.u. are comprised of multiple exosomes, the number of single exosomes was estimated to be less than $1 \%$ of the total exosome population.

Collectively, the flow cytometry results suggested two points. First, the sensitivity of the flow cytometry assay limited our ability to assess exosome biomarkers to those proteins that exhibited high copy numbers. As an alternative to using antibodies that are directly conjugated to fluorophores, a primary antibody directed against the protein of interest plus a fluorophore-conjugated secondary antibody that binds to multiple epitopes on the primary antibody may improve the ability to detect lower abundant proteins, as used in $^{62}$. While a polyclonal secondary antibody may improve the detection signal, the mean fluorescent 
A

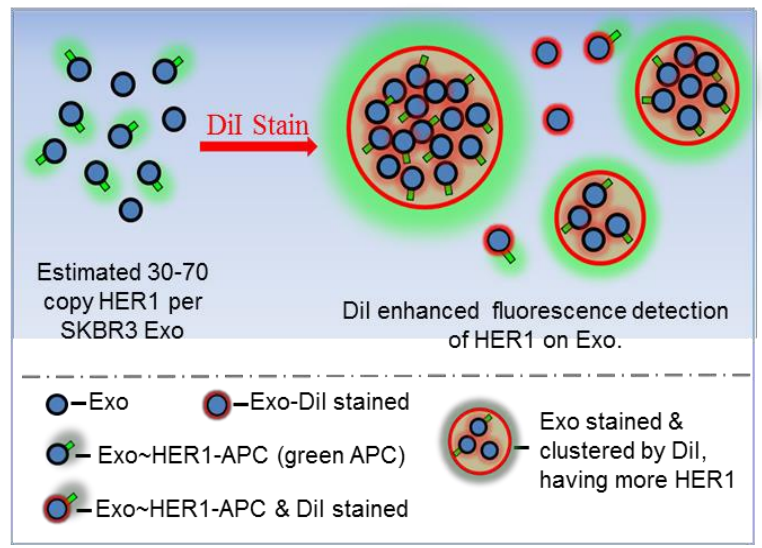

B
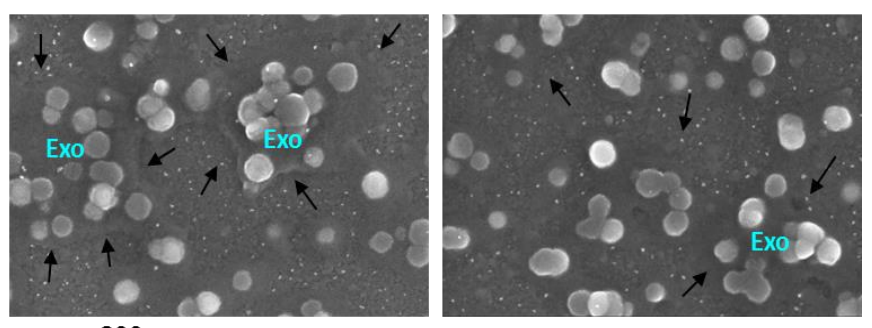

Figure 10 Exosomes were clustered using the lipophilic tracer Dil. Exosome clusters had more HER1 copies and bigger particle sizes, which enhanced HER1 detection by conventional flow cytometry using anti HER1-APC mAbs. (A) A schematic diagram illustrating that Dil was used to cluster nanoscaled exosomes into microscaled clusters. (B) A representative SEM image of Dil clustered exosomes, where "Exo" indicates the clusters of exosomes and black arrows indicates the edges of microscaled clusters induced by Dil.

intensity cannot be used in this context to quantify exosomal copy number, as described here. Second, a lipophilic dialkylcarbocyanine tracer (i.e. DiI, in this work) can be used to enhance the detection of low copy number proteins through unbiased clustering of exosomes and creating a lipophilic phase that favour the clustering of exosomes. This observation is schematically illustrated in (Figure 10A) and also supported by SEM imaging of exosomes stained by DiI (Figure 10B). Moreover, the addition of the lipophilic tracer enabled discriminating exosome-related flow cytometric events from background debris. This unbiased clustering increased the detection of the fluorescent signal associated with antibody binding. Collectively, these results illustrate how conventional flow cytometric analysis can be improved to leverage the high-throughput and 
quantitative potential of the method to characterize protein expression on exosomes with minimal potential bias.

\subsection{Conclusions}

In summary, we found that subtle differences in producing and storing exosomes can distort experimental observations of the purity of exosome samples, the size of exosomes, and the quality of exosomal RNA. In comparing two methods for direct imaging using electron microscopy, scanning electron microscope (SEM) provided a less time-consuming alternative to transmission electron microscope (TEM) to image the native morphology of exosomes and to assess sample purity. Using SEM, we were able to assess the impact of two different cell culture media on exosome production and of storage conditions on exosome quality. Within the first 24-36 hours, using serum-free media during exosome production did not appreciably alter exosome quality. The isolated exosomes also contained intact RNA transcripts. If the isolated exosomes need to be stored for a prolonged period, DMSO can be used to cryopreserve the morphology of exosomes but the sample quality is best characterized using fresh samples. In terms of biological activity, exosomal RNAs were preserved by freezing for short periods of time but became degraded with prolonged cryostorage, which may alter function. We also show that flow cytometry can be used to detect the presence of membrane-bound proteins on exosomes without specific bias toward any potential subpopulation in exosomes. Protein epitopes at high copy numbers could be readily detected while the lipophilic tracer, DiI, was 
used to cluster exosomes and enhance the detection of lower copy number proteins. The flow cytometry results also demonstrate that exosomes isolated from SKBR3 cells, a model of human HER2+ breast cancer, contain HER1 and HER2, two members of the epidermal growth factor family of receptors. Exosomes are approximately 100-times smaller in diameter than the mammalian cells and, therefore, contain less HER1 or HER2 copies in comparison with the parental cells. In addition, we found that the relative densities of HER1 and HER2 on the membrane surfaces were similar in SKBR3 exosomes as they were in the parental SKBR3 cells. In closing, we hope that, by identifying key process parameters, these improved methods will help to ensure a consistent framework in identifying the role that exosomes play in regulating cell-to-cell communication. 


\section{References for Chapter 2}

1. Théry, C., Ostrowski, M. \& Segura, E. Membrane vesicles as conveyors of immune responses. Nat. Rev. Immunol. 9, 581-593 (2009).

2. EL Andaloussi, S., Mäger, I., Breakefield, X. O. \& Wood, M. J. Extracellular vesicles: biology and emerging therapeutic opportunities. Nat. Rev. Drug Discov. 12, 347-357 (2013).

3. Robbins, P. D. \& Morelli, A. E. Regulation of immune responses by extracellular vesicles. Nat. Rev. Immunol. 14, 195-208 (2014).

4. Harding, C., Heuser, J. \& Stahl, P. Receptor-mediated endocytosis of transferrin and recycling of the transferrin receptor in rat reticulocytes. J. Cell Biol. 97, 329-339 (1983).

5. Pan, B. T., Teng, K., Wu, C., Adam, M. \& Johnstone, R. M. Electron Microscopic Evidence for Externalization of the Transferrin Receptor in Vesicular Form in Sheep Reticulocytes. J. Cell Biol. 101, 942-948 (1985).

6. Valadi, H. et al. Exosome-mediated transfer of mRNAs and microRNAs is a novel mechanism of genetic exchange between cells. Nat. Cell Biol. 9, 654-659 (2007).

7. Skog, J. et al. Glioblastoma microvesicles transport RNA and proteins that promote tumour growth and provide diagnostic biomarkers. Nat. Cell Biol. 10, 1470-1476 (2008).

8. Taylor, D. D. \& Gercel-Taylor, C. MicroRNA signatures of tumor-derived exosomes as diagnostic biomarkers of ovarian cancer. Gynecol. Oncol. 110, 13-21 (2008).

9. Al-Nedawi, K. et al. Intercellular transfer of the oncogenic receptor EGFRvIII by microvesicles derived from tumour cells. Nat. Cell Biol. 10, 619-624 (2008).

10. Peinado, H. et al. Melanoma exosomes educate bone marrow progenitor cells toward a pro-metastatic phenotype through MET. Nat. Med. 18, 883-891 (2012).

11. Peinado, H., Lavotshkin, S. \& Lyden, D. The secreted factors responsible for premetastatic niche formation: old sayings and new thoughts. Semin. Cancer Biol. 21, 139-146 (2011).

12. Luketic, L. et al. Antigen presentation by exosomes released from peptide-pulsed dendritic cells is not suppressed by the presence of active CTL. J. Immunol. 179, 5024-5032 (2007).

13. Balaj, L. et al. Tumour microvesicles contain retrotransposon elements and amplified oncogene sequences. Nat. Commun. 2, 180 (2011).

14. Boelens, M. C. et al. Exosome Transfer from Stromal to Breast Cancer Cells Regulates Therapy Resistance Pathways. Cell 159, 499-513 (2014).

15. Bronisz, A. et al. Extracellular vesicles modulate the glioblastoma microenvironment via a tumor suppression signaling network directed by miR-1. Cancer Res. 74, 738-750 (2014).

16. Clayton, A. et al. Human Tumor-Derived Exosomes Down-Modulate NKG2D Expression. J. Immunol. 180, 7249-7258 (2008).

17. Iero, M. et al. Tumour-released exosomes and their implications in cancer immunity. Cell Death Differ. 15, 80-88 (2008). 
18. Webber, J. P. et al. Differentiation of tumour-promoting stromal myofibroblasts by cancer exosomes. Oncogene 34, 290-302 (2015).

19. Webber, J., Steadman, R., Mason, M. D., Tabi, Z. \& Clayton, A. Cancer exosomes trigger fibroblast to myofibroblast differentiation. Cancer Res. 70, 9621-9630 (2010).

20. Kulkarni, Y. M., Klinke II, D. J., Wu, Y. \& Byrne-Hoffman, C. Inferring alterations in cell-to-cell communication in HER2+ breast cancer using secretome profiling of three cell models. Biotechnol. Bioeng. 111, 1853-1863 (2014).

21. Ratajczak, J., Wysoczynski, M., Hayek, F., Janowska-Wieczorek, A. \& Ratajczak, M. Z. Membrane-derived microvesicles: important and underappreciated mediators of cell-to-cell communication. Leukemia 20, 1487-1495 (2006).

22. Somasundaram, R. \& Herlyn, M. Melanoma exosomes: messengers of metastasis. Nat. Med. 18, 853-854 (2012).

23. Hood, J. L., San, R. S. \& Wickline, S. A. Exosomes released by melanoma cells prepare sentinel lymph nodes for tumor metastasis. Cancer Res. 71, 3792-3801 (2011).

24. Andre, F. et al. Mechanisms of disease Malignant effusions and immunogenic tumour-derived exosomes. 360, 295-305 (2002).

25. Hood, J. L., Pan, H., Lanza, G. M. \& Wickline, S. A. Paracrine induction of endothelium by tumor exosomes. Lab. Investig. 89, 1317-1328 (2009).

26. Taylor, D. D. \& Gerçel-Taylor, C. Tumour-derived exosomes and their role in cancer-associated T-cell signalling defects. Br. J. Cancer 92, 305-311 (2005).

27. Dai, S. et al. More efficient induction of HLA-A*0201-restricted and carcinoembryonic antigen (CEA)-specific CTL response by immunization with exosomes prepared from heat-stressed CEA-positive tumor cells. Clin. Cancer Res. 11, 7554-7563 (2005).

28. Wolfers, J. et al. Tumor-derived exosomes are a source of shared tumor rejection antigens for CTL cross-priming. Nat. Med. 7, 297-303 (2001).

29. Nilsson, J. et al. Prostate cancer-derived urine exosomes: a novel approach to biomarkers for prostate cancer. Br. J. Cancer 100, 1603-1607 (2009).

30. Mitchell, P. J. et al. Can urinary exosomes act as treatment response markers in prostate cancer? J. Transl. Med. 7, 4 (2009).

31. Villarroya-Beltri, C., Baixauli, F., Gutiérrez-Vázquez, C., Sánchez-Madrid, F. \& Mittelbrunn, M. Sorting it out: Regulation of exosome loading. Semin. Cancer Biol. 1-11 (2014). doi:10.1016/j.semcancer.2014.04.009

32. Filipazzi, P., Bürdek, M., Villa, A., Rivoltini, L. \& Huber, V. Recent advances on the role of tumor exosomes in immunosuppression and disease progression. Semin. Cancer Biol. 22, 342-349 (2012).

33. Keller, S., Ridinger, J., Rupp, A.-K., Janssen, J. W. G. \& Altevogt, P. Body fluid derived exosomes as a novel template for clinical diagnostics. J. Transl. Med. 9, 86 (2011).

34. Clayton, A. \& Mason, M. D. Exosomes in tumour immunity. Current Oncology 16, 46-49 (2009).

35. Gross, J. C., Chaudhary, V., Bartscherer, K. \& Boutros, M. Active Wnt proteins are secreted on exosomes. Nat. Cell Biol. 14, 1036-1045 (2012). 
36. $\mathrm{Xu}, \mathrm{D} . \&$ Tahara, H. The role of exosomes and microRNAs in senescence and aging. Adv. Drug Deliv. Rev. 65, 368-75 (2013).

37. Sharma, P., Schiapparelli, L. \& Cline, H. T. Exosomes function in cell-cell communication during brain circuit development. Curr. Opin. Neurobiol. 23, 9971004 (2013).

38. Okoye, I. S. et al. MicroRNA-Containing T-Regulatory-Cell-Derived Exosomes Suppress Pathogenic T Helper 1 Cells. Immunity 41, 89-103 (2014).

39. Fleming, A. B. \& Saltzman, W. M. Simultaneous delivery of an active protein and neutralizing antibody: Creation of separated regions of biological activity. $J$. Control. Release 70, 29-36 (2001).

40. Cocucci, E., Racchetti, G. \& Meldolesi, J. Shedding microvesicles: artefacts no more. Trends Cell Biol. 19, 43-51 (2009).

41. Raposo, G. \& Stoorvogel, W. Extracellular vesicles: exosomes, microvesicles, and friends. J. Cell Biol. 200, 373-383 (2013).

42. Mathivanan, S., Ji, H. \& Simpson, R. J. Exosomes: Extracellular organelles important in intercellular communication. Journal of Proteomics 73, 1907-1920 (2010).

43. Kulkarni, Y. M. et al. A quantitative systems approach to identify paracrine mechanisms that locally suppress immune response to Interleukin-12 in the B16 melanoma model. Integr. Biol. 4, 925-936 (2012).

44. Kulkarni, Y. M. \& Klinke II, D. J. Protein-based identification of quantitative trait loci associated with malignant transformation in two HER2+ cellular models of breast cancer. Proteome Sci. 10, 11 (2012).

45. Théry, C., Amigorena, S., Raposo, G. \& Clayton, A. Isolation and characterization of exosomes from cell culture supernatants and biological fluids. Curr. Protoc. Cell Biol. Chapter 3, Unit 3.22 (2006).

46. Hu, W., Zhang, C., Fang, Y. \& Lou, C. Anticancer properties of 10hydroxycamptothecin in a murine melanoma pulmonary metastasis model in vitro and in vivo. Toxicol Vitr. 25, 513-520 (2011).

47. Théry, C. et al. Proteomic Analysis of Dendritic Cell-Derived Exosomes: A Secreted Subcellular Compartment Distinct from Apoptotic Vesicles. J. Immunol. (2001).

48. Klinke II, D. J. \& Brundage, K. M. Scalable analysis of flow cytometry data using R/Bioconductor. Cytometry. A 75, 699-706 (2009).

49. Van der Pol, E. et al. Optical and non-optical methods for detection and characterization of microparticles and exosomes. J. Thromb. Haemost. 8, 2596-2607 (2010).

50. Sokolova, V. et al. Characterisation of exosomes derived from human cells by nanoparticle tracking analysis and scanning electron microscopy. Colloids Surf. B. Biointerfaces 87, 146-150 (2011).

51. Sharma, S. et al. Structural-mechanical characterization of nanoparticle exosomes in human saliva, using correlative AFM, FESEM, and force spectroscopy. ACS Nano 4, 1921-1926 (2010).

52. György, B. et al. Membrane vesicles, current state-of-the-art: emerging role of extracellular vesicles. Cell. Mol. Life Sci. 68, 2667-2688 (2011). 
53. Tang, L., Fan, T. M., Borst, L. B. \& Cheng, J. Synthesis and biological response of size-specific, monodisperse drug-silica nanoconjugates. ACS Nano 6, 3954-3966 (2012).

54. Reddy, S. T. et al. Exploiting lymphatic transport and complement activation in nanoparticle vaccines. Nat. Biotechnol. 25, 1159-1164 (2007).

55. Irvine, D. J., Swartz, M. A. \& Szeto, G. L. Engineering synthetic vaccines using cues from natural immunity. Nat. Mater. 12, 978-990 (2013).

56. Van der Pol, E., van Gemert, M. J., Sturk, A., Nieuwland, R. \& van Leeuwen, T. G. Single vs. swarm detection of microparticles and exosomes by flow cytometry. $J$. Thromb. Haemost. 10, 919-930 (2012).

57. Maas, S. L. N. et al. Possibilities and limitations of current technologies for quantification of biological extracellular vesicles and synthetic mimics. J. Control. Release 200, 87-96 (2015).

58. Erlandsen, S. L. et al. High-resolution immunogold localization of Giardia cyst wall antigens using field emission SEM with secondary and backscatter electron imaging. J. Histochem. Cytochem. 38, 625-632 (1990).

59. Speirs, V., Eich-Bender, S., Youngson, C. R. \& Cutz, E. Localization of MOC-1 cell surface antigen in small-cell lung carcinoma cell lines: an immunohistochemical and immunoelectron microscopic study. J. Histochem. Cytochem. 41, 1303-1310 (1993).

60. Nolte-'t Hoen, E. N. et al. Quantitative and qualitative flow cytometric analysis of nanosized cell-derived membrane vesicles. Nanomedicine 8, 712-720 (2012).

61. Van der Vlist, E. J., Nolte-'t Hoen, E. N., Stoorvogel, W., Arkesteijn, G. J. \& Wauben, M. H. Fluorescent labeling of nano-sized vesicles released by cells and subsequent quantitative and qualitative analysis by high-resolution flow cytometry. Nat. Protoc. 7, 1311-1326 (2012).

62. Higginbotham, J. N. et al. Amphiregulin exosomes increase cancer cell invasion. Curr. Biol. 21, 779-786 (2011). 


\section{CHAPTER 3:}

\section{MELANOMA B16F0 EXOSOMES DELIVERA UNIQUE BUT COMPLEX BIOLOGICAL PAYLOAD TO SUPPRESS T LYMPHOCYTE FUNCTION}

\subsection{Introduction}

Recent clinical successes using immune checkpoint modulators (i.e. antiCTLA-4, anti-PD-1/anti-PD-L-1) and adoptive cell therapy using engineered CD8+ $\mathrm{T}$ cells (chimeric antigen receptor $\mathrm{T}$ cells, called CAR $\mathrm{T}$ cells) are exciting developments in using immunotherapies for the treatment of cancer ${ }^{1-3}$. While the clinical response in a subset of cancer patients is quite durable, expanding the clinical benefit to the broader patient population remains a challenge $e^{4,5}$. These recent studies suggest that the clinical regression of a solid tumor is correlated with immune contexture within the tumor microenvironment and the local infiltration of active cytotoxic $\mathrm{T}$ cells. Specifically, proliferating $\mathrm{CD} 8+\mathrm{T}$ cells are present throughout tumors in patients who respond well to anti-PD- 1 therapy ${ }^{6}$. In contrast, tumors from patients that do not respond to therapy exhibit one of three patterns of CD8+ T cells: little to no infiltration of CD8+ $\mathrm{T}$ cells, CD8+ $\mathrm{T}$ cells present but non-functional, and an increased density of CD8+ $\mathrm{T}$ cell around the tumor ${ }^{6,7}$. These clinical data complement a broad body of literature suggesting that potent immunosuppressive mechanisms are present within the tumor microenvironment 
and play major roles in suppressing the anti-cancer activities of cytotoxic $\mathrm{T}$ lymphocytes ${ }^{8}$.

Organizing host immunity against a malignancy involves engaging a variety of immune cell types through a complex network of intercellular interactions. As tumors develop, they alter this network of interactions to construct a tissue niche favoring malignant cell survival that includes malignant cells, supportive stromal cells, alterations in the extracellular matrix, changes in metabolic substrates, and an immunological context associated with regulatory $\mathrm{T}$ cells, myeloid-derived suppressor cells, and inflammatory cytokines that suppressed anti-tumor immunity 9,10. Interestingly, an immunosuppressive environment within a tumor can be established relatively quickly. For instance, the ability of an anti-CTLA-4 therapy to control tumor growth using a variant of the B16 model of metastatic melanoma depended on time such that administration of an anti-CTLA-4 therapy up to 4 days after tumor implantation was able to eliminate tumors while waiting 12 days after implantation abrogated the therapeutic effect ${ }^{11}$. Similar to the selection and editing of tumor-associated antigens ${ }^{12}$, the results suggest that profile of proteins secreted by malignant cells may also reflect the selective pressure associated with oncogenesis. To develop this hypothesis, we used a proteomics workflow to identify proteins secreted into media conditioned by B16F0 cells, that is the B16F0 secretome, and found that the majority of secreted proteins were associated with exosomes $^{13}$. 
Exosomes are nano-scaled membrane vesicles derived from the endocytic compartments of mammalian cells and are released constitutively by both normal and malignant cells ${ }^{14}$. Emerging as an important mode of intercellular communications, exosomes can potentially transfer a variety of functional molecules including proteins, lipids, and coding and non-coding RNAs between cells. Transmembrane receptors and ligands that regulate and suppress the activity of immune cells have also been identified on tumor exosomes (9, 10). Previous studies have reported that melanoma exosomes deliver onco-protein MET to BMDCs that can stimulate pre-metastatic transformation in distant organs ${ }^{15,16}$. Focused studies on particular miRNA Exosome production and release are thought to be enhanced by a p53-mediated stress response ${ }^{17}$ and can be inhibited by depleting Rab27 family proteins that are involved in intracellular trafficking and release of exosomes ${ }^{18}$. While microarrays have been used to characterize in a systematic way the distribution of exosomal RNAs relative to the parental cells ${ }^{19-23}$ , a re-analysis of these data suggests that exosomal RNAs are primarily fragmented 24. In contrast, more focused studies suggest that exosomes can deliver biologically active miRNAs and mRNAs that can be translated in recipient cells ${ }^{19,21,23}$. As we have recently found that common methods for exosome storage degrade exosome morphology and the quality of exosomal RNA ${ }^{25}$, the objective of this study was to characterize exosomes freshly isolated from three different cell models of melanoma with a particular emphasis on exosomal mRNA and their potential impact on $\mathrm{T}$ cell function. Specifically, we focused on the B16F0, a non- 
immunogenic cell model of malignant melanoma; Cloudman S91, a cell model of immunogenic melanoma; and Melan-A, an immortalized melanocyte cell line.

\subsection{Materials and Methods}

\subsubsection{Antibodies and reagents.}

Cytokines, drugs, kits, and pharmacological inhibitors were obtained from commercial sources and used according to the suppliers' recommendations unless otherwise indicated. Western blot Abs: IL12RB2 pAbs (Santa Cruz Biotechnology; clone M-20) and GAPDH mAbs (Cell Signaling Technology; clone 14C10); LICOR IR secondary Abs (LI-COR Biosciences). Fluorophore-conjugated mAbs were used in flow cytometry: PE-PTPN11 mAb (Santa Cruz Biotechnology; clone B-1), PE-IFN- $\gamma$ mAb (BD Pharmingen; clone XMG1.2), DyLight 488-DDK mAb (OriGene Technologies; clone 4C5), PE-IL12RB2 mAb (R\&D Systems; clone 305719). Isotype control mAbs were rat and mouse mAbs conjugated with PE, APC (BD Biosciences). Blocking reagent was mouse IgG (Jackson Laboratory) in PBSAz for cells (DPBS mixed with $2 \%$ FBS and $0.02 \%$ sodium azide). Phosflow Lyse/Fix buffer and Perm Buffer III (used in PTPN11 mAbs staining), Cytofix/Cytoperm Fixation/Permeabilization kit (used for IFN- $\gamma$ mAbs and DDKprotein-tag mAbs staining) were from BD Biosciences. CellTrace Violet (CTV) and Live/Dead Yellow staining were purchased from Invitrogen. PBSAz buffer for exosomes is DPBS mixed with $0.05 \%$ BSA and $0.02 \%$ sodium azide, which was double-filtered through $0.02 \mu \mathrm{m}$ filters. CD8a+ T Cell Isolation Kit II, anti$\mathrm{CD} 3 \varepsilon / a n t i-C D 28$ beads for $\mathrm{T}$ cell activation (anti-CD3/CD28 beads), and 
fluorophore-conjugated Abs used in CD8 $\mathrm{T}$ cell staining including APC-CD3 $\varepsilon$ $\mathrm{mAb}$, VioBlue-CD8 $\alpha \mathrm{mAb}$, FITC-CD44 mAb, and PE-CD62 mAb were from Miltenyi Biotec Inc.

\subsubsection{Mice and primary $T$ cell isolation.}

Eight- to 12-week-old transgenic B6.Cg-Thy1a/Cy $\mathrm{Tg}$ (TcraTcrb)8Rest/J female mice were obtained from Jackson Laboratory. Mice were housed in sterilized microisolator cages in the university vivarium, and facility sentinel animals were regularly screened for specific pathogen agents. All studies were performed in accordance with all federal and institutional guidelines for animal use and were approved by the West Virginia University IACUC. From mouse spleen, primary CD8+ $\mathrm{T}$ cells were isolated from mouse splenocytes by automated magnetic cell sorting using methods described previously ${ }^{26}$ and by using the CD8 $\alpha+\mathrm{T}$ Cell Isolation Kit II according to the manufacturer's instructions. Enrichment for naive $\mathrm{CD} 8+\mathrm{T}$ cells $(\mathrm{CD} 8+, \mathrm{CD} 3+, \mathrm{CD} 44-$, and $\mathrm{CD} 62 \mathrm{~L}+)$ was confirmed by flow cytometry using corresponding Abs conjugated with fluorophores.

\subsubsection{Cell line culture and stimulation.}

The mouse melanoma cell lines, B16F0 and Cloudman S91 (clone M-3), and a cytotoxic T lymphocyte cell line, CTLL-2, were acquired from American Type Culture Collection (ATCC). An immortalized mouse melanocyte cell line, MelanA, was provided by V. Hearing (National Cancer Institute, Bethesda, MD, USA)

27. The $\mathrm{T}_{\mathrm{H}} 1$ cell model, 2D6, was provided by M. Grusby (Harvard University, 
Cambridge, MA) and cultured as described previously ${ }^{28}$. B16F0 and Cloudman S91 cells were maintained ${ }^{29}$ in DMEM (Cellgro/Corning) supplemented with $10 \%$ heat-inactivated fetal bovine serum (FBS, Hyclone) and penicillin/streptomycin (Gibco). Melan-A cell line was maintained in DMEM supplemented with 10\% nonheat-inactivated FBS, $20 \mathrm{mM}$ hydrogen chloride, $10 \mathrm{mM}$ HEPES (Gibco), $100 \mathrm{U} /$ $\mathrm{ml}$ penicillin and $100 \mu \mathrm{g} / \mathrm{ml}$ streptomycin (penicillin/streptomycin), $200 \mathrm{nM} \mathrm{12-} \mathrm{o-}$ tetradecanoyl phorbol 13-acetate (TPA, Sigma) and $200 \mu \mathrm{M}$ phenylthiourea (PTU, Sigma). CTLL-2 cell line was maintained in RPMI 1640 medium supplemented with 10\% T-STIM without con A containing IL-2 (BD Biosciences), 10\% FBS, penicillin/streptomycin, $2 \mathrm{mM}$ L-glutamine, $1 \mathrm{mM}$ sodium pyruvate,

$1.5 \mathrm{~g} / \mathrm{l}$ sodium bicarbonate, $10 \mathrm{mM}$ HEPES, 4ppm $\beta$-mercaptoethanol ( $\beta$-ME; $2 \mu 1$ in $500 \mathrm{ml}$ medium). Primary CD8+ $\mathrm{T}$ cells were cultured in RPMI 1640 supplemented with $10 \% \mathrm{FBS}$, penicillin/streptomycin, $2 \mathrm{mM}$ L-glutamine, $1 \mathrm{mM}$ sodium pyruvate, $10 \mathrm{mM}$ HEPES, $4 \mathrm{ppm} \beta-\mathrm{ME}, 70 \mathrm{U} / \mathrm{ml} \mathrm{IL}-2,90 \mathrm{pM}$ rmIL-12 (eBiosciences), $5 \mu \mathrm{g} / \mathrm{ml}$ anti IL-4 $\mathrm{mAb}$ (eBiosciences), with or without the costimulation from anti-CD3/CD28 beads (1:1 cell:bead ratio). All cells were cultured at $37^{\circ} \mathrm{C}$ in $5 \% \mathrm{CO}_{2}$.

\subsubsection{Exosome isolation, scanning electron microscopy (SEM) imaging and Western blot analysis.}

Fresh extracellular vesicles were isolated using a differential centrifugation protocol from serum-free media that have been conditioned by the B16F0, Cloudman S91 and Melan-a cell lines, respectively, for the indicated time periods 
and imaged using SEM, as described previously ${ }^{13}$. Exosome sizes were quantified from the SEM images using ImageJ and summarized as distributions using kernel density estimation in $\mathrm{R}$ 2.15.2. All numbers are reported as mean \pm standard deviation, unless otherwise noted. The abundance of proteins contained in $\mathrm{B} 16 \mathrm{~F} 0$ exosomes were compared against whole cell lysates of B16F0 by Western blot targeting IL12RB2 and GAPDH, using methods as described previously ${ }^{30}$. Whole cell lysates from 2D6 cells were used as a positive control. In summary, protein samples were denatured by Laemmli sample buffer plus $\beta \mathrm{ME}$, loaded onto a $8 \%$ Tris polyacrylamide gel with a $4 \%$ stacking gel for SDS-PAGE, and then transferred to a PVDF membrane (PALL Life Sciences) for blotting. Following blocking by SEA blocking buffer (Pierce), membranes were probed with mixed primary Abs of goat anti-mouse IL12RB2 pAb (1:300, clone M-20, Santa Cruz Biotechnology) and rabbit anti-mouse GAPDH mAbs (1:2000, clone 14C10, Cell Signaling Technology) in 5\% dry milk in PBS-T (PBS plus 0.1\% Tween-200 and 0.04\% sodium nitride), then incubated in secondary Abs conjugated with fluorophores (1: 20,000 IRDye800CW donkey anti-goat IgG Abs, 1: 60,000 IRDye680LT donkey anti-rabbit IgG Abs, LI-COR Biosciences) in PBS-T supplemented with 5\% dry milk and $0.01 \%$ SDS, rinsed in PBS-T, and imaged using the Odyssey Infrared Imaging System (LI-COR).

\subsubsection{Microarray analysis.}

Total RNA isolated from B16F0 exosomes and cells by RNeasy Plus kit (Qiagen) was quantified using Nanodrop and analyzed by on-chip-electrophoresis using the Agilent Bioanalyzer. RNA sample (100 ng) with an RNA integrity 
number value greater than 7 was processed by the Ambion WT Expression Kit according to the manufacturer's instructions. Each reaction yielded between 6 to 9 micrograms of cDNA, whereby $5.5 \mu \mathrm{g}$ of cDNA was fragmented and labeled with biotin by the GeneChip WT Terminal Labeling Kit (Affymetrix). The efficiency of fragmentation reaction was checked via Agilent Bioanalyzer. The entire reaction of fragmented and biotin-labeled cDNA $(50 \mu \mathrm{l})$ with added hybridization controls was hybridized to the mouse GeneChip 1.0 ST Exon Arrays (Affymetrix) at $45^{\circ} \mathrm{C}$ for 17 hours in GeneChip Hybridization Oven 640 (Affymetrix). Mouse GeneChip 1.0 ST Exon Arrays were stained using FS 450_0001 protocol in Affymetrix GeneChip Fluidics Station 450. Phycoerythrin labeling was detected within the Affymetrix GeneChip Scanner 3000 7G plus using $532 \mathrm{~nm}$ light and detected by a photomultiplier tube. Expression Console software (Affymetrix) was used to check quality controls of hybridized chips. All chips that passed quality controls were RMA normalized using Expression Console software. Gene expression was estimated based on the average expression of all core probesets for a gene. The probability of a gene being expressed above background by random chance was estimated using the negative control probesets and a Welch's t-test, where the degrees of freedom were calculated using the Welch-Satterthwaite equation. A p-value of less than 0.05 was used for estimating the distribution of mRNA expression between cells and exosomes while a p-value of less than 1e-9 was used for qRT-PCR validation and pathway enrichment analysis.

Quantitative reverse-transcription PCR (q-RT-PCR) was used to validate the cDNA microarray results. RNA samples were purified using an RNeasy mini kit 
(Qiagen) and reversely transcribed with Superscript III First-Strand (Invitrogen). Quantitative PCR was carried out on an ABI PRISM 7900HT Sequence Detection System (Applied Biosystems) using Perfecta SYBR Green SuperMix, ROX (Quanta Biosciences). Proprietary primer mixtures were purchased from Qiagen for the corresponding genes: Kpnb1 (Cat. \# QT00153419), Rnf14 (Cat. \#QT00157241), Rnd2 (Cat. \#QT00314216), Ptp4a3 (Cat. \#QT00138243), Eif2c2 (Cat. \#QT01757833), Hipk2 (Cat. \#QT00197890), Eif4ebp2 (Cat. \#QT00144606), Dnmt3a (Cat. \#QT00106519), Wsb2 (Cat. \#QT01747739). The delta/delta CT method using the Sequence Detector Software version 2.2 (Applied Biosystems) was for data analysis. In addition, the semi-quantitative PCR was used to amplify the full-length coding sequences (ORFs) of the indicated genes from same cDNAs, in which the amplified DNA products were monitored from certain cycles after the desired fragments showed up, and compared before the amplification was saturated. The primer sequences are listed as follows: Ptpnl1 forward ATGACATCGCGGAGATGGTTTC, reverse TCATCTGAAACTCCTCTGCTGCTG; Kpnb1 forward ATGGAGCTCATAACCATCCTCG, reverse TCAAGCCTGGTTCTTCAGTTTCC; Ptp4a3 forward ATGGCCCGCATGAACCGGC, reverse CTACATGACGCAGCATCTGGTC; $\begin{array}{lll}\text { Eif4ebp2 forward } & \text { ATGTCCGCGTCGGCCGGTG, } & \text { reverse }\end{array}$ TCAGATGTCCATCTCAAACTGAG; Rnd2 forward ATGGAGGGGCAGAGTGGC, reverse TCACATGAGGTTACAGCTCTTG; and 
Wsb2

forward

ATGGAGGCCGGAGAGGAG,

reverse

\section{CTAGAAAGTCCTGTATGTGAGG.}

\subsubsection{Cell stimulation with exosomes.}

Prior to exposure to exosomes, 2D6 T cells $\left(6 \times 10^{4}\right.$ cells/well $)$ were cultured in 96-well u-bottomed culture plates for $12 \mathrm{~h}$ in the absence of IL-12p70. Following pre-conditioning, 2D6 $\mathrm{T}$ cells were stimulated with complete media containing the indicated concentrations of fresh exosomes that had been isolated aseptically from B16F0, Cloudman S91 and Melan-A cells, and resuspended in PBS. Cells were cultured with exosomes for $30 \mathrm{~min}$ at $37^{\circ} \mathrm{C}$ in $5 \% \mathrm{CO}_{2}$ and then prepared for flow cytometric analysis, as described in $^{28}$. Briefly, cells were fixed using Phosflow Lyse/Fix buffer, permeabilized using Perm Buffer III, blocked using mouse IgG, stained using PE-PTPN11 mAb, and suspended in PBSaz for flow cytometry analysis.

Prior to exposure to exosomes, primary $\mathrm{CD} 8+\mathrm{T}$ cells were stained by CellTrace Violet (CTV). Following CTV staining, primary CD8+ T cells $\left(6 \times 10^{4}\right.$ cells/well) were cultured in 96-well u-bottomed culture plates for 24 hours at $37^{\circ} \mathrm{C}$ in $5 \% \mathrm{CO}_{2}$ in complete media containing anti-CD3/CD28 beads at a $1: 1$ ratio with cells and the indicated concentrations of fresh exosomes that were isolated aseptically from B16F0, Cloudman S91, and Melan-A cells. Primary CD8+ T cells cultured in complete media that contained only blank beads at a 1:1 ratio was used as a negative control. At the indicated time points, cells were stained using Live/Dead Yellow, fixed using Phosflow Lyse/Fix buffer, blocked using mouse 
IgG, stained with PE-IL12RB2 mAb, resuspended in PBSaz and analyzed by flow cytometry. All experiments were performed in triplicate.

\subsubsection{PTPN11 transfection and assay of CTLL-2 $T$ cell proliferation.}

CTLL-2 T cells were transiently transfected with two different Ptpn11 expression plasmids with CMV promoters (Cat.\# MC219480 for isoform variant

1, Cat.\# MC219394 for isoform variant 2, OriGene Technologies), and a GFP expression plasmid with a CMV promoter (pmaxGFP Vector from Lonza) using a Nucleofector electroporation 2b device, program L-029 and solution L (Lonza). CTLL-2 cells electroporated in the presence of plasmid TE buffer was used as a negative control. Following transfection, cells were cultured in calcium-free medium containing $10 \% \mathrm{FBS}$ at $37^{\circ} \mathrm{C}$ for 10 minutes and then cultured in complete medium containing $50 \mathrm{ng} / \mathrm{ml}$ TPA (PMA; Sigma) to induce gene expression for 40 hours. Following this pre-conditioning period, CTLL-2 cells were labeled with CTV to record cell proliferation, transferred in triplicate to 96-well-plate at a density of $1 \times 10^{5}$ cells $/ \mathrm{ml}$ and stimulated with $2000 \mathrm{U} / \mathrm{ml} \mathrm{IL-2}$ for the indicated time points, up to 72 hrs. After IL-2 stimulation, cells stained with Live/Dead Yellow, fixed, permeabilized, blocked, stained using PE-conjugated PTPN11 mAbs and subjected to flow cytometric analysis. At least two biological replicates of transfection where performed. For each batch of transfected cells, experiments were performed in triplicates.

\subsubsection{DNMT3A transfection and assay of IFN- $\gamma$ production in $2 \mathrm{D} 6 \mathrm{~T}$ cells.}


DNMT3A expression was induced using two different CMV-driven expression plasmids that contained isoforms of Dnmt3a with a C-terminal mycDKK tag (MR211146 Dnmt3a variant 1, MR226152 Dnmt3a variant 2; OriGene Technologies) 2D6 $\mathrm{T}$ cells were transfected and recovered in complete medium for 48 hrs containing TPA as it was performed on CTLL-2 T cells, except using Nucleofector program T-030 for electroporation. Following this pre-conditioning period, 2D6 $\mathrm{T}$ cells were cultured without IL-12p70 for $12 \mathrm{hrs,} \mathrm{transferred} \mathrm{in}$ triplicate to 96-well-plate, u-bottom, at a density of $6 \times 10^{5}$ cells $/ \mathrm{ml}$, stimulated for 5 hours with $1 \mu \mathrm{g} / \mathrm{ml}$ calcium ionophore (Sigma), $25 \mathrm{ng} / \mathrm{ml}$ TPA and GolgiStop monensin (protein transport inhibitor; BD Biosciences) in complete medium without IL-12p70. Incubating 2D6 cells in medium containing monensin, without calcium ionophore or TPA was used as a negative control. After the stimulation, cells were stained by Live/Dead Yellow staining, fixed, permeabilized, stained with DyLight488-conjugated anti-DDK $\mathrm{mAb}$ and PE-conjugated anti-IFN- $\gamma \mathrm{mAb}$, and analyzed by flow cytometry.

\subsubsection{Flow cytometry.}

Immunostaining of surface proteins on exosomes was performed using methods described ${ }^{28}$. In brief, freshly isolated exosomes were resuspended in PBSAz buffer, blocked using mouse IgG, stained with PE-conjugated IL12RB2

$\mathrm{mAb}$, washed in $20 \mathrm{ml} \mathrm{PBSAz}$ and spun down at $150,000 \times \mathrm{g}$ for 1 hour at $4^{0} \mathrm{C}$.

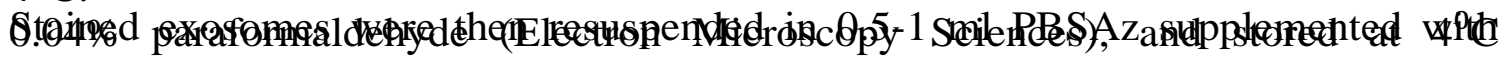


before flow cytometry analysis. For all flow cytometric analyses, FACSAria or 
LSRFortessa flow cytometers were used (BD Biosciences). The fluorescent intensity for each parameter was reported as a pulse area using 18-bit resolution. Single-stain controls were used to establish fluorescent compensation parameters. Unstained cells were used as negative flow cytometry controls. Flow cytometry data was exported as FCS3.0 files and analyzed using R/Bioconductor software ${ }^{31}$.

\subsubsection{Statistics.}

The differences in Western blots were compared for statistical significances using Student's t-test. RNA expressions in Microarray analysis were compared with the loading controls using Welsh t-test. Statistically significant differences in PE MFI (IFN- $\gamma)$ distributions were compared using a Pearson's $\chi 2$ test. P value < 0.05 was considered as statistically significant. 


\subsection{Results}

\subsubsection{Exosomes are secreted by both normal and malignant melanocytes.}

In a previous proteomic study of $\mathrm{B} 16 \mathrm{~F} 0$ secretome, we identified that the majority of secreted proteins were associated with exosomes ${ }^{13}$. To validate and extend this prior work, we isolated extracellular vesicles from in vitro cell cultures of mouse melanoma cells, B16F0 and Cloudman S91, and from immortalized melanocytes, Melan-A, using a differential centrifugation protocol. As cells secrete exosomes in addition to a number of other extracellular vesicles, we used scanning electron microscopy (SEM) to image directly the morphology and size distribution of these isolated extracellular particles. The extracellular particles exhibited round morphology (see Figure 1) with frequent membrane connections between the nanoscaled vesicles. In analyzing the SEM images, we found that the extracellular vesicles were uniformly distributed with average diameters of $163 \pm 13 \mathrm{~nm}(\mathrm{n}=$ 66) for B16F0 exosomes, $160 \pm 18 \mathrm{~nm}(\mathrm{n}=62)$ for Cloudman S91 exosomes, and $166 \pm 22 \mathrm{~nm}(\mathrm{n}=123)$ for Melan-A exosomes. Given that apoptotic vesicles and necrotic vesicles exhibit heterogeneous distributions with smaller sized vesicles under $\mathrm{EM}^{25}$ and our prior proteomics analysis of the $\mathrm{B} 16 \mathrm{~F} 0$ secretome, we concluded that the isolated extracellular vesicles secreted by all three cell lines were exosomes. 
a

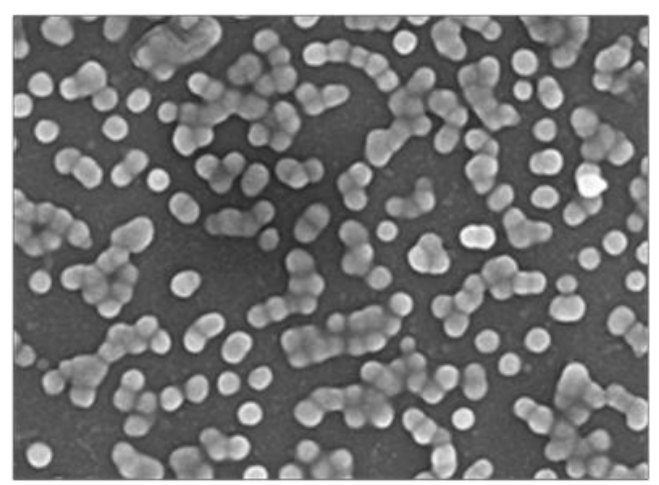

$500 \mathrm{~nm}$

C

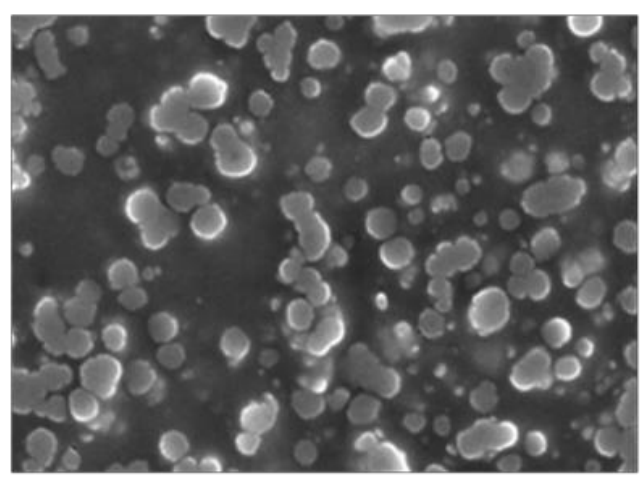

b
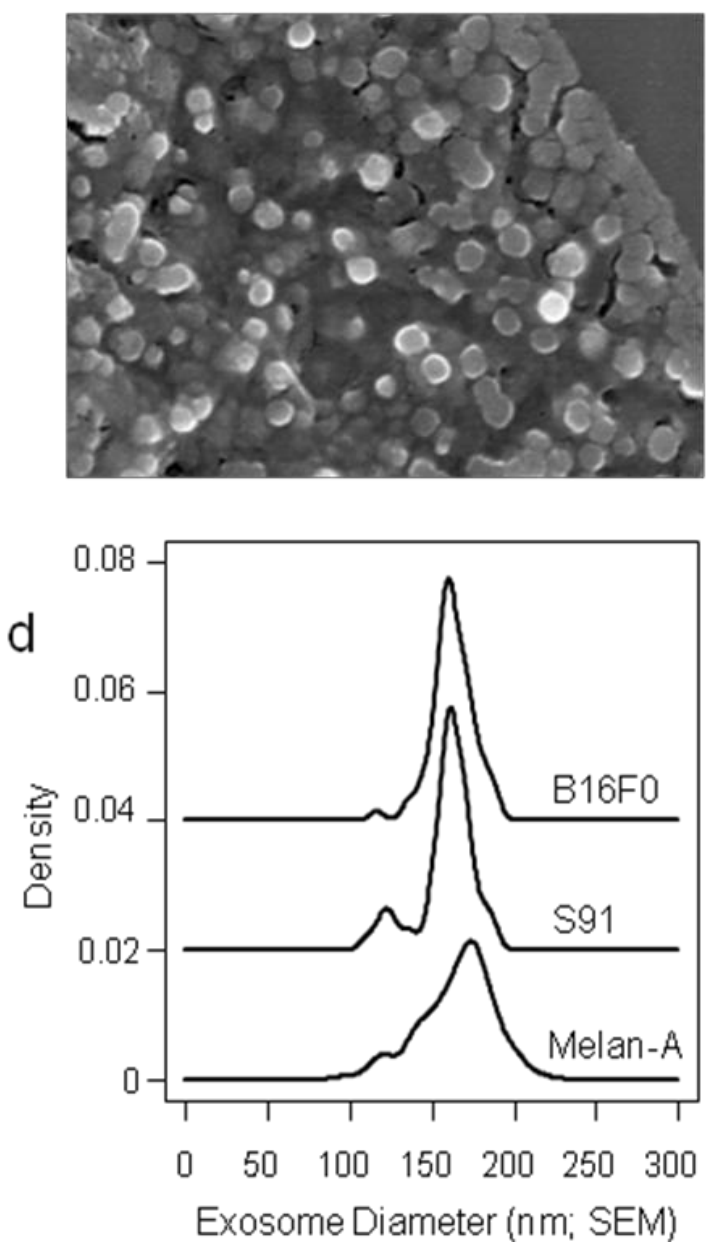

Figure 1 Mouse melanoma and immortalized melanocytes release exosomes. Extracellular vesicles were isolated from media conditioned by B16FO cells (a), Cloudman S91 (b), and Melan-A cells (c) and imaged using SEM (bar indicates $500 \mathrm{~nm}$ used for $\mathrm{a}, \mathrm{b}$ and c). SEM images were representative of more than 3 replicates. (d) The diameters of the extracellular vesicles from B16F0 (black solid line, $N=66$ ), Cloudman S91 (black dotted line, $N=62$ ), and Melan-A cells (gray shadowed, $\mathrm{N}=123$ ) were estimated from the SEM images using ImageJ and summarized using a density distribution, where the density distributions were offset vertically for clarity.

\subsubsection{B16F0 exosomes express IL-12RB2 on the surface.}

Exosomes have been reported to transport transmembrane receptors between cells ${ }^{32} \cdot \mathrm{In}^{29}$, we observed that the B16F0 cell line overexpressed IL12RB2, which 
a

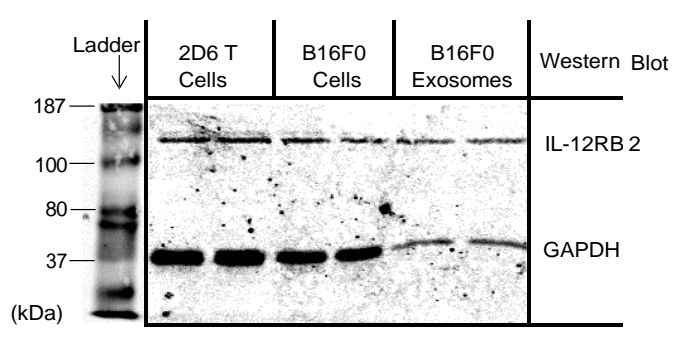

b

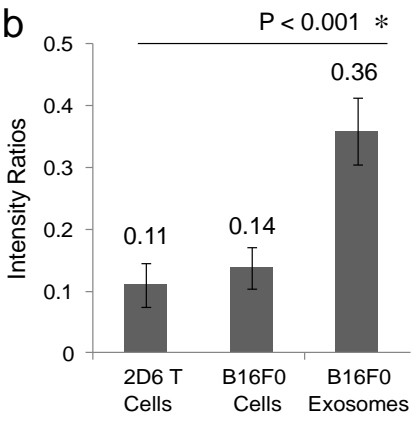

C

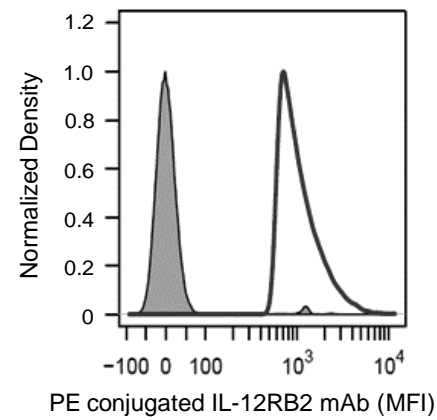

Figure 2. Similar to parental cells, exosomes isolated from B16F0 cells contain IL-12 receptor beta 2 (IL12RB2), which is localized on the exosome surface. (a) A Western blot analysis identified IL12RB2 as being present in B16F0 exosomes, B16F0 cells and 2D6 T cells, as illustrated by a representative image (a) and normalized intensity ratios $(b)(* P<0.001, N=4)$. GAPDH was a loading control and whole cell lysate from 2D6 T cells was used as a positive control for IL12RB2 expression. (c) The presence of IL12RB2 on the surface of exosomes was detected by flow cytometry using IL-12RB2 mAbs-PE. Unstained exosomes were used as a negative control (gray shaded). Results were representative of three replicates.

is one component of the Interleukin-12 (IL12) receptor, and that the B16F0 sequestered IL12. Collectively, the results suggest that the B16F0 cells create a cytokine sink for IL12. Here, we wanted to know whether exosomes released by the B16F0 cells also contained IL12RB2. In comparing B16F0 exosome lysates with whole cell lysates, Western blot analysis revealed a single band with an apparent molecular weight of $130 \mathrm{kDa}$ for samples from B16F0 cells as well as B16F0 exosomes (see Figure 2a). As a positive control, we also included whole cell lysates from 2D6 $\mathrm{T}$ cells, which activate STAT4 in response to IL12 stimulation $^{28}$. The relative abundance of IL12RB2 appeared to be more in the exosomes compared to either the B16F0 or 2D6 T cells (see Figure 2b, p < 0.001), where GAPDH was used as a loading control, as it is present in both cells and exosomes. As IL12RB2 may be encapsulated within the exosomes rather than expressed on the surface, we stained exosomes using a PE-conjugated IL12RB2 
antibody and analyzed exosomes using flow cytometry, which indicated that B16F0 exosomes expressed IL12RB2 on the surface (Figure 2c). Collectively, the results suggest that $\mathrm{B} 16 \mathrm{~F} 0$ cells release exosomes with an average diameter of 163 $\mathrm{nm}$ that contain IL12RB2 on the surface.

\subsubsection{Exosomes contain intact mRNAs that exhibit differential enrichment relative to the parent cells}

As exosomes have been reported to contain coding RNA, we used an exonlevel cDNA Affymetrix microarray to quantify mRNA transcripts in B16F0 exosomes and the parental B16F0 cells. First, we used an Agilent Bioanalyzer for on-chip-electrophoresis to assess the quality and the distribution in length of RNA in samples isolated from $\mathrm{B} 16 \mathrm{~F} 0$ cells and freshly isolated $\mathrm{B} 16 \mathrm{~F} 0$ exosomes (Figure 3a). In contrast to the predominant peaks associated with ribosomal RNAs (5S, $18 \mathrm{~S}$, and 28S) in the samples from B16F0 cells, the exosome samples had RNA that was broadly distributed between the 120 and 1800 nucleotides in length and were negative for $28 \mathrm{~S}$ ribosomal RNA. Affymetrix microarrays were then used to quantify differential expression of mRNA between B16F0 cells and exosomes. Hierarchical clustering was used to illustrate differences among the different samples versus among the probed genes (Figure 3b). Overall the samples were similar between replicates of the same RNA source and different between the cell and exosome samples. In comparing the ratio of average expression between exosome and cell samples, we found that $67 \%$ mRNAs probed were more prevalent in the cell, $30 \%$ of the mRNAs were equally distributed between the cell 
a

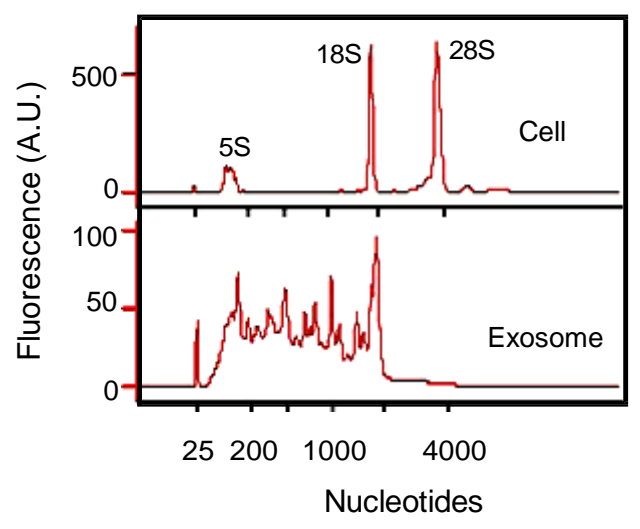

C

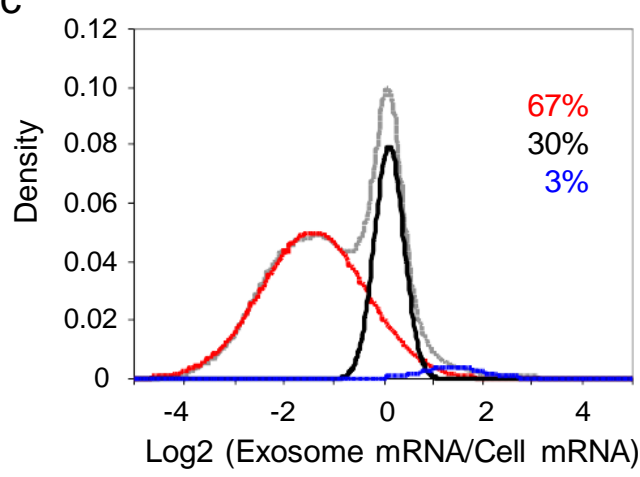

b

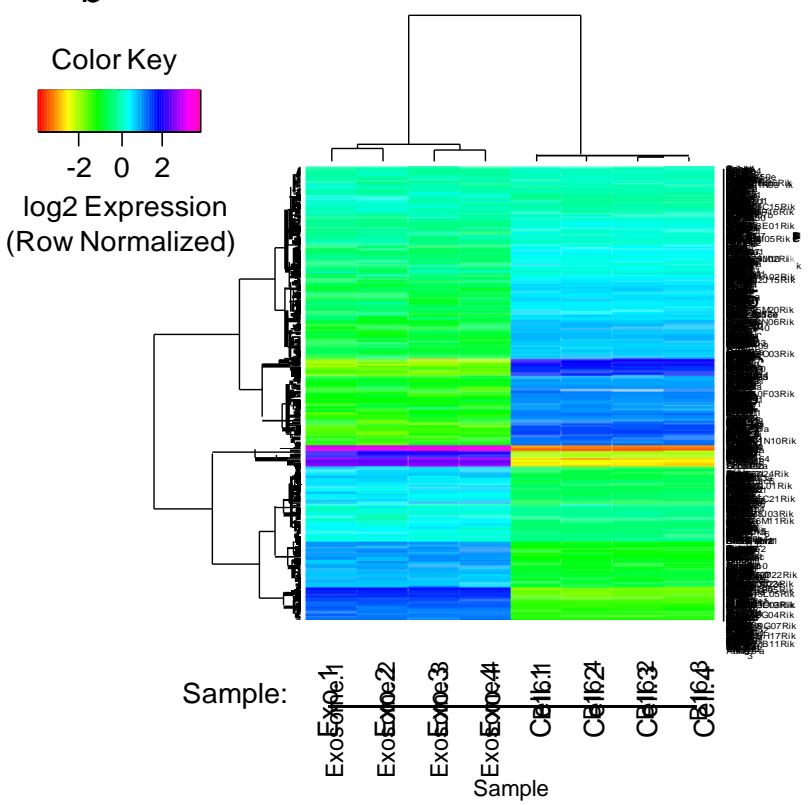

d

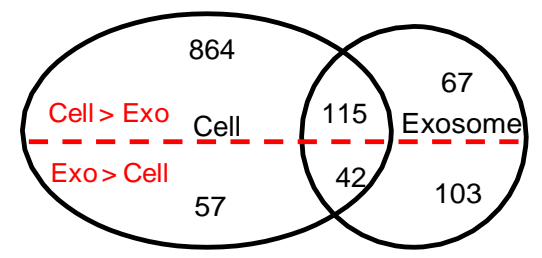

Figure 3 B16F0 exosomes contain mRNAs that are differentially expressed relative to parental cells. (a) The distribution in RNA contained within the parental B16F0 cells (top panel) and B16F0 exosomes (bottom panel) was quantified using microfluidic electrophoresis (Agilent 2100 Bioanalyzer). (b) Hierarchical clustering of mRNA detected above background $(p<0.01)$ from four B16F0 exosomes and four B16F0 cell samples using Affymetrix Exon-level cDNA microarrays. (c) The overall distribution in exosome versus cellular abundance of mRNAs (gray curve) was deconvoluted into three normally distributed populations: mRNAs enriched in cells (red curve $67 \%$ of total), mRNAs equally distributed between cell and exosomes (black curve $-30 \%$ of total), and mRNAs enriched in exosomes (blue curve $-3 \%$ of total). (d) Using a more stringent gene call $\left(\mathrm{P}_{\text {Gene }}<1 \mathrm{e}-9\right)$, a Venn diagram summarizes the number of mRNA genes differentially expressed between cell and exosome samples.

and exosome, and $3 \%$ of the mRNAs had a higher abundance in the exosomes (Figure 3c, $\mathrm{P}<0.01$ vs. the negative control probesets). Using a Bonferroni correction for multiple hypothesis testing, a Venn diagram summarized the distribution in the gene expression that were significantly above background. In particular, we focused on 145 mRNAs for genes that were more abundant in 
a

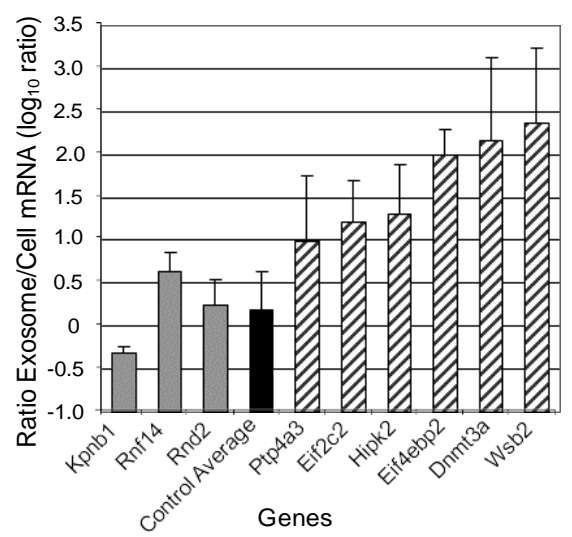

b

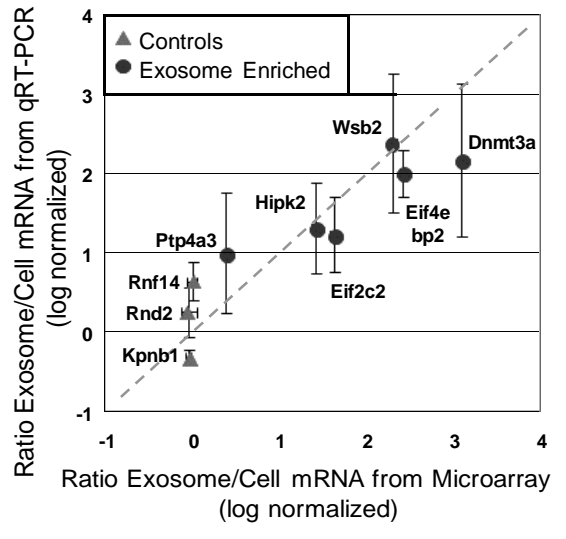

C

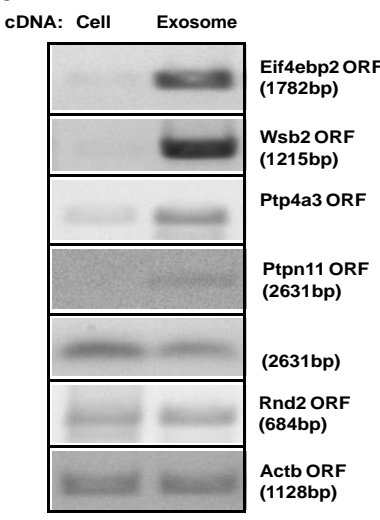

Figure 4. Relative mRNA abundance between B16F0 exosomes and cells were consistent between qRT-PCR and microarray analyses. (a) The abundance of eight genes (Kpnb1, Rnf14, Rnd2, Ptp4a3, Eif2c2, Hipk2, Eif4ebp2, Dnmt3a, and Wsb2) in B16F0 exosomes versus B16F0 cells were quantified by quantitative RT-PCR (mean \pm s.d., $N=3$ ). The qRT-PCR results were normalized to the average differential abundance of three "control" genes: Kpnb1, Rnf14, and Rnd2. (b) The relative abundances of mRNAs assayed by qRT-PCR were compared against the relative abundances of mRNAs assayed by cDNA microarray. The dotted line indicates that the two different assays provide the same results for relative abundance. (c) Full-length coding sequences (ORFs) were amplified by semi-quantitative RT-PCR. Equal concentrations of RNA were reverse-transcribed into cDNA and amplified by PCR. After 25 cycles, full-length openreading frame amplicons were monitored every three cycles and resolved on agarose gel before the amplification was saturated.

$\mathrm{B} 16 \mathrm{~F} 0$ exosomes for subsequent pathway enrichment analysis (Figure 3d, P <1e-9 vs. the negative control probesets).

To validate the cDNA microarray results, we amplified a subset of the mRNA using quantitative RT-PCR (Figure $4 \mathrm{a}$ and $\mathrm{b}$ ). As endogenous loading controls for exosomes are unclear, we selected three genes to serve as loading controls, Rnf14, Rnd2 and Kpnb1, that had equal abundance between the cell and exosome samples based on the microarray results. In addition, we selected an additional subset of genes that appeared to be more abundance in exosomes: Ptp4a3, Hipk2, Eif $2 c 2$, Wsb2, Eif4ebp2 and Dnmt3a. Overall, the qRT-PCR results were consistent with 
the cDNA microarray results in assaying the relative abundance between cells and exosomes for the different genes as the correlation coefficient was determined to be 0.922 (Figure 4b). Dnmt3a was the most abundant of the mRNAs assayed by PCR. We also used semi-quantitative PCR to confirm that the exosomal mRNAs were intact rather than fragmented (Figure 4c). We amplified 7 ORFs, Ptpn11, Eif4ebp2, Wsb2, Ptp4a3, Kpnb1, Rnd2 and Actb, out of the total RNAs purified from both B16F0 cells and exosomes (Figure 4c). Similar to the qRT-PCR results, ORFs of the 3 loading control genes, Kpnb1, Rnd2 and Actb, seemed to have similar abundance between the two samples and mRNA for the genes, Ptpn11, Eif4ebp2, Wsb2 and Ptp4a3 displayed enriched abundance in the B16F0 exosome samples. Collectively, the gene expression results suggest that mRNAs are selectively packaged into exosomes and that the mRNAs are intact ORFs.

\subsubsection{B16F0 exosomes can deliver biological payload to $T$ lymphocytes.}

As a subset of mRNAs were selectively enriched in exosomes, we used a pathway enrichment algorithm to identify biological pathways that are associated with mRNAs that are enriched in exosomes. As indicated in Figure 3d, the Enrichr

pathway enrichment algorithm ${ }^{33}$ was used to annotate 145 enriched mRNAs in B16F0 exosomes and identified 18 signaling pathways that had positive combined scores (see Table 1). Interestingly, several of the pathways are closely associated to the anti-tumor immunity, with the Type I Interferon signaling pathway having the lowest $\mathrm{p}$-value and the $\mathrm{IL}-2$, the $\mathrm{T}$ cell receptor, and Type II Interferon signaling pathways all having a positive combined score. One of the challenges 
Table 1 Pathways that influenced by the enriched mRNAs from B16F0 exosomes.

\begin{tabular}{|c|c|c|c|c|}
\hline Pathways & *P-value & $\begin{array}{c}* \mathrm{Z}- \\
\text { score }\end{array}$ & $\begin{array}{c}* \text { Combined } \\
\text { Score }\end{array}$ & Enriched Genes \\
\hline $\begin{array}{l}\text { Signaling of hepatocyte growth factor } \\
\text { receptor }\end{array}$ & 0.033 & -1.685 & 0.732 & RAPGEF1; PTPN11 \\
\hline Triacylglyceride synthesis & 0.022 & -1.652 & 0.718 & GNPAT; PPAP2C \\
\hline Type I interferon signaling & 0.013 & -1.565 & 0.680 & PTPN11; RAPGEF1 \\
\hline \multirow[t]{3}{*}{ IL-3 signaling pathway } & 0.050 & -1.698 & 0.532 & RAPGEF1; CREB1; PTPN11; MAPK14 \\
\hline & 0.069 & -1.537 & 0.325 & ELK4; SMAD5 \\
\hline & 0.090 & -1.406 & 0.189 & HMGA1; PTPN11; MAPK14 \\
\hline IL-J signaung paunway & 0.104 & -1.292 & 0.174 & RAPGEF1; PTPN11; MAPK14 \\
\hline $\begin{array}{l}\text { IL-2 signaling pathway } \\
\text { B cell receptor signaling pathway }\end{array}$ & $\begin{array}{l}0.124 \\
0.151\end{array}$ & $\begin{array}{l}-1.550 \\
-1.393\end{array}$ & $\begin{array}{c}0.135 \\
6.12 \mathrm{E}-02\end{array}$ & $\begin{array}{l}\text { CREB1; PTPN11; MAPK14 } \\
\text { RAPGEF1; PTPN11; CREB1; MAPK14 }\end{array}$ \\
\hline $\begin{array}{l}\text { EGFR1 signaling pathway } \\
\text { Wnt signaling pathway }\end{array}$ & $\begin{array}{l}0.189 \\
0.262\end{array}$ & $\begin{array}{l}-1.301 \\
-0.772\end{array}$ & $\begin{array}{l}5.72 \mathrm{E}-02 \\
3.39 \mathrm{E}-02\end{array}$ & $\begin{array}{l}\text { RALB;ELK4; PTPN11; CREB1; MAPK14 } \\
\text { CTBPI; CCND1; HIPK2; CSNKID }\end{array}$ \\
\hline $\mathrm{T}$ cell receptor signaling pathway & 0.296 & -0.619 & $2.72 \mathrm{E}-02$ & RAPGEF1; PTPN11; CREB1 \\
\hline Insulin signaling & 0.396 & -0.376 & 1.65E-02 & RAPGEF1; PTPN11; MAPK14 \\
\hline $\begin{array}{l}\text { Myometrial relaxation and contraction } \\
\text { pathways }\end{array}$ & 0.380 & -0.372 & $1.64 \mathrm{E}-02$ & ADCY7; GRK6; CREB1 \\
\hline p38 MAPK signaling pathway & 0.253 & -0.204 & $8.95 \mathrm{E}-03$ & CREB1; MAPK14 \\
\hline IL-9 signaling pathway & 0.174 & -0.134 & $5.89 \mathrm{E}-03$ & PTPN11 \\
\hline TGF $\beta$ signaling pathway & 0.355 & $-6.27 \mathrm{E}-02$ & 2.76E-03 & SMAD5 \\
\hline Type II interferon signaling (IFNG) & 0.260 & $-6.63 \mathrm{E}-03$ & 2.91E-04 & PTPN11 \\
\hline
\end{tabular}

*: P-value is computed from the Fisher exact test. The Z-score is a statistical ranking metric derived from running the Fisher exact test for many random gene sets in order to compute a mean rank and standard deviation from the expected rank for each term in the gene-set library and finally calculating a z-score to assess the deviation from the expected rank. Combined score is calculated from p-value and $\mathrm{z}$-score.

with pathway enrichment results is that genes associated with a specific pathway can either promote or inhibit signal transduction. The gene that was common to 12 out of the 18 signaling pathways was Ptpn11. Ptpn11 encodes protein tyrosine phosphatase, non-receptor type 11 , which is also known as SHP2, and negatively regulates a variety of signaling pathways through two tandem Src homology-2 domains. 
a

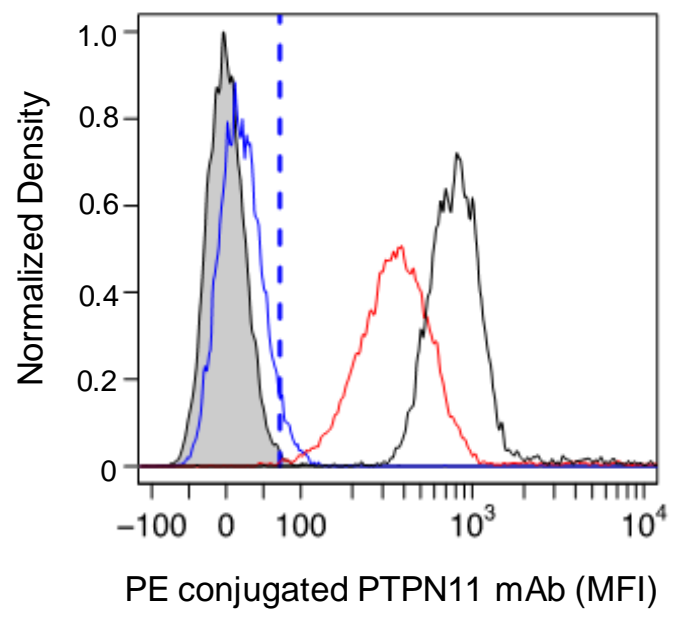

b

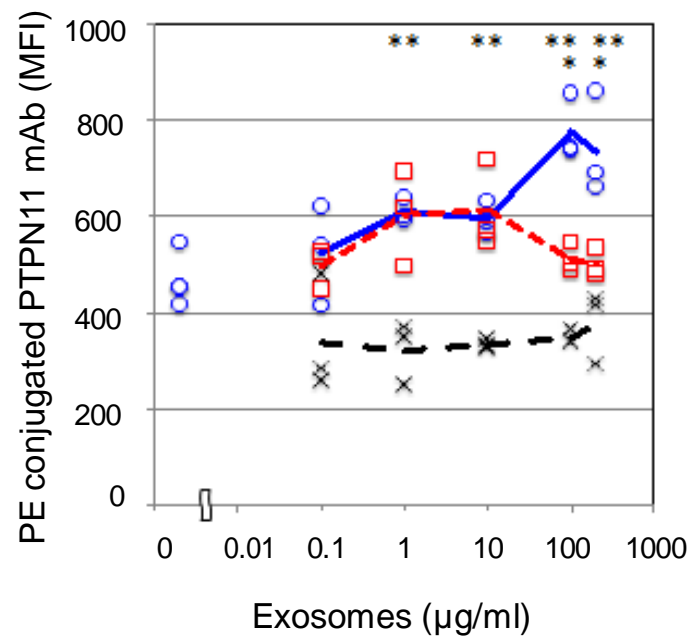

Figure 5. PTPN11 was dose-dependently increased in T lymphocytes when treated with exosomes from B16F0 but not Cloudman S91 or Melan-A cell lines. (a) Representative flow cytometry results for 2D6 T cells stained using a PE-conjugated PTPN11 mAb following incubation with $200 \mu \mathrm{g}$-protein/ml B16F0 exosomes (NanoDrop Assayed) for 30 minutes (black curve). Background level of PTPN11 was assayed in untreated 2D6 cells (red curve). Isotype stained (blue curve) and unstained 2D6 cells (gray shaded) were used as negative controls. (b) The median MFI associated with PTPN11 staining in 2D6 cells following incubation with different sources of exosomes at different concentrations $(0.1,1,10,100$ and $200 \mu \mathrm{g}$-protein/ml denoted on $\mathrm{x}$-axis). The 2D6 cells were incubated with the indicated concentrations of B16F0 exosomes (blue circles), Cloudman 591 exosomes (red squares), and Melan-A exosomes (black crosses). Statistical differences were assessed using Student's t-test, * $\mathrm{P}<0.05$ for B16F0 exosomeincubated cells versus Cloudman S91 exosome-incubated cells, ${ }^{* *} \mathrm{P}<0.01$ for B16F0 exosomeincubated cells versus Melan-A exosome-incubated cells

Given the potential role for PTPN11in negatively regulating these Interferon, IL-2, and $\mathrm{T}$ cell receptor signaling pathways, we focused next on whether exosomes can deliver a biological payload to upregulate PTPN11 in $T$ lymphocytes. To answer this question, we incubated 2D6 $\mathrm{T}$ cells with freshly purified exosomes derived from either B16F0, Cloudman S91, and Melan-A cells and monitored the abundance of PTPN11 in the 2D6 T cells by flow cytometry (Figure 5). Under basal conditions, 2D6 T cells had a median MFI associated 
with PTPN11 staining equal to 450. Exposing 2D6 T cells to $200 \mu \mathrm{g} / \mathrm{ml}$ of B16F0 exosomes doubled the PTPN11 levels in 2D6 T cells. This increase in PTPN11 levels was dose-dependent and unique to the B16F0 exosomes, as shown in Figure 5b. In contrast, PTPN11 levels in 2D6 T cells stimulated with either Cloudman S91 exosomes or Melan-A exosomes were not significantly different for increasing concentrations of exosomes. As these results suggested that exosomes from B16F0 but not Cloudman S91 or Melan-A cells can deliver a biological payload to increase PTPN11, we next tested whether an increase in the corresponding proteins for mRNAs that are highly enriched in B16F0 exosomes can, in isolation, impact $\mathrm{T}$ cell function. In particular, we focused on two proteins, PTPN11 and DNMT3A, that had enriched mRNA in B16F0 exosomes.

\subsubsection{Increased PTPN11 inhibited T cell proliferation in response to IL-2.}

Given the association of local proliferation of $\mathrm{CD} 8+\mathrm{T}$ cell with tumor regression and the role of PTPN11 in negatively regulating both IL-2 and T cell receptor signaling pathways, we hypothesized that an increase in PTPN11 levels could inhibit $\mathrm{T}$ cell proliferation. As a model for CD8+ cytotoxic $\mathrm{T}$ lymphocytes that proliferates in response to IL-2 stimulation, we used the CTLL-2 cell line to test whether $\mathrm{T}$ cell proliferation was inhibited by an increase in PTPN11 in response to gene transfection using two different Ptpnl1 expression plasmids that each encoded a different Ptpnll isoform. The two isoforms differed in that isoform 2 uses an alternative in-frame splice site in the 3' coding region and encodes a slightly shorter protein. As the two expression plasmids containing the 

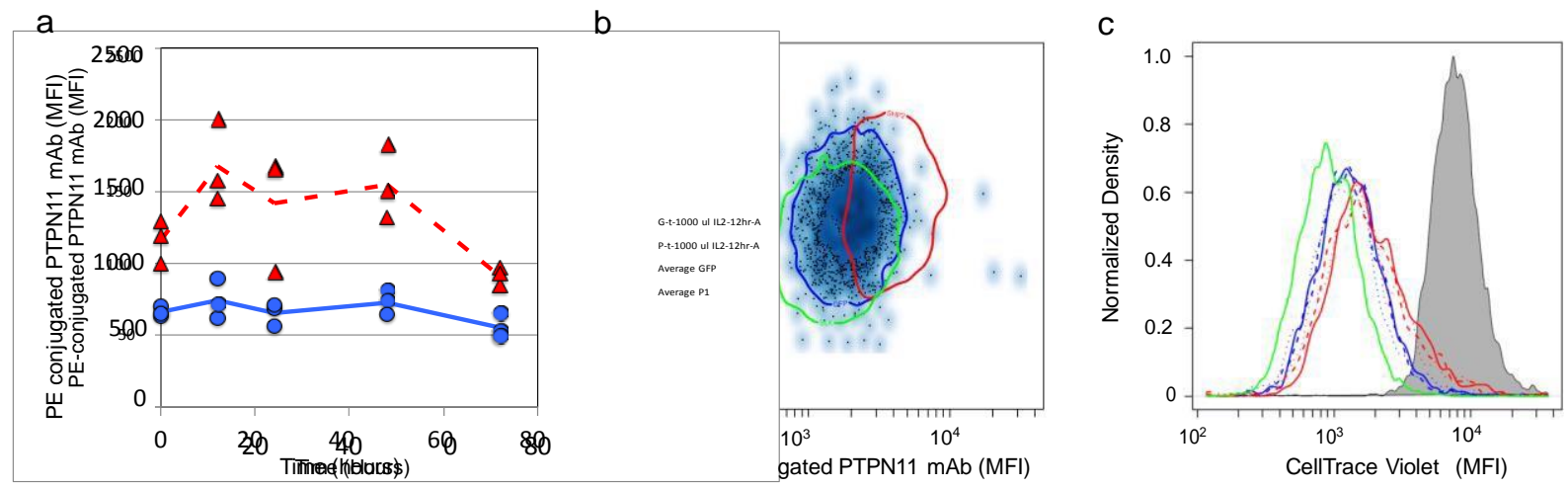

Figure 6. An increase in PTPN11 inhibited the proliferation of CTLL-2 cells in response to IL-2. (a) At the indicated time points, PTPN11 was assayed in CTLL-2 cells following a 40 hour recovery in complete medium after transient transfection with expression plasmids containing either the gene for GFP (blue circles and solid line) or Ptpn11 (red triangles and dotted line). (b, c) CTLL-2 T cells were transfected with Ptpn11 plasmids (red), GFP plasmids (blue), or no plasmid control (green), recovered for 40 hours in complete medium, stained using CellTrace Violet (CTV), and then stimulated with $2000 \mathrm{U} / \mathrm{ml}$ IL-2. Following 48 hours of stimulation with IL-2, the levels of PTPN11 and dilution of CellTrace Violet in live cells were assayed by flow cytometry, where at least 20,000 events were acquired. The results are representative of at least three replicates. (b) Scatter plots summarized the intensity of PTPN11 staining versus CellTrace Violet staining for cells transfected with a GFP plasmid. Similar results for untransfected CTLL-2 cells and cells transfected with a PTPN11 plasmid are shown as a single contour that encloses $95 \%$ of the population (green oval: untransfected CTLL-2 cells, red oval: PTPN11-tranfected CTLL-2 cells). (c) Histograms of CellTrace Violet staining in three biological replicates of untransfected (green curves), GFP-transfected (blue curves), and PTPN11-transfected (red curves) observed after 48 hours were compared to CTLL-2 cells fixed at 0 hours (gray shaded curve).

two different Ptpn11 isoforms behaved similarly in our hands, the results using the plasmid containing Ptpnl1 isoform 1 are shown (Figure 6). Following posttransfection conditioning, PTPN11 transiently increased in CTLL-2 cells transfected with the Ptpn11 plasmid, in comparison with CTLL-2 cells transfected by a plasmid encoding GFP. Based on these results, we used the 48 hour time point to assay PTPN11 levels and differences in cell proliferation. Using CTLL-2 cells transfected with the plasmids encoding either Ptpnl1 or gfp or without a plasmid, we stained the cells using CellTracer Violet (CTV) and stimulated the 
cells with $2000 \mathrm{U} / \mathrm{ml}$ of IL2. After 48 hours, we assayed CTV staining and PTPN11 levels in live CTLL-2 cells associated with the different treatment groups by flow cytometry (Figure $6 \mathrm{~b}$ and c). In looking at the distribution in PTPN11 abundance versus CTV staining, we saw an inverse correlation between an increase in PTPN11 abundance and a decrease in cell proliferation, as measured by an increase in CTV staining (Figure 6b). The decrease in cell proliferation in cells transfected with the plasmid encoding Ptpnl1 was consistently observed across the biological replicates (Figure 6c). These results suggested that, in isolation, an increase in PTPN11 abundance functionally inhibited CTLL-2 proliferation in response to IL-2 stimulation.

\subsubsection{Increased DNMT3A inhibited T cell production of IFN- $\gamma$}

DNA Methyltransferase (DNMT) 3A reportedly represses Th1 gene expression, including IFN- $\gamma$ production, through DNA methylation ${ }^{34,35}$. As we had found that Dnmt3a was highly enriched in B16F0 exosomes relative to the parental cells (Figure 3f), we hypothesized that delivery of Dnmt3a to $\mathrm{T}$ cells could inhibit IFN- $\gamma$ production. To test this, we used 2D6 $\mathrm{T}$ cells as a model system and assayed intracellular accumulation of IFN- $\gamma$ in response to calcium ionophore and TPA stimulation as a functional response. We first transfected 2D6 $\mathrm{T}$ cells with different plasmids encoding one of two DDK-tagged isoforms of $D n m t 3 a$, or gfp. The second isoform of Dnmt3a initiates translation at a downstream in-frame start codon that results in a shorter $\mathrm{N}$-terminus compared to isoform 1. Following transfection, DNMT3A expressed by both isoforms increased 

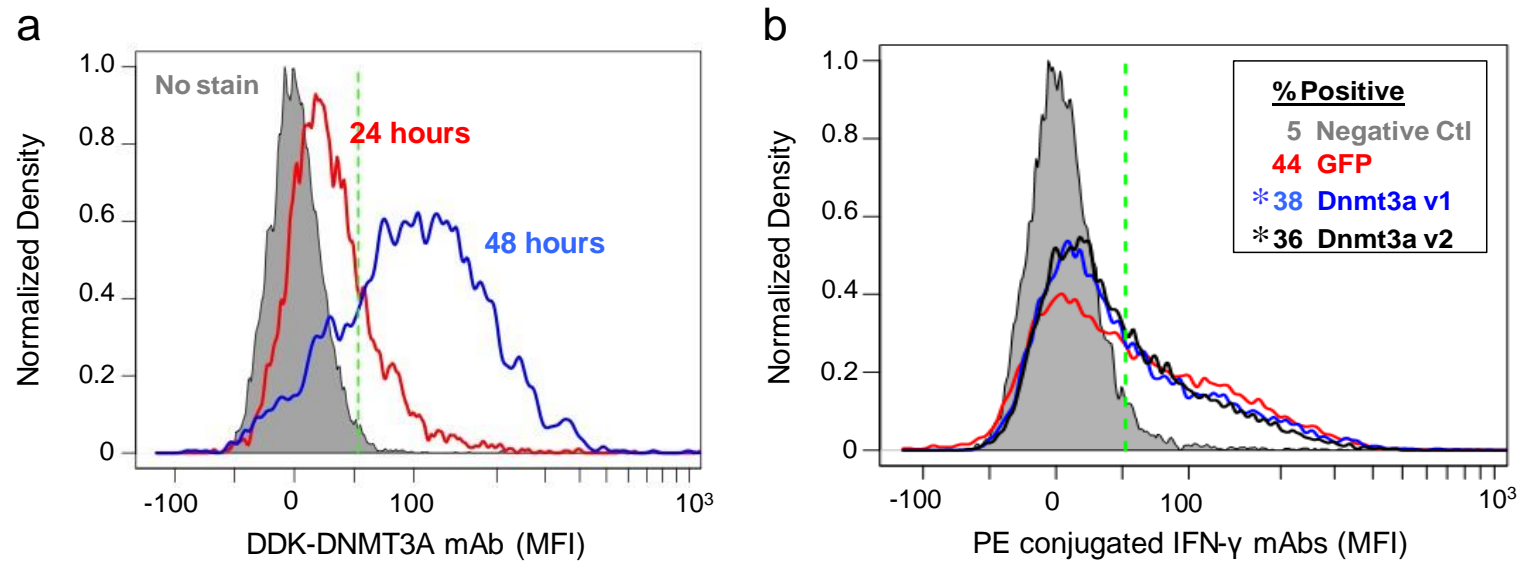

Figure 7. Dnmt3a protein upregulation inhibited IFN- $\gamma$ production. (a) DDK-tagged Dnmt3a expression was assessed by flow cytometry in 2D6 cells at 24 and 48 hours following transfection with Dnmt3a cDNA-containing plasmids. (b) Following treatment with calcium ionophore and TPA in conjunction with GolgiStop, intracellular levels of IFN- $\gamma$ were assayed by flow cytometry in live 2D6 cells transfected using the following cDNA plasmids: Dnmt3a variant 1 (blue), Dnmt3a variant 2 (black), or GFP (red). GFP-transfected 2D6 cells were used as a positive control. The negative control was 2D6 cells treated with GolgiStop but not calcium ionophore or TPA (gray shaded). Green dotted vertical line indicates a data-driven threshold for positive IFN- $\gamma$ expression, where $95 \%$ of the negative control cells have lower IFN- $\gamma$ MFIs. The results are representative of at least two independent experiments. Using at least 6,000 live cell events, statistical significance of the distributions in PE MFI (IFN- $\gamma$ ) was assessed with a probability binning approach whereby the univariate distribution was discretized into 100 bins and the number of events in the positive control and sample bins were compared with a Pearson's $\chi^{2}$ test $(*$ P-value $<1 \mathrm{e}-10)$.

in cellular abundance over time such that most cells were positive by 48 hours (Figure 7a). Using 48 hours as a pre-conditioning period following transfection, we then stimulated 2D6 cells from the different experimental groups for IFN- $\gamma$ production and analyzed intracellular IFN- $\gamma$ expressions by flow cytometry (Figure 7b). Unstimulated 2D6 cells were used as a negative control. While the differences between groups were subtle, fewer 2D6 cells transfected with expression plasmids for either isoform of Dnmt3a were positive for intracellular IFN- $\gamma$ staining (36$38 \%$ ) compared with GFP-expressing $2 \mathrm{D} 6$ cells (44\%) and the distributions were 
significantly different (Pearson's $\chi^{2}$ test, $\left.\mathrm{p}<1 \mathrm{e}-10\right)$. In summary, an increase in DNMT3A, in isolation, inhibited IFN- $\gamma$ production in 2D6 T cells.

\subsubsection{B16F0 exosomes inhibited multiple aspects of an antigenic response in primary CD8+ T cells.}

Collectively, the transfection studies suggest that Ptpn11 and Dnmt3a, two genes that had mRNA enriched in $\mathrm{B} 16 \mathrm{~F} 0$ exosomes relative to parental cells, can individually inhibit aspects of $\mathrm{T}$ cell function. Yet, other aspects of this study suggest that exosomes contain a more complicated composition of mRNAs (see Figures 3 and 4) and that this composition may vary between cell lines (see Figure 5). To directly assess whether exosomes influence $\mathrm{T}$ cell function, we characterized the impact of B16F0, Cloudman S91, and Melan-A exosomes on primary CD8+ $\mathrm{T}$ cells. First, we isolated transgenic CD8+ $\mathrm{T}$ cells from mouse splenocytes, of which $94.6 \%$ were positive for CD3+ CD8+ and $71.8 \%$ were considered to be naïve CD8+ $\mathrm{T}$ cells (CD3+ CD8+ CD62L+ CD44-). After isolation, the primary CD8+ T cells were all stained by CellTrace Violet, cultured in media containing IL-12 and anti-IL-4 mAb to promote a Tc1 phenotype, and activated with anti-CD3/CD28 beads, where blank beads where used as a negative control. In addition, CD8+ $\mathrm{T}$ cells activated with anti-CD3/CD28 beads were also stimulated with different concentrations of exosomes freshly isolated from B16F0, Cloudman S91, and Melan-A cells. After 24 hours, cell viability, cell proliferation, and IL12RB2 expression were assayed under the different experimental conditions 

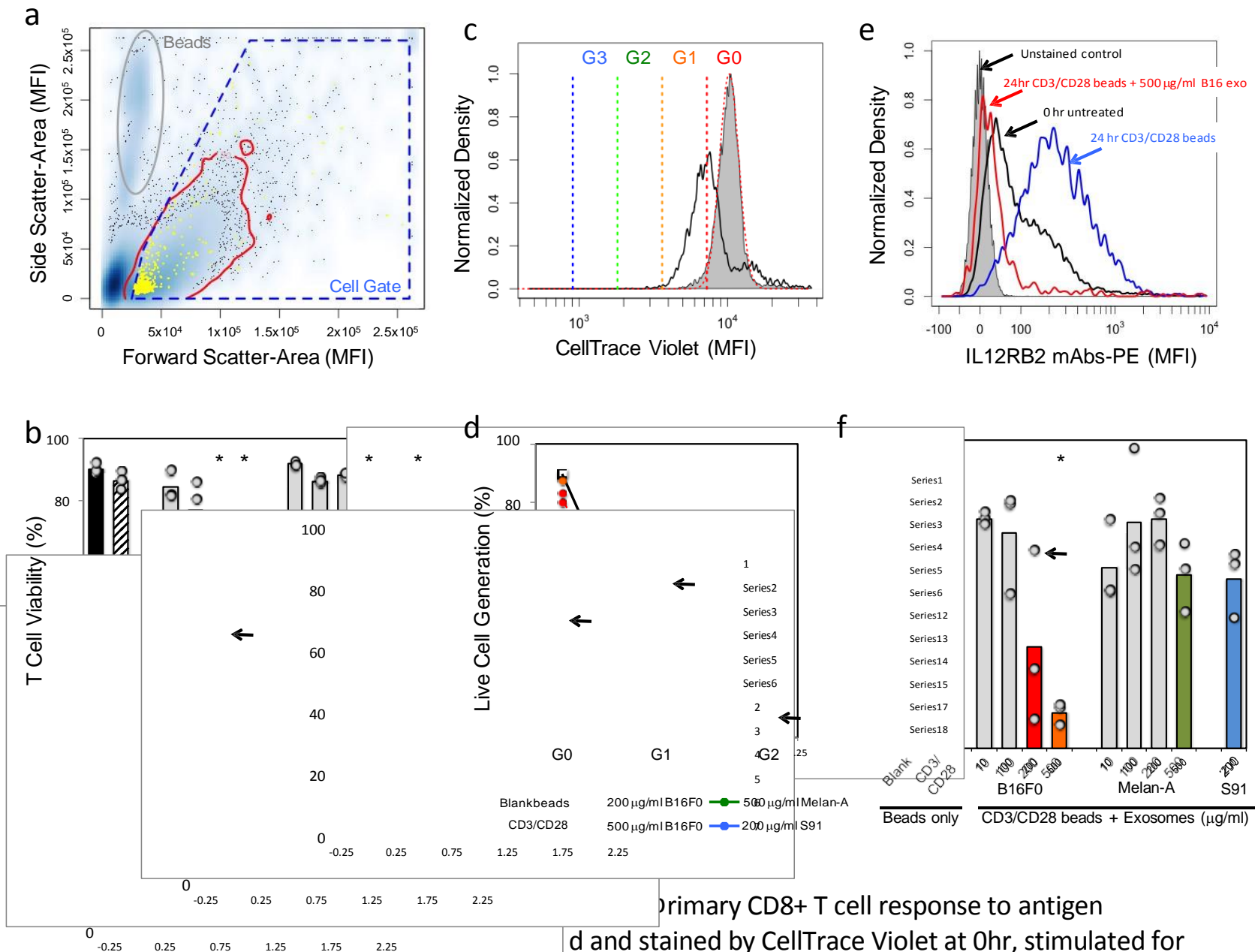

$24 \mathrm{hrs}$ with anti-CD3/CD28 beads and exosomes derived from B16F0, Cloudman S91, and Melan-A cells. (a) Flow cytometric events were gated into cells (blue polygon) and dead/dying cells were excluded based on Live/Dead staining (yellow). (b) The percentage of viable cell events were compared between CD8+ T cells stimulated for 24 hrs with anti-CD3/CD28- conjugated beads (CD3/CD28 beads) and different concentrations of exosomes derived from B16F0, Cloudman S91, and Melan-A cells. (c) Cell proliferation was assessed using a shift in CellTracer Violet, as assayed by flow cytometry. Cells at 0 hours were used as a reference condition (gray shaded) and cells stimulated for 24 hours with CD3/CD28 beads were a positive control (black curve). Colored lines indicate intensity thresholds associated with progressive cell proliferation. (d) The relative T cell proliferation for the indicated experimental conditions are summarized, where individual data points are shown and lines indicate the average response. (e) IL12RB2 was assayed in CD8+ T cells by flow cytometry, where representative histograms for the indicated experimental conditions are shown. ( $f$ ) The median IL12RB2 staining results were compared between CD8+ T cells stimulated with CD3/CD28 beads and different concentrations of exosomes derived from B16F0, Cloudman S91, and Melan-A cells. Results were obtained in biological triplicate. A significant difference between exosome-treated and the positive control was assessed using a two-sided Student's t-test assuming unequal variance $(* \mathrm{P}<0.01)$. One replicate at the $200 \mathrm{\mu} \mathrm{g} / \mathrm{ml} \mathrm{B16F0}$ exosome condition was considered an outlier, as indicated by the arrow in panels $b, d$, and $f$. 
by flow cytometry (Figure 8 ). Viability was $>85 \%$ in $\mathrm{T}$ cells activated with either blank or anti-CD3/CD28 beads (Figure 8b). In contrast, B16F0 exosomes dosedependently decreased cell viability with an EC50 equal to $136 \mu \mathrm{g} / \mathrm{ml}$ while the Cloudman S91 exosomes had an EC50 equal to $200 \mu \mathrm{g} / \mathrm{ml}$. Melan-A exosomes had a minimal effect on cell viability, where viability was decreased to $65 \%$ only at the highest concentration $(500 \mu \mathrm{g} / \mathrm{ml})$. In live CD8+ T cells, CellTrace Violet was used to quantify the extent of $\mathrm{T}$ cell proliferation under the different experimental conditions (Figure 8c). In primary CD8+ T cells activated with blank beads, $90 \%$ of the population was comprised of generation 0 (G0) cells after 24 hours (Figure 8d). Activation using anti-CD3/CD28 beads promoted cell proliferation, where $67 \%$ of the population was comprised of G0 cells and $32 \%$ of the population had proliferated once (G1). Interestingly, the exosomes had different effects on these primary CD8+ T cells, where B16F0 exosomes inhibited cell proliferation $(81.2 \% \mathrm{G} 0 / 16.4 \% \mathrm{G} 1$ for $200 \mu \mathrm{g} / \mathrm{ml})$ and Cloudman $\mathrm{S} 91$ promoted cell proliferation (46.5\% G0/48.7\% G1/4.4\% G2). Again, the Melan-A exosomes seemed to have minimal effect with a subtle promotion of cell proliferation seen at the $500 \mu \mathrm{g} / \mathrm{ml}$ dose $(58.2 \%$ G0/ $35.1 \%$ G1/3.3\% G2). The addition of IL-12 and anti-IL-4 mAb promoted the upregulation of IL12RB2 over the 24 hour culture conditions (Figure 8e). This increase in IL12RB2 receptor expression was dose-dependently inhibited by B16F0 exosomes with an EC50 equal to $171 \mu \mathrm{g} / \mathrm{ml}$, while the Cloudman S91 and Melan-A exosomes had no effect on IL12RB2 expression (Figure 8f). Overall, the primary CD8+ T cell studies suggest that $\mathrm{B} 16 \mathrm{~F} 0$ exosomes impact $\mathrm{T}$ cell function by inhibiting cell viability, 
decreasing cell proliferation, and by inhibiting the polarization of CD8+ $\mathrm{T}$ cells towards a type 1 phenotype. In contrast, exosomes derived from the other two melanocyte cell lines have very different effects. Cloudman S91 exosomes inhibit cell viability but promote cell proliferation and have no effect on Tc1 polarization, while exosomes from Melan-A cells seem to have little functional impact on primary CD8+ $\mathrm{T}$ cells. 


\subsection{Discussion}

Supported by the emerging clinical data using immunotherapies for cancer, identifying local mechanisms of immunosuppression within the tumor microenvironment is a key barrier for broadening the clinical benefit of immunotherapies for cancer ${ }^{36}$. As exosomes represent an emerging mode of cellto-cell communication through the delivery of proteins and coding and non-coding RNAs, the objective of this study was to characterize the impact of exosomes derived from three melanocyte cell lines on $\mathrm{T}$ cell function, with an emphasis on exosomal mRNA. The three melanocyte cell lines include the B16F0, a nonimmunogenic transplantable model for malignant melanoma; the Cloudman S91, an immunogenic transplantable model for malignant melanoma; and Melan-A, a model of normal melanocytes ${ }^{37,38}$. In short, we found that all three cell lines secrete exosomes of a similar size and morphology but exosomes derived from each cell line elicit a different response in T cells. Exosomes derived from B16F0 cells contain proteins present in the parental cell and intact mRNAs that are differentially packaged into exosomes. Exosomal mRNAs that are enriched in B16F0 exosomes target a number of pathways that are important for anti-tumor immunity, including $\mathrm{T}$ cell proliferation ${ }^{6}$, IFN $-\gamma$ production $^{39}$, and responsiveness to IL12 $2^{40,41}$. In contrast, exosomes derived from Cloudman S91 increased T cell proliferation over anti-CD3/CD28 antigen presentation beads alone while Melan-A exosomes seemed to have little effect on primary CD8+ T cells. 
Therapeutic modulation of immune checkpoints is one of the most recent clinical advances in the treatment of melanoma ${ }^{4,5,42}$. Conceptually, immune checkpoints limit the clonal expansion and effector activity of $\mathrm{T}$ cells by engaging signaling proteins that inhibit $\mathrm{T}$ cell signal transduction. Antibodies against these immune checkpoints, such as anti-CTLA4 mAbs, enable increased clonal expansion and enhanced immune cell infiltration into and proliferation within the tumor microenvironment ${ }^{6}$. Pre-clinical studies using the B16 model indicate that the efficacy of immune checkpoint modulation depends inversely on tumor load ${ }^{11}$. In comparing exosomes from these three melanoma models, we found that only B16F0 exosomes were able to increase PTPN11 dose-dependently, which suppressed $\mathrm{T}$ cell proliferation. While the exact role that PTPN11 plays in signal transduction remains controversial, reviewed $\mathrm{in}^{43,44}$, PTPN11 is a phosphatase that can be engaged by both the PD-1/PD-L1 and CTLA-4 signaling pathways to inhibit $\mathrm{T}$ cell signaling ${ }^{45-47}$. We also observed that fresh exosomes derived from all three cell lines were uniformly distributed in size with average diameters between 160 and $166 \mathrm{~nm}$. This is important as the size of exosomes can establish concentration gradients within tissues, where the local concentration is increased by the rate of cellular production within a tissue and decreased by convective and diffusive transport mechanisms. While exosomes are released by essentially all cells, malignant cells derived from melanoma release exosomes at a greater rate compared to normal controls ${ }^{48}$, which may be attributed to a p53-mediated stress response $^{17}$. The convective and diffusive transport mechanisms depend on molecular size, such that macromolecules (3-5 $\mathrm{nm}$ in diameter) and nanoparticles 
that are less than $50 \mathrm{~nm}$ are easily transported to the draining lymphatics from the interstitial tissue by convective flow while the extracellular matrix sterically hinders the movement of larger particles ${ }^{49,50}$. Specifically, nanoparticles with a diameter of $200 \mathrm{~nm}$ have 10-20 times worse tissue penetration than nanoparticles of $50 \mathrm{~nm}$ in $\operatorname{size}^{51}$. While our observed exosome sizes may seem at odds with the conventional wisdom that exosomes are $30-100 \mathrm{~nm}$ in diameters ${ }^{52,53}$, prior measurements of exosome sizes may be biased by storage conditions prior to imaging that result in exosome shrinkage and fragmentation ${ }^{25,54}$. Collectively, the results suggest that tumor-derived exosomes can locally accumulate with time within the tumor microenvironment to deliver a complex payload that dosedependently suppresses immune cell function. As observed previously in the B16 model $^{11}$, the time dependence of this immunosuppressive effect can explain a common criticism of pre-clinical mouse models where immunotherapies are tested before the local immunosuppressive network has established ${ }^{55}$.

Organizing an effective anti-tumor immune response among a variety of cell types involves a complicated network of intercellular communication. An emerging idea that follows from thinking of cancer as an evolutionary process is that malignant cells develop mechanisms to alter this local intercellular network of communication $^{56}$. Given the importance of Interleukin-12 in locally promoting antitumor immunity, exosomes derived from B16F0 suppress cell response to IL12 in two ways. The first is an indirect mechanism where B16F0 cells create a cytokine sink for Interleukin-12 by over-expressing one component of the IL-12 receptor, IL12RB2 $2^{29}$. Here, we find that exosomes secreted by B16F0 cells also 
contain IL12RB2, which can enhance the cytokine sink effect. The second is a direct mechanism where the delivery of B16F0 exosomes to primary CD8+ $\mathrm{T}$ cells dose-dependently inhibited IL12RB2 expression. These mechanisms for inhibiting immune cell response to IL12 complement previous observations that tumorderived Wnt-inducible signaling protein 1 (WISP1) suppresses immune cell response to IL12 $2^{29,57}$. In contrast to secreted proteins that have a defined biological function, we also observed that all of the cell lines secreted exosomes with a similar morphology but elicited different biological effects through delivery of unique biological payloads. Supported by the non-random loading of intact open reading frames into $\mathrm{B} 16 \mathrm{~F} 0$ exosomes that targeted a number of immune-related pathways, the exosomal payload appears to be a remnant of selective pressure associated with somatic evolution. We note that the mouse species from which these cell lines were derived have different propensities for oncogenesis. Specifically, DBA/2 mice are sensitive and C57B1/6 mice are resistant to skin oncogenesis using carcinogens (DMBA plus TPA) ${ }^{58}$, which were used to isolate the B16 and Cloudman S91 cell lines from spontaneous tumors, respectively ${ }^{59,60}$. It follows then that inbred mouse strains that are resistant to oncogenesis have strong selective pressure to maintain normal tissue homeostasis. Collectively, malignant cells that arise in resistant mouse strains, as exemplified by the B16 model, must develop multiple mechanisms to escape from this selective pressure. Secretion of WISP1, creation of a cytokine sink for IL12, and exosomal delivery of a complex biological payload to suppress $\mathrm{T}$ cell proliferation, viability, and IL12RB2 expression are some of the additional mechanisms that we have 
identified in the B16 model. While in vivo studies will be necessary to establish the sensitivity of these mechanisms to therapeutic modulation, identifying how the local networks for intercellular communication are changed during oncogenesis is the first step in developing therapeutic strategies to restore the intercellular signaling networks associated with normal tissue homeostasis and to enhance the response rate for existing cancer immunotherapy, such as immune checkpoint modulators. 


\section{References for Chapter 3}

1. Mellman, I., Coukos, G. \& Dranoff, G. Cancer immunotherapy comes of age. Nature 480, 480-489 (2011).

2. Chen, D. S. \& Mellman, I. Oncology meets immunology: the cancer-immunity cycle. Immunity 39, 1-10 (2013).

3. Restifo, N. P., Dudley, M. E. \& Rosenberg, S. A. Adoptive immunotherapy for cancer: harnessing the T cell response. Nat. Rev. Immunol. 12, 269-281 (2012).

4. Hodi, F. S. et al. Improved Survival with Ipilimumab in Patients with Metastatic Melanoma. N. Engl. J. Med. 363, 711-723 (2010).

5. Robert, C. et al. Pembrolizumab versus Ipilimumab in Advanced Melanoma. $N$. Engl. J. Med. 372, 2521-2532 (2015).

6. Tumeh, P. C. et al. PD-1 blockade induces responses by inhibiting adaptive immune resistance. Nature 515, 568-571 (2014).

7. Herbst, R. S. et al. Predictive correlates of response to the anti-PD-L1 antibody MPDL3280A in cancer patients. Nature 515, 563-567 (2014).

8. Gabrilovich, D. I. \& Hurwitz, A. A. Tumor-induced immune suppression Mechanisms and Therapeutic Reversal. New York, New York, USA: Springer-Verlag, (2008).

9. Psaila, B. \& Lyden, D. The metastatic niche: adapting the foreign soil. Nat. Rev. Cancer 9, 285-293 (2009).

10. Nguyen, D. X., Bos, P. D. \& Massagué, J. Metastasis: from dissemination to organspecific colonization. Nat. Rev. Cancer 9, 274-284 (2009).

11. Van Elsas, a, Hurwitz, a a \& Allison, J. P. Combination immunotherapy of B16 melanoma using anti-cytotoxic T lymphocyte-associated antigen 4 (CTLA-4) and granulocyte/macrophage colony-stimulating factor (GM-CSF)-producing vaccines induces rejection of subcutaneous and metastatic tumors accompanied . J. Exp. Med. 190, 355-366 (1999).

12. Matsushita, H. et al. Cancer exome analysis reveals a T-cell-dependent mechanism of cancer immunoediting. Nature 482, 400-404 (2012).

13. Klinke, D. J. et al. Inferring alterations in cell-to-cell communication in HER2+ breast cancer using secretome profiling of three cell models. Biotechnol. Bioeng. 111, 1853-1863 (2014).

14. Théry, C., Ostrowski, M. \& Segura, E. Membrane vesicles as conveyors of immune responses. Nat. Rev. Immunol. 9, 581-593 (2009).

15. Peinado, H. et al. Melanoma exosomes educate bone marrow progenitor cells toward a pro-metastatic phenotype through MET. Nat. Med. 18, 883-891 (2012).

16. Somasundaram, R. \& Herlyn, M. Melanoma exosomes: messengers of metastasis. Nat. Med. 18, 853-854 (2012).

17. Yu, X., Harris, S. L. \& Levine, A. J. The regulation of exosome secretion: A novel function of the p53 protein. Cancer Res. 66, 4795-4801 (2006).

18. Bobrie, A. \& Théry, C. Unraveling the physiological functions of exosome secretion by tumors. Oncoimmunology 2, e22565 (2013). 
19. Valadi, H. et al. Exosome-mediated transfer of mRNAs and microRNAs is a novel mechanism of genetic exchange between cells. Nat. Cell Biol. 9, 654-659 (2007).

20. Taylor, D. D. \& Gercel-Taylor, C. MicroRNA signatures of tumor-derived exosomes as diagnostic biomarkers of ovarian cancer. Gynecol. Oncol. 110, 13-21 (2008).

21. Ratajczak, J. et al. Embryonic stem cell-derived microvesicles reprogram hematopoietic progenitors: evidence for horizontal transfer of mRNA and protein delivery. Leukemia 20, 847-856 (2006).

22. Skog, J. et al. Glioblastoma microvesicles transport RNA and proteins that promote tumour growth and provide diagnostic biomarkers. Nat. Cell Biol. 10, 1470-1476 (2008).

23. Ekström, K. et al. Characterization of mRNA and microRNA in human mast cellderived exosomes and their transfer to other mast cells and blood CD34 progenitor cells. J. Extracell. Vesicles 1, 1-12 (2012).

24. Batagov, A. O. \& Kurochkin, I. V. Exosomes secreted by human cells transport largely mRNA fragments that are enriched in the 3'-untranslated regions. Biol. Direct 8, 12 (2013).

25. Wu, Y., Deng, W. \& Klinke II, D. J. Exosomes: improved methods to characterize their morphology, RNA content, and surface protein biomarkers. Analyst 140, 66316642 (2015).

26. Finley, S. D. et al. Inferring relevant control mechanisms for interleukin-12 signaling in naïve CD4+ T cells. Immunol. Cell Biol. 89, 100-110 (2011).

27. Le Pape, E., Wakamatsu, K., Ito, S., Wolber, R. \& Hearing, V. J. Regulation of eumelanin/pheomelanin synthesis and visible pigmentation in melanocytes by ligands of the melanocortin 1 receptor. Pigment Cell Melanoma Res. 21, 477-486 (2008).

28. Klinke II, D. J. et al. Quantifying crosstalk among interferon-gamma, interleukin-12, and tumor necrosis factor signaling pathways within a TH1 cell model. Sci Signal 5, ra32-ra32 (2012).

29. Kulkarni, Y. M. et al. A quantitative systems approach to identify paracrine mechanisms that locally suppress immune response to Interleukin-12 in the B16 melanoma model. Integr. Biol. 4, 925-936 (2012).

30. Kulkarni, Y. M. \& Klinke II, D. J. Protein-based identification of quantitative trait loci associated with malignant transformation in two HER2+ cellular models of breast cancer. Proteome Sci. 10, 11 (2012).

31. Klinke II, D. J. \& Brundage, K. M. Scalable analysis of flow cytometry data using R/Bioconductor. Cytometry. A 75, 699-706 (2009).

32. Al-Nedawi, K. et al. Intercellular transfer of the oncogenic receptor EGFRvIII by microvesicles derived from tumour cells. Nat. Cell Biol. 10, 619-624 (2008).

33. Chen, E. Y. et al. Enrichr: interactive and collaborative HTML5 gene list enrichment analysis tool. BMC Bioinformatics 14, 128 (2013).

34. $\mathrm{Yu}, \mathrm{Q}$. et al. DNA methyltransferase 3a limits the expression of interleukin-13 in T helper 2 cells and allergic airway inflammation. Proc. Natl. Acad. Sci. 109, 541-546 (2012). 
35. Pham, D. et al. Opposing roles of STAT4 and Dnmt3a in Th1 gene regulation. $J$. Immunol. 191, 902-911 (2013).

36. Ascierto, P. A. et al. The additional facet of immunoscore: immunoprofiling as a possible predictive tool for cancer treatment. J. Transl. Med. 11, 54 (2013).

37. Overwijk, W. W. \& Restifo, N. P. B16 as a mouse model for human melanoma. Curr. Protoc. Immunol. Chapter 20, Unit 20.1 (2001).

38. Peter, I., Mezzacasa, A., LeDonne, P., Dummer, R. \& Hemmi, S. Comparative analysis of immunocritical melanoma markers in the mouse melanoma cell lines B16, K1735 and S91-M3. Melanoma Res. 11, 21-30 (2001).

39. Kaplan, D. H. et al. Demonstration of an interferon gamma-dependent tumor surveillance system in immunocompetent mice. Proc. Natl. Acad. Sci. U. S. A. 95, 7556-7561 (1998).

40. Airoldi, I. et al. Lack of Il12rb2 signaling predisposes to spontaneous autoimmunity and malignancy. Blood 106, 3846-3853 (2005).

41. Billerbeck, E. et al. Insufficient IL-12 signaling favors differentiation of human CD4+ and CD8+ T cells into GATA-3(+) and GATA-3(+) T-bet(+) subsets in humanized mice. Immunology 143, 202-218 (2014).

42. Robert, C. et al. Ipilimumab plus dacarbazine for previously untreated metastatic melanoma. N. Engl. J. Med. 364, 2517-2526 (2011).

43. Lorenz, U. SHP-1 and SHP-2 in T cells: Two phosphatases functioning at many levels. Immunol. Rev. 228, 342-359 (2009).

44. Li, S., Hsu, D. D., Wang, H. \& Feng, G.-S. Dual faces of SH2-containing proteintyrosine phosphatase Shp2/PTPN11 in tumorigenesis. Front. Med. 6, 275-279 (2012).

45. Li, J. et al. PD-1/SHP-2 Inhibits Tc1/Th1 Phenotypic Responses and the Activation of T Cells in the Tumor Microenvironment. Cancer Res. 75, 508-518 (2014).

46. Chemnitz, J. M., Parry, R. V, Nichols, K. E., June, C. H. \& Riley, J. L. SHP-1 and SHP-2 associate with immunoreceptor tyrosine-based switch motif of programmed death 1 upon primary human $\mathrm{T}$ cell stimulation, but only receptor ligation prevents $\mathrm{T}$ cell activation. J. Immunol. 173, 945-954 (2004).

47. Schneider, H. \& Rudd, C. E. Tyrosine phosphatase SHP-2 binding to CTLA-4: absence of direct YVKM/YFIP motif recognition. Biochem. Biophys. Res. Commun. 269, 279-283 (2000).

48. Logozzi, M. et al. High levels of exosomes expressing CD63 and caveolin-1 in plasma of melanoma patients. PLoS One 4, e5219 (2009).

49. Fleming, A. B. \& Saltzman, W. M. Simultaneous delivery of an active protein and neutralizing antibody: Creation of separated regions of biological activity. $J$. Control. Release 70, 29-36 (2001).

50. Irvine, D. J., Swartz, M. A. \& Szeto, G. L. Engineering synthetic vaccines using cues from natural immunity. Nat. Mater. 12, 978-990 (2013).

51. Tang, L., Fan, T. M., Borst, L. B. \& Cheng, J. Synthesis and biological response of size-specific, monodisperse drug-silica nanoconjugates. ACS Nano 6, 3954-3966 (2012).

52. Simons, M. \& Raposo, G. Exosomes - vesicular carriers for intercellular communication. Curr. Opin. Cell Biol. 21, 575-581 (2009). 
53. Taylor, D. D. \& Gercel-Taylor, C. Exosomes/microvesicles: mediators of cancerassociated immunosuppressive microenvironments. Semin. Immunopathol. 33, 1-14 (2011).

54. Sokolova, V. et al. Characterisation of exosomes derived from human cells by nanoparticle tracking analysis and scanning electron microscopy. Colloids Surf. B. Biointerfaces 87, 146-150 (2011).

55. Wen, F. T., Thisted, R. a., Rowley, D. a. \& Schreiber, H. A systematic analysis of experimental immunotherapies on tumors differing in size and duration of growth. Oncoimmunology 1, 172-178 (2012).

56. Klinke II, D. J. Eavesdropping on altered cell-to-cell signaling in cancer by secretome profiling. Mol. Cell. Oncol. (in press) (2015).

57. Klinke, D. J. Induction of Wnt-Inducible Signaling Protein-1 Correlates with Invasive Breast Cancer Oncogenesis and Reduced Type 1 Cell-Mediated Cytotoxic Immunity: A Retrospective Study. PLoS Comput. Biol. 10, e1003409 (2014).

58. Angel, J. M., Caballero, M. \& DiGiovanni, J. Identification of novel genetic loci contributing to 12-O-tetradecanoylphorbol-13-acetate skin tumor promotion susceptibility in DBA/2 and C57BL/6 mice. Cancer Res. 63, 2747-2751 (2003).

59. Filder, I. J. Selection of successive tumour lines for metastasis. Nat. New Biol. 242, 148-149 (1973).

60. Cloudman, A. M. The effect of an extra-chromo-somal influence upon transplanted spontaneous tumors in mice. Science 93, 380-381 (1941). 


\section{CHAPTER 4: PATH FORWARD}

As advances in cancer immunotherapy tries to improve patients' survival, understanding how exosomes influence intercellular communication has piqued a great amount of research interests. In this dissertation, our work suggests that cancer exosomes have the potential to suppress anti-tumor immunity in multiple ways. In particular, we identified multiple functional molecules including RNAs and transmembrane receptor components are enriched on melanoma exosomes. These functional molecules correspond to distinct mechanisms of regulating cellular signal transduction and modulate cytokine activity. Our findings provide insight into the potential of cancer exosomes in repressing immunity, which highlights the need for further investigation into the intersection of exosome biology and cancer immunology. Motivated by our present work, future directions may focus on the following three topics. First, overexpression of IL12RB2 within the melanoma microenvironment may be shaped by cross-talk between inflammatory IL12 and/or immunosuppressive IL35 signaling. Therefore, identifying how IL12RB2 overexpression influences these signaling pathways is an interesting topic that will improve our understanding of the role of melanoma exosomes in cancer immunotherapy. Since exosomes contain a complex mixture of mRNA and miRNAs, the second topic involves identifying the collective effect of those coding and non-coding RNAs on gene expression of a recipient cell. This may shed light on potential mechanisms to block tumor immunosuppression mediated by exosomes. In our study, the upregulation of PTPN11 or DNMT3A in 
$\mathrm{T}$ cells inhibit their functions. The third topic is to investigate whether the inhibitors of the PTPN11 or DNMT3A proteins, such as cryptotanshinone ${ }^{1}$ (inhibiting PTPN11), and decitabine ${ }^{2}$ (inhibiting DNMT), have adjuvant effects that can stabilize the anti-tumor effects of lymphocytes in vivo, in a purpose of extending the durable immune response for cancer treatment. Such studies may identify novel medicines for cancer immunotherapy and increase overall survival. In the following paragraphs, we will discuss these future research topics in more detail.

The first future research direction is to investigate the impact of IL12RB2 overexpression within the melanoma microenvironment. IL12RB2 is binding and signaling component of the receptors for two cytokines: IL12 and IL35, both belonging to IL12 family. Yet, those two cytokines act in opposing ways for regulating the host immunity. IL12 is proinflammatory in that it boosts the natural killer cells and cytotoxic T lymphocyte (CTL) activity, causes polarization of T helper cells towards Th1 phenotype $\mathrm{e}^{3,4}$. By contrast, IL-35 is produced by Treg and is suppressive, in that IL35 functions in repressing the proliferation of conventional $\mathrm{T}$ cells, stimulating conversion of naive $\mathrm{T}$ cells into Treg cell population that can produce IL35 and expand such immunosuppression ${ }^{5-8}$. The IL12 cytokine family includes IL12, IL35, IL23 and IL27. Chain sharing of cytokines as well as among the receptors is a unique feature of the IL12 family ${ }^{9,10}$. Pertaining to IL12RB2, a functional IL12 receptor is a transmembrane protein comprised by heterodimer IL12RB1IL12RB2 $2^{11-13}$, whereas IL35 has been found being capable of binding and signaling through either heterodimer IL12RB2-gp130, or homodimers IL12RB2-IL12RB2 and gp130-gp1309,10,14,15. For IL12 binding and signaling, IL12RB2 predominates this 
processes over IL12RB1 because previous study has revealed that the IL12RB2-deficient mice are defective in IL12-mediated signaling despite the presence of high affinity IL12 binding sites on IL12RB $1^{16}$. Such critical role of IL12RB2 to IL12 might extend to IL35 binding and signaling, due to the ubiquitous expression of gp130 17 . In the previous chapters, our discussion about the IL12RB2 expression on melanoma exosomes focuses on IL12 signaling, due to the prominent populations of therapeutically-induced Th1 cells in cancer immunotherapy, for instance, "preparative lymphodepletion" is currently recommended and widely performed for temporary ablation of autologous lymphocytes (including Treg that produces IL35) in patients for a purpose of improving the efficacy of adoptive cell transfer that follows. For future investigation, it is interesting to interrogate whether and how the two cytokines, IL12 and IL35, compete for IL12RB2, as well as how their distinct functional profiles interact, in the context of immune cells and also in the cancer cells, i.e. melanoma cells. It is worth to identify the expression of gp130 and IL12RB1 on those B16F0 exosomes, also, to investigate the potential dimeric structures of those receptor components of IL12RB2, IL12RB1 and gp130. Moreover, the binding of cytokines IL12, IL35, and the fate of such cytokine bond with the extracellular vesicles, are fundamental inquiries that will improve our understanding of the roles that cancer exosomes play. For instance, will cancer exosomes bind cytokines and forward them to modulate either immune or cancer cells? Will such exosome-mediated cytokine binding/delivery take part in the tumor growth and metastasis? Does "cytokine sink" of IL12 exist at the tumor microenvironment due to the overexpression of receptor components on melanoma exosomes? Those are all interesting directions. 
Other than IL12RB functions, the interaction of those coding and non-coding RNAs enclosed in melanoma exosomes is an interesting research topic that may shed light on developing counteracting strategies to deactivate the gene regulations and tumor resistance mediated by cancer exosomes. Exosomes contain miRNAs and mRNAs, however, the roles of mRNAs from those extracellular vesicles are much less reported in comparison with the miRNAs, partly due to some previous arguments have thought only miRNAs and degraded mRNAs in small pieces can be contained by exosomes. In this work, we demonstrate the intactness of mRNAs from exosomes. We also investigate the functions of those mRNAs being delivered by cancer exosomes and the inhibitory effect of Ptpn11 and Dnmt3a genes influencing Th1 immune response. Recent studies have suggested that the cellular internalization of exosomes can actively occur in recipient cells via several engulf pathways, i.e. endocytosis ${ }^{18}$ and phagocytosis ${ }^{19}$. This inspires our belief that the melanoma exosomes and the coding and non-coding esRNAs are potentially able to be uptaken by multiple types of cells present at the tumor sites, either cancer cells in heterogeneity, therapeutically-induced effector $\mathrm{T}$ cells or other immune cells surrounding a tumor. Obviously, the mechanisms of how exosomal mRNA and miRNA affect in recipient cells are distinct, in that the mRNA induces expression whereas miRNA function through inhibiting gene transcription and/or expression. Therefore, the interactions of those coding and non-coding RNAs are one direction need to be studied and this may provide new perspectives to the current immunosuppressive mechanisms that facilitate tumor resistance. To achieve those goals, computing and modeling methods are useful tools in terms of exploring the network constructed by multiple active elements in those coding and noncoding RNAs. Experimental methods are also required especially to confirm results out of 
calculations. This study will provide a system perspective to the roles of cancer exosomes conveying multiplex functional RNAs that are capable of shaping a complicated, and potentially reactive microenvironment at the tumor site. Particularly relevant to our study in this work, the PTPN11 and DNMT3A signaling in T cells are two pathways worth to be studied in terms of understanding the dynamics of their upregulations, confirming their prominent effects, potentially conjugating complex, and trying to explore counteracting strategies that may deactivate such gene regulations. RNA interference tests and chemical reagents that are inhibitors of PTPN11 and DNMT, cryptotanshinone (inhibiting PTPN11), and hypomethylating agents (inhibiting DNMT), i.e. decitabine, can be useful tools, especially for in vitro studies. This will enhance our understanding of the two pathways, in addition the results will be the basis of our next topic for future directions, to explore the anti-tumor effects of those inhibitory agents antagonizing specific mRNA derived from melanoma exosomes.

Based on our understanding of the immunosuppressive mechanism mediated by cancer exosomes and their exosomal mRNAs, antagonists of PTPN11 and/or DNMT are potentially immunomodulatory agents that may stop the negative effect from melanoma exosomes, stabilize anti-tumor immune response at the tumor milieu and extend the durable benefits in cancer immunotherapy. Elevated levels of DNA methylation with aberrant promoter regions hypermethylation of tumor suppressor genes are characteristics of many cancer types. High frequency of DNMT3A mutations have been discovered in human cancers $^{20,21}$ and have association with poor prognosis ${ }^{22,23}$. Hypomethylating agents (HMAs) that can downregulate DNMTS, azacitidine and decitabine, have proved tumor regression effects and the mechanisms were thought as HMAs can induce silenced tumor suppressor 
genes $^{24-26}$ and/or cytotoxicity due to DNA-hypermetholation in cancers ${ }^{27-30}$. FDA have approved those drugs for the treatment of myelodysplastic syndrome due to improved survival in clinics as well as the durable effects ${ }^{31}$. Other than those two mechanisms for cancer treatment, mounting evidences have recently suggested the immunomodulatory role of low-dose decitabine that can induce or alter autologous anti-tumor immune response that target cancer testis antigens (CTAs) expressed via MHC class I ${ }^{2,32-35}$, i.e. MAGE (melanoma associated antigen genes) and NY-ESO-1 in melanoma, ovarian and other cancers. Such expression of CTAs were thought as induced and maintained by HMAs administration, however, the drug-effect dynamics cannot be fully explained in clinics ${ }^{2,32-}$ 35. Our study on melanoma exosomes provides basis for the effectiveness of HMAs assisting the immunotherapies in the light of preventing cancer-exosomes-mediated immunosuppression, i.e. IFN- $\gamma$ production and signaling. We suspect that IFN- $\gamma$ and cytotoxic T lymphocytes are not the only active pathway hindered by the cancer-exosomesinduced DNMT3A. In fact, the actual networking of DNMTs in the development and differentiation of effector $\mathrm{T}$ lymphocytes, as well as to other immune cells pivotal on the cancer-immunity cycle, are still far from fully unresolved. Currently, as the adoptive cell transfer (ACT) based cancer management, i.e. CART, is coming into broader application in clinics, failure to induce durable response and occurrence of tumor resistance motivate the active investigation on various enhancing methods for immunotherapy. We propose the effect of HMAs as potentially adjuvant agents in the context of CART therapy is one interesting direction for the future work, targeting the DNMTs upregulation from the cancer-induced exosomes. Particularly, in vivo melanoma tumor model and activities of TILs in CART therapy are worth to be analyzed in the light of HMAs efficacy. In addition 
to the HMAs, the inhibitory agent for PTPN11, cryptotanshinone, might be another novel drug potentially useful in cancer therapy. PTPN11 is ubiquitously expressed and widely functions in a variety of signaling pathway, including Ras-Erk, PI3K-Akt, Jak-Stat and NF- $\kappa \mathrm{B}^{36-38}$. PTPN11 mutations occurring in cancers, and also in Noonan syndrome, frequently lose the autoinhibition of the SH2 domains (Src homology-2 domains) at Nterminus to the protein tyrosine phosphatase (PTP), therefore, PTP activity and the substrate transformation in patients can be abnormally altered ${ }^{39,40}$. Our study on PTPN11 mRNAs in melanoma exosomes and its experiment-proved, repressive effect on effector T cell proliferation suggested a novel mechanism in cancerous origins and tumor immunology. However, due to the broad involvements of PTPN11 in cellular activities, the pivotal role of function are still not completely known. The potential of PTPN11 inhibitors as immunomodulatory agents needs proof-of-concept and investigations on in vivo animal tumor models. 


\section{Reference for Chapter 4}

1. Liu, W. et al. Identification of cryptotanshinone as an inhibitor of oncogenic protein tyrosine phosphatase SHP2 (PTPN11). J. Med. Chem. 56, 7212-7221 (2013).

2. Odunsi, K. et al. Epigenetic potentiation of NY-ESO-1 vaccine therapy in human ovarian cancer. Cancer Immunol. Res. 2, 37-49 (2014).

3. Klinke 2nd, D. J., Cheng, N. \& Chambers, E. Quantifying crosstalk among interferon-gamma, interleukin-12, and tumor necrosis factor signaling pathways within a TH1 cell model. Sci Signal 5, ra32 (2012).

4. Trinchieri, G. Interleukin-12 and the regulation of innate resistance and adaptive immunity. Nat. Rev. Immunol. 3, 133-146 (2003).

5. Collison, L. W. et al. The inhibitory cytokine IL-35 contributes to regulatory T-cell function. Nature 450, 566-569 (2007).

6. Chaturvedi, V., Collison, L. W., Guy, C. S., Workman, C. J. \& Vignali, D. A. A. Cutting edge: Human regulatory T cells require IL-35 to mediate suppression and infectious tolerance. J. Immunol. 186, 6661-6666 (2011).

7. Collison, L. W., Pillai, M. R., Chaturvedi, V. \& Vignali, D. A. A. Regulatory T cell suppression is potentiated by target $\mathrm{T}$ cells in a cell contact, IL-35- and IL-10dependent manner. J. Immunol. 182, 6121-6128 (2009).

8. Collison, L. W. et al. IL-35-mediated induction of a potent regulatory $\mathrm{T}$ cell population. Nat. Immunol. 11, 1093-1101 (2010).

9. Collison, L. W. \& Vignali, D. A. A. Interleukin-35: Odd one out or part of the family? Immunological Reviews 226, 248-262 (2008).

10. Jones, L. L. \& Vignali, D. A. A. Molecular interactions within the IL-6 / IL-12 cytokine / receptor superfamily. Immunol. Res. 51, 5-14 (2011).

11. Presky, D. H. et al. A functional interleukin 12 receptor complex is composed of two $\beta$-type cytokine receptor subunits. Proc. Natl. Acad. Sci. U. S. A. 93, 1400214007 (1996).

12. Chua, a O., Wilkinson, V. L., Presky, D. H. \& Gubler, U. Cloning and characterization of a mouse IL-12 receptor-beta component. J. Immunol. 155, 42864294 (1995).

13. Chua, a O. et al. Expression cloning of a human IL-12 receptor component. A new member of the cytokine receptor superfamily with strong homology to gp130. J. Immunol. 153, 128-136 (1994).

14. Collison, L. W. et al. The composition and signaling of the IL-35 receptor are unconventional. Nature Immunology 13, 290-299 (2012).

15. Vignali, D. A. A. \& Kuchroo, V. K. IL-12 family cytokines: immunological playmakers. Nat. Immunol. 13, 722-728 (2012).

16. Wu C., Wang X., Gadina M., O’Shea J.J., Presky D.H., M. J. IL-12 receptor beta 2 (IL-12R beta 2)-deficient mice are defective in IL-12-mediated signaling despite the presence of high affinity IL-12 binding sites. J Immunol. 165, 6221-6228 (2000).

17. Silver, J. S. \& Hunter, C. A. gp130 at the nexus of inflammation, autoimmunity, and cancer. J. Leukoc. Biol. 88, 1145-1156 (2010). 
18. Raimondi, L. et al. Involvement of multiple myeloma cell-derived exosomes in osteoclast differentiation. Oncotarget 6, 13772-13789 (2015).

19. Feng, D. et al. Cellular internalization of exosomes occurs through phagocytosis. Traffic 11, 675-687 (2010).

20. Shih, A. H., Abdel-Wahab, O., Patel, J. P. \& Levine, R. L. The role of mutations in epigenetic regulators in myeloid malignancies. Nat.Rev. Cancer 12, 599-612 (2012).

21. Shah, M. Y. \& Licht, J. D. DNMT3A mutations in acute myeloid leukemia. Nat. Genet. 43, 289-290 (2011).

22. Ahn, J.S. et al. DNMT3A R882 mutation with FLT3-ITD positivity is an extremely poor prognostic factor in patients with normal-karyotype AML after allogeneic hematopoietic cell transplantation. Biol. Blood Marrow Transplant. 1-10 (2015).

23. Shen, Y. et al. Mutations of Epigenetic Modifier Genes as a Poor Prognostic Factor in Acute Promyelocytic Leukemia Under Treatment With All-Trans Retinoic Acid and Arsenic Trioxide. EBioMedicine 2, 563-571 (2015).

24. Garzon, R. et al. MicroRNA-29b induces global DNA hypomethylation and tumor suppressor gene reexpression in acute myeloid leukemia by targeting directly DNMT3A and 3B and indirectly DNMT1. Blood 113, 6411-6418 (2009).

25. Datta, J. et al. A new class of quinoline-based DNA hypomethylating agents reactivates tumor suppressor genes by blocking DNA methyltransferase 1 activity and inducing its degradation. Cancer Res. 69, 4277-4285 (2009).

26. Gros, C. et al. DNA methylation inhibitors in cancer: Recent and future approaches. Biochimie 94, 2280-2296 (2012).

27. Karpf, A. R., Moore, B. C., Ririe, T. O. \& Jones, D. A. Activation of the p53 DNA damage response pathway after inhibition of DNA methyltransferase by 5-aza-2'deoxycytidine. Mol. Pharmacol. 59, 751-757 (2001).

28. Karpf, A. R. \& Jones, D. a. Reactivating the expression of methylation silenced genes in human cancer. Oncogene 21, 5496-5503 (2002).

29. Fandy, T. E. et al. Early epigenetic changes and DNA damage do not predict clinical response in an overlapping schedule of 5-azacytidine and entinostat in patients with myeloid malignancies. Blood 114, 2764-2773 (2009).

30. Fandy, T. E. et al. Decitabine induces delayed reactive oxygen species (ROS) accumulation in leukemia cells and induces the expression of ROS generating enzymes. Clin. Cancer Res. 20, 1249-1258 (2014).

31. Estey, E. H. Epigenetics in clinical practice: the examples of azacitidine and decitabine in myelodysplasia and acute myeloid leukemia. Leukemia 27, 1803-12 (2013).

32. Coral, S. et al. Immunomodulatory activity of SGI-110, a 5-aza-2-deoxycytidinecontaining demethylating dinucleotide. Cancer Immunol. Immunother. 62, 605-614 (2013).

33. Srivastava, P. et al. Immunomodulatory action of SGI-110, a hypomethylating agent, in acute myeloid leukemia cells and xenografts. Leuk. Res. 38, 1332-1341 (2014).

34. Goodyear, O. et al. Induction of a CD8+ T-cell response to the MAGE cancer testis antigen by combined treatment with azacitidine and sodium valproate in patients with acute myeloid leukemia and myelodysplasia. Blood 116, 1908-1918 (2010). 
35. Karpf, A. R. et al. Limited gene activation in tumor and normal epithelial cells treated with the DNA methyltransferase inhibitor 5-aza-2'-deoxycytidine. Mol. Pharmacol. 65, 18-27 (2004).

36. Xu, D. \& Qu, C.-K. Protein tyrosine phosphatases in the JAK/STAT pathway. Front. Biosci. 13, 4925-4932 (2008).

37. Chan, G., Kalaitzidis, D. \& Neel, B. G. The tyrosine phosphatase Shp2 (PTPN11) in cancer. Cancer Metastasis Rev. 27, 179-192 (2008).

38. Tonks, N. K. Protein tyrosine phosphatases: from genes, to function, to disease. Nat. Rev. Mol. Cell Biol. 7, 833-846 (2006).

39. Tartaglia, M. et al. Mutations in PTPN11, encoding the protein tyrosine phosphatase SHP-2, cause Noonan syndrome. Nat. Genet. 29, 465-468 (2001).

40. Keilhack, H., David, F. S., McGregor, M., Cantley, L. C. \& Neel, B. G. Diverse biochemical properties of Shp2 mutants: Implications for disease phenotypes. $J$. Biol. Chem. 280, 30984-30993 (2005). 